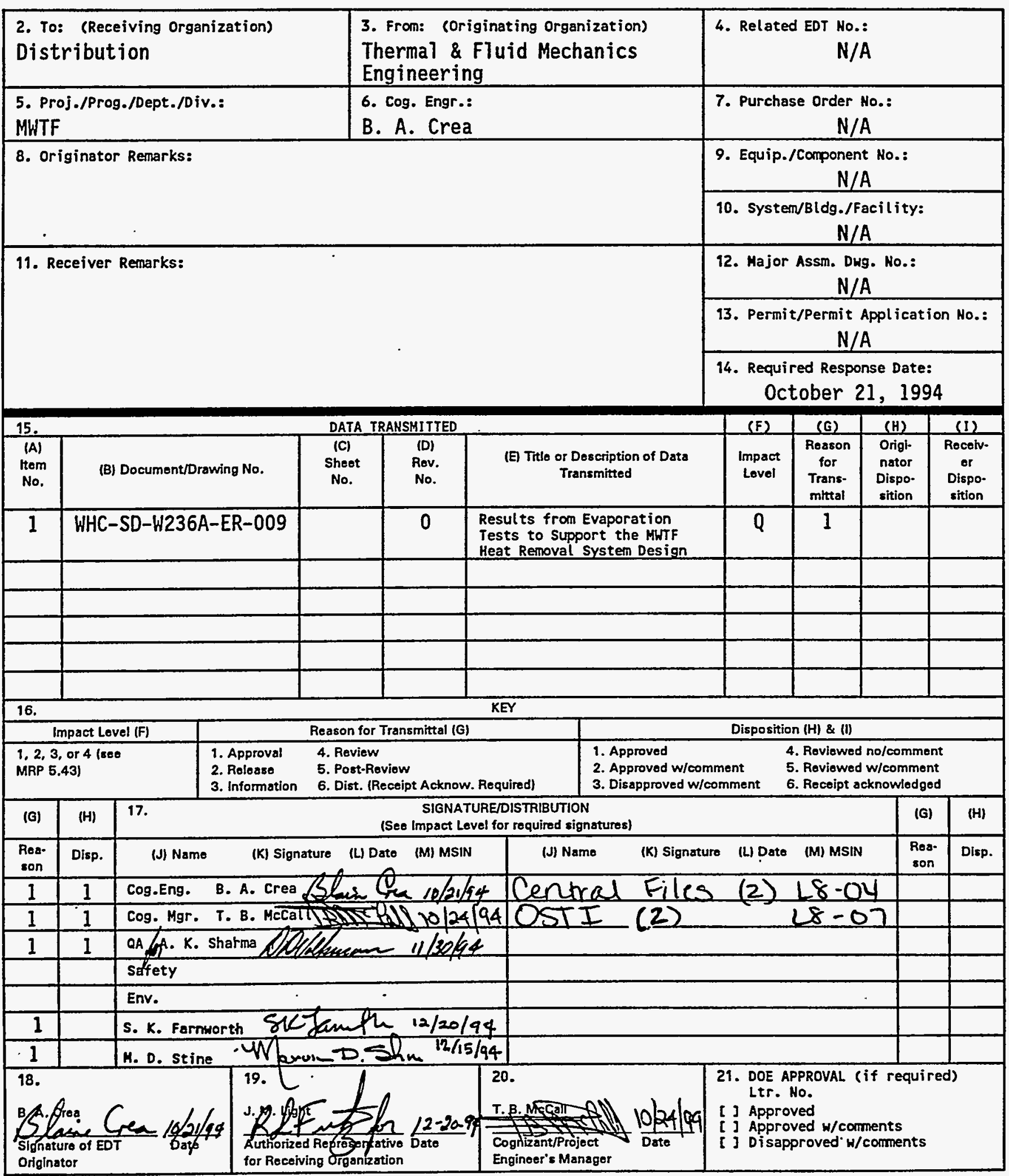

BD-7400-172-2 (07/91) GEF097 


\section{DISCLAIMER}

Portions of this document may be illegible in electronic image products. Images are produced from the best available original document. 


\section{RELEASE AUTHORIZATION}

Document

Number:

WHC-SD-W236A-ER-009, Rev. 0

Document

Title:

Results from Evaporation Tests to Support the MWTF Heat Removal System Design

Release Date: 12/21/94

\section{This document was reviewed following the procedures described in WHC-CM-3-4 and is:}

\section{APPROVED FOR PUBLIC RELEASE}

WHC Information Release Administration Specialist:

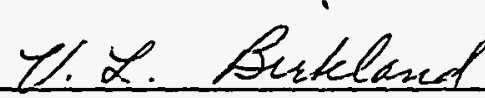

$12 / 21 / 94$

\section{v. L. Birk1 and}

TRADEMARK DISCLAIMER. Reference herein to ony specific commercial product, process, or service by trade name, trademark, manufacturer, or otherwise, does not necessarily constitute or imply its endorsement, recomendation, or favoring by the United States Government or any agency thereof or its contractors or subcontractors.

This report has been reproduced from the best available copy. Available in paper copy and nicrofiche. Printed in the United States of America. Available to the U.S. Department of Eneray and its contractors from:

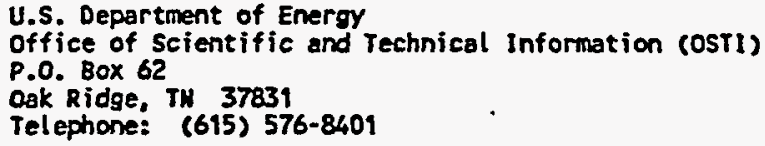

Avallable to the public from:

U.S. Department of Commerce

National Technical Information Service (NTIS)

5285 Port Royal Rosd

Springfield, VA 22161

Telephone: (703) 487-4650 


\begin{tabular}{|l|l|c|}
$\begin{array}{l}\text { 2. Title } \\
\text { Results from Evaporation Tests to Support the MWTF } \\
\text { Heat Removal System Design }\end{array}$ & $\begin{array}{l}\text { 3. Number } \\
\text { WHC-SD-W236A-ER-009 }\end{array}$ & $\begin{array}{c}\text { Rev No. } \\
\text { 5. key Hords }\end{array}$ \\
$\begin{array}{l}\text { evaporation, cooling, waste tank, MWTF, test, } \\
\text { ventilation system }\end{array}$ & $\begin{array}{l}\text { 6. Author } \\
\text { Name: B. A. Crea }\end{array}$ \\
\hline Signature \\
Organization/Charge code 71410/DTTC6
\end{tabular}

\section{Abstract}

An experimental test program was conducted to measure the evaporative heat removal from the surface of a tank of simulated waste. The results contained in this report constitute definition design data for the latest heat removal function of the MWTF primary ventilation system.

\section{DISCLAIMER}

This report was prepared as an account of work sponsored by an agency of the United States Government. Neither the United States Government nor any agency thereof, nor any of their employees, makes any warranty, express or implied, or assumes any legal liability or responsibility for the accuracy, completeness, or usefulness of any information, apparatus, product, or process disclosed, or represents that its use would not infringe privately owned rights. Reference herein to any specific commercial product, process, or service by trade name, trademark, manufacturer, or otherwise does not necessarily constitute or imply its endorsement, recommendation, or favoring by the United States Government or any agency thereof. The views and opinions of authors expressed herein do not necessarily state or reflect those of the United States Government or any agency thereof.

8. RELEASE STAMP

OFFICIAL RELEASE BY W-236A IMT

DEC 221994 DATE STATION 
WHC-SD-W236A-ER-009

Rev. 0

\title{
RESULTS FROM EVAPORATION TESTS TO SUPPORT THE MWTF HEAT REMOVAL SYSTEM DESIGN
}

November 23, 1994

Prepared by:

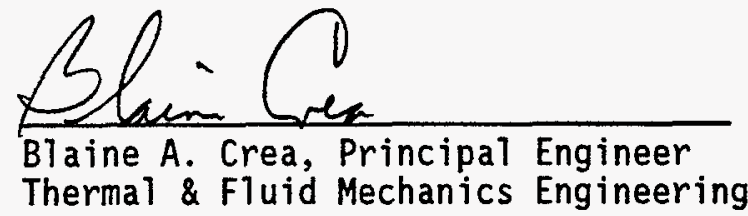

Reviewed by:
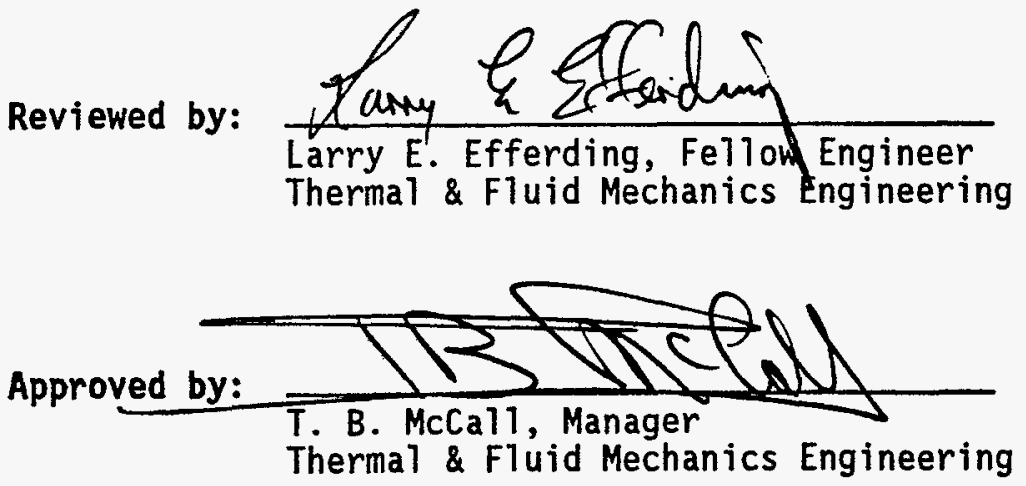

\author{
Issued by \\ WESTINGHOUSE HANFORD COMPANY \\ for the
}

U.S. DEPARTMENT OF ENERGY

RICHLAND FIELD OFFICE

RICHLAND, WASHINGTON 


\section{Table of Contents}

1.0 Introduction ......................... I

1.1 Scope......................... 1

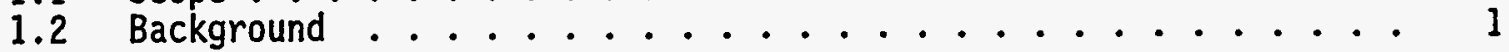

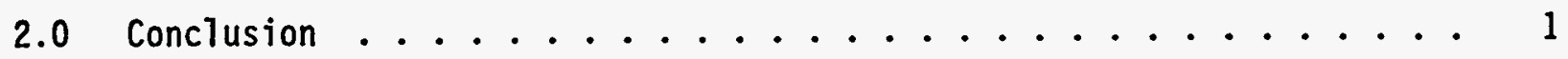

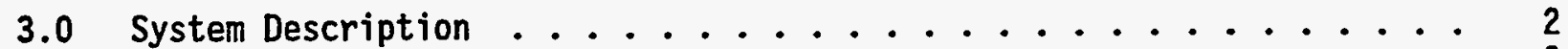

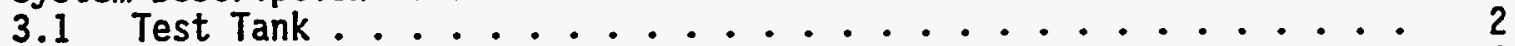

3.2 Instrumentation and Control System ............. 4

3.3 Makeup Hater Control and Measurement System . . . . . . . . 5

3.4 Test Fluids ................... 7

4.0 Test Procedure ..................... . . . 8

5.0 Results ........................ 10

\section{List of Figures}

Figure 1. Fabrication Sketch of Tank . . . . . . . . . . . . . 3

Figure 2. Test Tank prior to Installation in Test Facility. . . . . . . 4

Figure 3. Schematic Diagram of Test Facility. . . . . . . . . . . . 5

Figure 4. Solution Vapor Pressures ................. 8

Figure 5. Test Results Compared to Correlations . . . . . . . . . . . 12

Figure 6. Recommended Design Values for MWTF . . . . . . . . . . . . 13

\section{List of Tables}

Table 1. Original Test Matrix . . . . . . . . . . . . . 99

Table 2. Test Results in Chronological Order. . . . . . . . . . . 14

\section{Appendices}

A. Vapor Pressure Measurements of Test Solutions . ... . . . . . . . A-j

B. Instrument List ......................... B-j

C. Test Data . . . . . . . . . . . . . . . . . C C-i

D. Vapor Pressure Experiment on MHTF Surrogate Solution . . . . . . . . D-i

E. Literature Review ........................ E-i

F. Scaling Discussion ................... F-i 
WHC-SD-W236A-ER-009

Rev. 0

\section{RESULTS FROM EVAPORATION TESTS TO SUPPORT THE MWTF} HEAT REMOVAL SYSTEM DESIGN

\subsection{Introduction}

\subsection{Scope}

The objective of this test program was to provide design data for the Multi-Function Waste Tank Facility (MWTF) vapor space heat removal system. These tests will also provide reliable data for evaporation evaluation for a wide range of waste temperature and air flows. This investigation was conducted based on a test plan prepared as impact level $Q$ (Reference 1 ) and the results contained herein have been assigned the same impact level.

\subsection{Background}

The current design of the MWTF primary tank ventilation system includes a continuous flow of air through the vapor space above the liquid waste. This flow of air has multiple uses. One use is to maintain a negative pressure in the dome space so that any vapors or aerosols that are derived from the waste can be passed through a filter bank before they are released to the environment. Another use of this airflow is a net removal of sensible heat from the dome space if the temperature of the waste exceeds the mean inlet air temperature. In addition, this air flow will remove potentially harmful (explosive or corrosive) vapors from the vapor space which also ensures that any water vapor evolved from the waste through evaporation will be swept out also. The removal of this water vapor is an important part of the cooling process for the tank.

A dependable calculation of the evaporative heat removal in the vapor space has proven to be an elusive item. Several calculational methodologies based on the approach recommended in Reference 6 as well as the results in Appendix $A$ and $B$ of Reference 7 have been used, but the answers provided via these means have significant discrepancies between them. A review of the literature associated with this subject has shown that there is no directly applicable test data in existence. A summary of that review is included as Appendix $E$. Therefore, a scale test to determine the evaporative heat removal was a necessary and costeffective task to accurately specify the heat removal system requirements for the MWTF design.

The test has been designed so that when a scale factor of unity is applied to the heat flux results the design data will be conservative for the full-scale MWTF. Appendix F contains a detailed discussion of the scaling issues associated with transferring the test data to the full size MWTF.

\subsection{Conclusion}

The evaporative heat removal function of the vapor space ventilation system for the MWTF is capable of removing $547,000 \mathrm{Btu} / \mathrm{hr}$ at the flow rate of $500 \mathrm{scfm}$, with design basis inlet conditions $\left(77{ }^{\circ} \mathrm{F}\right.$ inlet temperature and $.0047 \mathrm{bm} \mathrm{H}_{2} \mathrm{O} / 1 \mathrm{bm}$ air) when the waste temperature is $190^{\circ} \mathrm{F}$. This value is based on the resuits 
WHC-SD-H236A-ER-009

Rev. 0

presented in Figure 6. Data has been developed to predict evaporation heat removal rates for the waste temperature range of $90^{\circ}-200^{\circ} \mathrm{F}$ and air flow rates of 300 - 1000 scfm.

\subsection{System Description}

The MWTF heat removal system has three independent heat removal mechanisms. There is a ventilation system for the tank annulus that removes only sensible heat. There is a ventilation system for the dome that removes both sensible and latent heat from the waste. This test system is a model of the dome space ventilation system, with special emphasis placed on evaluating the latent heat removal capabilities of this ventilation system. Because the depth of the liquid is irrelevant to the test, only a minimal liquid depth was used for practical requirements of facility operation. One test with water was conducted with a liquid depth scaled to the maximum freeboard value for MWTF to evaluate whether there was any significant change in heat removal capabilities at the minimum allowable headspace.

\subsection{Test Tank}

The test article itself is a welded steel tank. Figure 1 is a dimensioned sketch of the tank. The tank has a shallow truncated cone top designed to be as geometrically similar as possible to the ellipsoidal section head that the MWTF will utilize. It is designed to give a scaled dome similar to the MWTF at the $1,000,000$ gallon level when filled with 6 inches of simulated waste. Figure 2 is a photo of the tank prior to installation.

When installed the tank was placed on a $11 / 2^{\prime \prime}$ thick layer of styrofoam insulation and covered with a 1 inch thick layer of flexible rubber insulation. The insulation had two functions. The most important function was to act as a guard so that the temperature of exterior surface of the vessel was reduced below the point where it would burn someone who inadvertently came into contact with it. The other function was to reduce heat loss to the environment. The test setup had a loss to the environment of $2-3 \mathrm{Kw}$ when operating at $190^{\circ} \mathrm{F}$ exclusive of the heat removal that resulted from the ventilation flow.

The tank has air inlet and exhaust ports at locations that are geometrically similar (azimuthally identical and scaled radially) to the locations of the Title I Design for the MHTF dome space ventilation system inlet and outlet. The test tank is 12 feet in diameter which has a $1: 6.25$ linear scale ratio to the actual tank which is 75 feet in diameter. 
Figure 1. Fabrication Sketch of Tank.

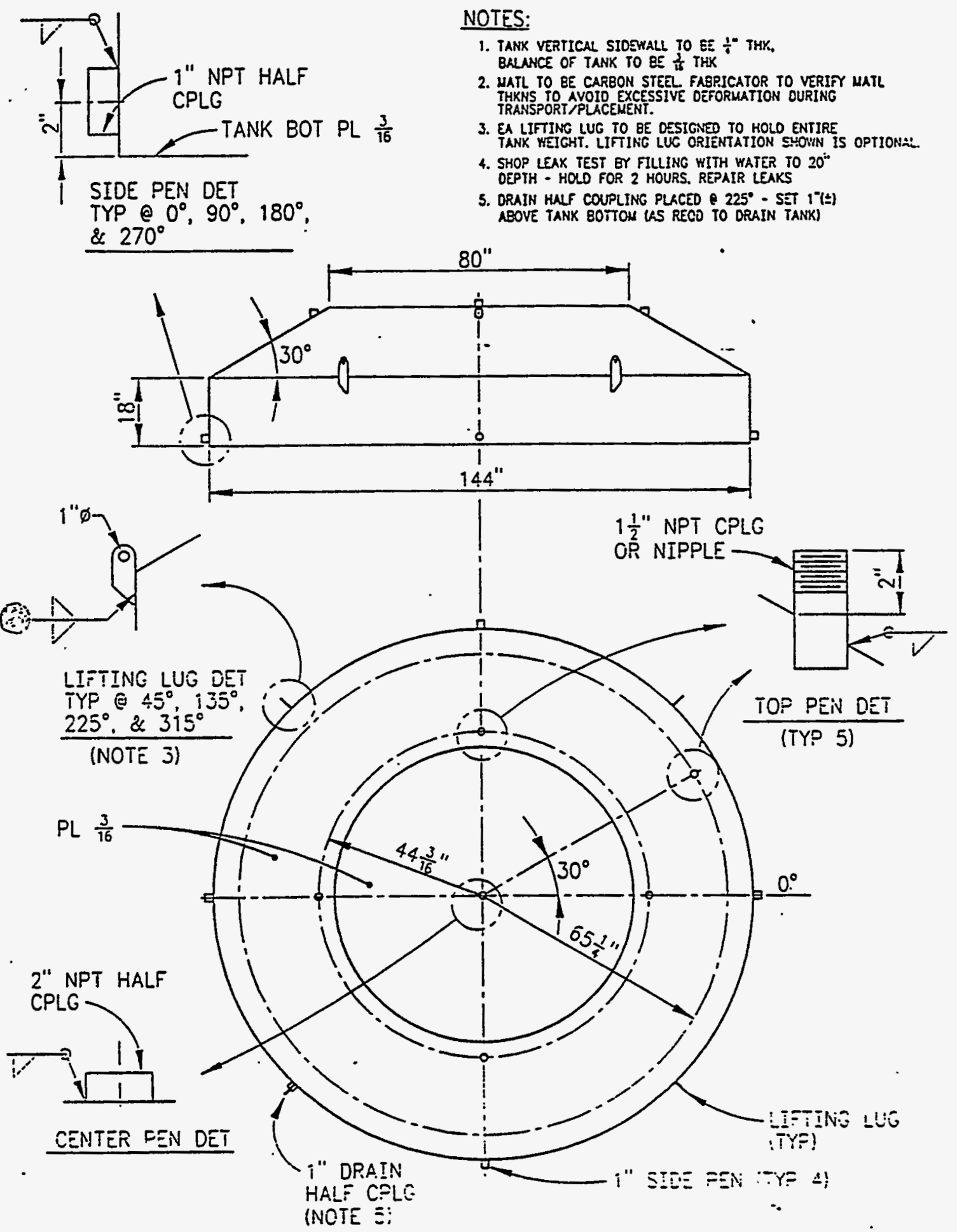




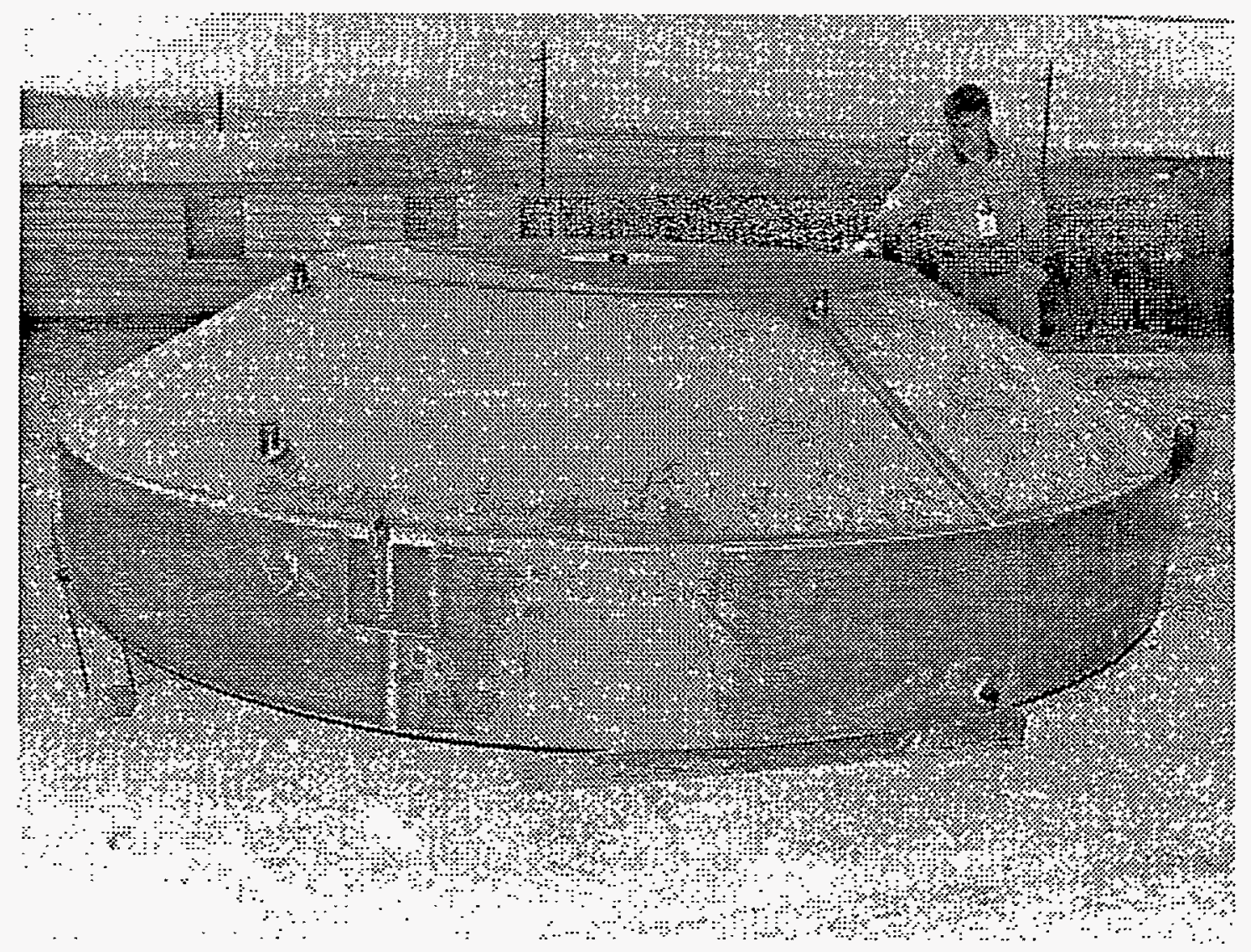

Figure 2. Test Tank prior to Installation in Test Facility.

\subsection{Instrumentation and Control System}

The tank inlet port has a heat exchanger attached to a temperature controlled water loop to stabilize the inlet temperature. It also has flow, temperature, and relative humidity monitoring instrumentation. The outlet port is connected to the suction of a centrifugal blower. The volumetric flowrate of the blower is controlled with a variable speed drive and a suction bypass valve. Monitoring of the exhaust conditions from the tank is accomplished by an integrated temperature/relative humidity probe installed in the outlet. The outlet flow is also monitored through the use of a calibrated pitot/static test section placed directly downstream of the temperature/relative humidity monitoring instrumentation. Appendix B contains a list of the instruments used to monitor the test. Included in that table are the WHC Standards $1 a b$ code number for the calibration of the instruments and the manufacturers accuracy specification for the instrument. All instruments except the thermocouples were calibrated by the 
WHC standards lab. The thermocouples were purchased to "special limits of accuracy" and used in the as received condition.

The temperature of the simulated waste solution in the tank is controlled through the use of an external circulation loop with an in-line $12 \mathrm{KW}$ circulation heater. The heater power is controlled by a thermocouple in the heater outlet, although the solution temperature for determining the proper setpoint for the heater is monitored by thermocouples in the tank itself. Figure 3 is a schematic diagram of the essential elements of the system. The circulation pump runs at about $10 \mathrm{gpm}$. This produces a mixed solution in the tank without excessive agitation.

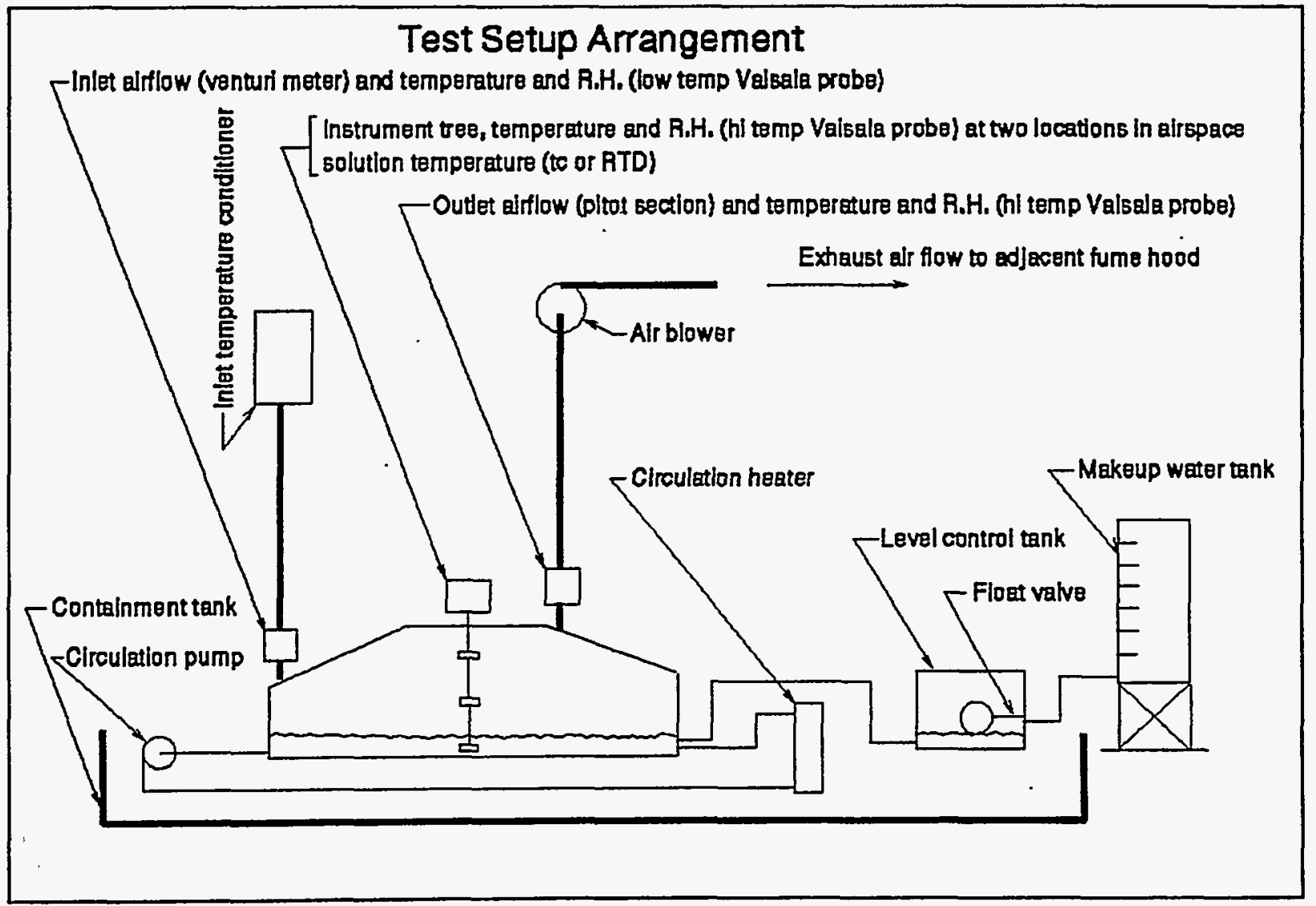

Figure 3. Schematic Diagram of Test Facility.

\subsection{Makeup Water Control and Measurement System}

An automatic makeup water system to replace that lost by evaporation is part of the facility. As water is evaporated from the simulant in the tank it needs to be replaced for several reasons. If the level drops too low the circulation pump will cavitate. In addition, the geometric conditions of the system would then change during the test. But most important, if water is evaporated over the duration of a test the concentration of the simulant solution will change and so 
will the vapor pressure of the solution at the test temperature. In addition to these practical reasons, it was desirable to accurately record the makeup water as a reality check for the test instrumentation. For these reasons a makeup system with level control was included. The source of the makeup water was a supply tank with a calibrated sight glass on the exterior of the tank so that changes in makeup level could be accurately recorded.

This system went through several major design iterations as the test program progressed. The initial design was a small external tank with an easily removed 1id. The subsequent changes made to this system in an effort to reduce uncertainty in the measured water consumption are described in the following paragraphs.

1. The first four tests, conducted with water in the tank, used the original system which consisted of a "toilet bowl" float and valve mounted in the rectangular polyethylene float tank. Because of force required to actuate the float valve this system had a level uncertainty of about \pm 0.25 in. (18 gallons)

2. Between tests 4 and 5 (the first $\mathrm{NaOH}$ test), the manual valve was replaced with an electric solenoid valve that was activated by a micro-switch mounted to the float stand. The float continued to be used to activate the micro-switch. Also, the small poly tube connecting the float tank to the test tank was lengthened and coiled to minimize back-flow into the float tank. This change improved the level control to the point that the uncertainty was reduced to about \pm 0.1 in. (7 gallons)

3. Between tests 8 and 11 , a sight glass was added to the test tank at the drain valve that allowed external measurement of the test tank level. This allowed a better measurement, reducing the uncertainty to approximately \pm 0.05 in. (3.5 gallons)

4. Between tests 12 and 10-10R, a hole was drilled into the test tank and make-up water was plumbed to feed directly into the tank. The coiled poly tubing from the float tank to the test tank was replaced with a short one inch iron pipe. The water was removed from the float tank and replaced with the same $\mathrm{NaOH}$ solution as the test tank. The float/microswitch in the float tank was used for Test $10 R$ to control make-up water addition. This change made the system operate with less operator attention, but didn't increase the accuracy.

5. Between tests $10-10 R$ and 17 , a conductivity level probe was installed in the test tank and the float tank was taken out of service. The conductivity probe signaled the solenoid valve for water addition. This system was used for Test 17 and for all tests that followed. This gave a dead band of about 0.09 in (6.4 gallons)

6. After test 20 the end of the conductivity probe was rounded to provide added sensitivity. This reduced the deadband by about a factor of 4 so the uncertainty with this system was about \pm 0.8 gallons. Tests $5 R, 6 R, 9,21,13,22$ used this make-up water system. 
WHC-SD-W236A-ER-009

Rev. 0

\subsection{Test Fiuids}

The test fluid for tests 1-4 was de-ionized water. The balance of the tests were run with a solution of sodium hydroxide. The sodium hydroxide solution was prepared to simulate the vapor pressure curve of waste simulants that had been previously tested to determine their vapor pressure (Appendix D). Rather than use the simulant for the previous small-scale experiments to determine the worst vapor pressure reduction for the wastes, a simple solution of $\mathrm{NaOH}$ was used to give the desired vapor pressure reduction. Based on the information in Appendix $D, a$ solution of $\mathrm{NaOH}$ was used that would have a vapor pressure that was $55 \%$ of pure water at the boiling point. Table 3-27 in reference 3 provides a tabulation of the equilibrium vapor pressure of aqueous solutions of $\mathrm{NaOH}$ as a function of wt\% $\mathrm{NaOH}$. Table 68 in Reference 4 provides a tabulation of specific gravity of $\mathrm{NaOH}$ solutions at $20^{\circ} \mathrm{C}$ as a function of concentration. The solution specific gravity of the target concentration is 1.335 .

The $\mathrm{NaOH}$ solution specific gravity was measured on a regular basis for all tests. The recorded values range from a high of 1.342 to a low of 1.318 . The mean for all tests was 1.331 . In addition to regular monitoring of the solution specific gravity a series equilibrium vapor pressure measurements on samples of the test solution were made. The reason for making these measurements was to provide an independent verification that the solutions used for the tests had been mixed correctly, and also to make sure that no unknown ingredients which might affect the resuits (such as a surfactant) had been introduced into the system. The results of these measurements are presented in Appendix A.

Figure 4 shows vapor pressure data from the measurements reported in Appendix $A$ and from Reference 3 . From this figure and the discussion in Appendix $A$ it is apparent that the Cottrell Apparatus that was used to measure the vapor pressure of the solutions wasn't able to exactly reproduce the values from Reference 3. The data is quite consistent and implies that the vapor pressure of a $30.5 \mathrm{wt} \% \mathrm{NaOH}$ solution is $1.5-2.0 \%$ less with respect to the vapor pressure of water than the handbook value from Reference 3 . Based on the test/calibration runs performed with deionized water as discussed in Appendix $A$ it isn' $t$ reasonable to attribute a deviation of this magnitude to instrumentation error. It is possible to draw the conclusion that the Cottrell Apparatus, while giving vapor pressure values for the solutions that are closer to the Reference 3 values than simply boiling the solution in a flask, still produces biased data values.

The reported values in Appendix A show that solution 6 has an $\mathrm{NaOH}$ concentration (based on specific gravity measurement) that is sightly less than the target value, although within the variation that was measured over the course of the testing program. Solution 5 has an $\mathrm{NaOH}$ concentration (based on specific gravity measurement) that is more than the target value, and is also slightiy outside the range of values that was measured over the course of the testing program ( 1.350 vs a max of 1.342 measured during the testing). Since it has been around 6 months since the samples were drawn from the evaporation test setup, and they have been run through several different types of apparatus in an attempt to measure their vapor pressure it is not unrealistic to expect that a small amount of water has been lost from one of them. For purposes of determining the appropriate vapor pressure suppression to use as a basis for reducing the data from this test series, the data from Appendix $A$ has been corrected/adjusted to the nominal value of specific gravity. Those adjustments make the data 
reported in Appendix A 7 ie in a fairly narrow band, which is consistently suppressed about $2 \%$ from the handbook values contained in Reference 3.

The original reason for making these measurements was to verify that the test fluid had been mixed properly and also that it hadn't been adulterated by some unknown constituent. The data in Appendix A clearly show this to be the case since the vapor pressure curves for solutions 5 and 6 agree within $1 \%$ with the vapor pressure curves for a 30.5 wt\% solution of $\mathrm{NaOH}$ mixed as a "calibration sample" in the lab when corrected for specific gravity variation. The "bias" that exists between the data in Reference 3 and the data reported in Appendix $A$ will be attributed to apparatus bias. The curve in Figure 4 that comes from Reference 3 will be used as the vapor pressure of the test solution for purposes of reducing the test data.

Figure 4. Solution Vapor Pressures.

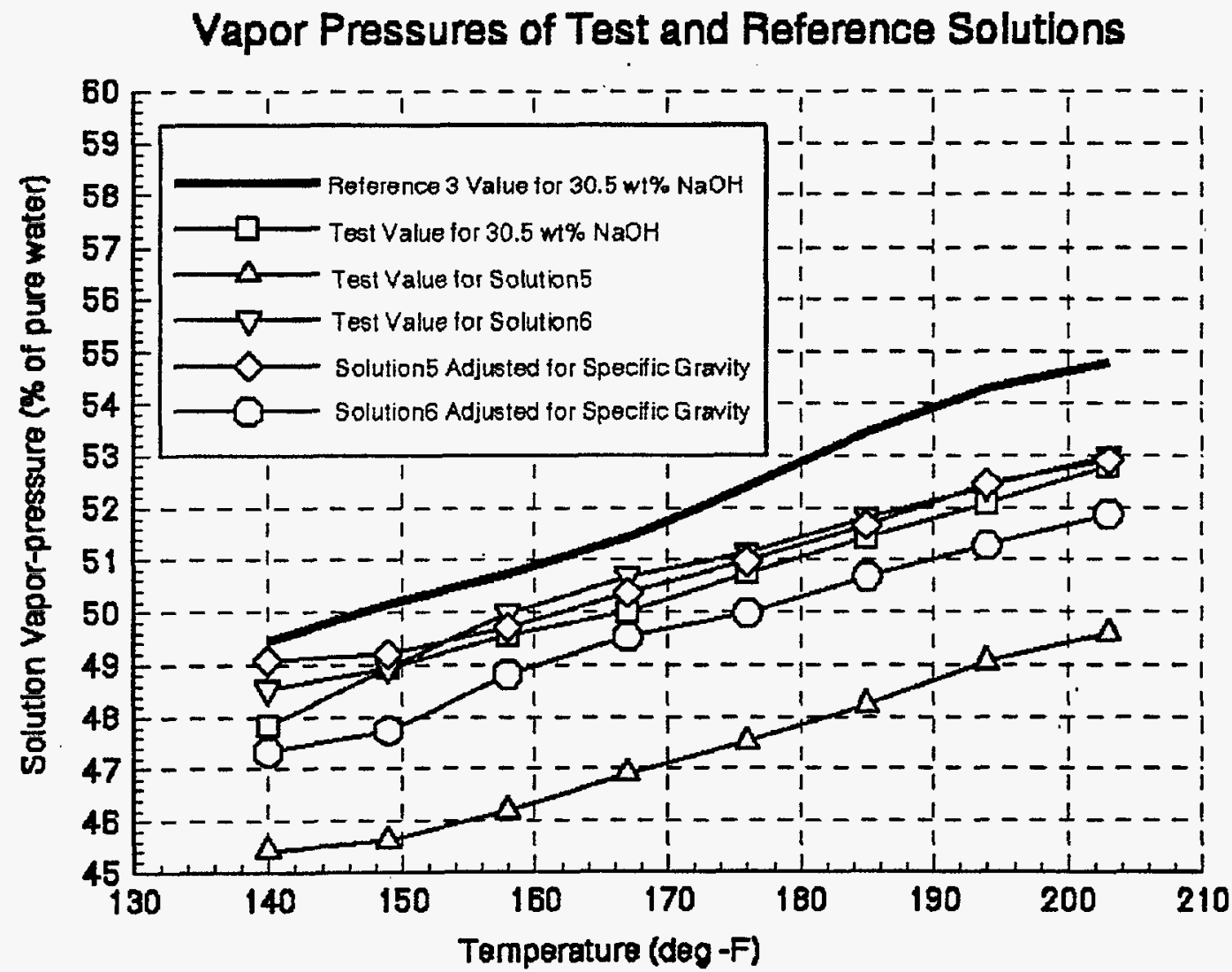

\subsection{Test Procedure}

The tests were run under the control of a detailed test procedure (Reference 2). The basic idea behind each test was to get the system set up at a desired condition, and let it run long enough so that the measured and calculated values of water usage were relatively large with respect to the uncertainties in those 


$$
\begin{gathered}
\text { WHC-SD-W236A-ER-009 } \\
\text { Rev. } 0
\end{gathered}
$$

values. Table 1 shows the test matrix as excerpted from the test plan. Tests 14, $15,16,18$, and 19 weren't run. Tests 14, 15, and 16 weren't run because of limitations of the test apparatus. Tests 18 and 19 weren't run because as the test program progressed additional tests, defined as 20,21 , and 22 were run which would be more desirable than 18 and 19.

Table 1. Original Test Matrix.

\begin{tabular}{|c|c|c|c|c|c|c|}
\hline $\begin{array}{c}\text { Test } \\
\text { No. }\end{array}$ & $\begin{array}{c}\text { Solution } \\
\text { Temp. } \\
\text { Deg. F }\end{array}$ & $\begin{array}{c}\text { Inlet Air } \\
\text { Flow } \\
\text { SCFM }\end{array}$ & $\begin{array}{c}\text { Inlet Air } \\
\text { Temp. } \\
\text { Deg.F }\end{array}$ & $\begin{array}{c}\text { Approximate } \\
\text { Test Duration } \\
\text { hours }\end{array}$ & $\begin{array}{c}\text { Solution } \\
\text { Level } \\
\text { inches }\end{array}$ & $\begin{array}{c}\text { Vapor Pressure } \\
\text { Suppression } \\
\%\end{array}$ \\
\hline 1 & 100 & 7.7 & 53 & 24 & 6 & 0 \\
\hline 2 & full $\mathrm{KW}^{*}$ & 7.7 & 53 & 24 & 6 & 0 \\
\hline 3 & ful1 $\mathrm{KW}^{*}$ & 25.6 & 53 & 6 & 6 & 0 \\
\hline 4 & ful1 $\mathrm{KW}^{*}$ & 7.7 & 53 & 24 & 15.3 & 0 \\
\hline 5 & 190 & 25.6 & 77 & 24 & 6 & 45 \\
\hline 6 & 190 & 7.7 & 77 & 6 & 6 & 45 \\
\hline 7 & 190 & 38.4 & 77 & 24 & 6 & 45 \\
\hline 8 & 200 & 15 & 53 & 24 & 6 & 45 \\
\hline 9 & 190 & 15 & 53 & 6 & 6 & 45 \\
\hline 10 & 170 & 15 & 53 & 6 & 6 & 45 \\
\hline 11 & 190 & 25.6 & 77 & 24 & 6 & 45 \\
\hline 12 & 135 & 15 & 53 & 6 & 6 & 45 \\
\hline 13 & 100 & 15 & 53 & 6 & 6 & 45 \\
\hline 14 & ful1 KW & 15 & 53 & 24 & 6 & 45 \\
\hline 15 & ful1 KW & 25.6 & 53 & 24 & 6 & 45 \\
\hline 16 & 200 & 7.7 & 77 & 6 & 6 & 45 \\
\hline 17 & 150 & 7.7 & 77 & 6 & 6 & 45 \\
\hline 18 & 100 & 7.7 & 77 & 6 & 6 & 45 \\
\hline 19 & 190 & 15 & 77 & 6 & 6 & 45 \\
\hline
\end{tabular}

full KW refers to full power operation of the heater and will be achieved by setting the temperature controller unachievably high 
Rev. 0

\subsection{Results}

A total of nineteen tests were run of which 15 were with simulated waste. The conditions and results are shown in Table 2. The lab notebook containing the raw data is Reference 8 . The two different inlet temperatures used caused no appreciable difference in latent heat removal. The heat flux shown in Figure 4 is plotted in two temperature ranges to give better resolution. The curves referred to as "Boelter" curves are derived from the relationship presented in Reference 5. The relationship is:

$$
\mathrm{e}=0.067\left(P_{\mathrm{vs}}-P_{v b}\right)^{1.22}
$$

where: $e=$ unit evaporation rate $\left(1 \mathrm{~b} / \mathrm{ft}^{2}-\mathrm{hr}\right)$

$P_{v 8}=$ Vapor pressure of water at the surface (inches $\mathrm{Hg}$ )

$P_{v b}^{v 8}=$ Vapor pressure of water in the bulk phase (inches $\mathrm{Hg}$ )

The curves referred to as "similarity" are based on the development presented in Reference 6 . The basic correlation is:

$$
\mathrm{Sh}=.14\left(\mathrm{Gr}_{\mathrm{m}} \mathrm{S}_{\mathrm{c}}\right)^{1 / 3}
$$

where: Sh is the Sherwood number

$S_{c}$ is the Schmidt number

$\mathrm{Gr}_{\mathrm{m}}$ is the mass transport Grashof number

Uncertainties were assigned based on the inherent error in the measuring devices for both the measured and the calculated water usage. The principal contributor to the uncertainty associated with the measured water usage was the measurement of the water/solution level in the tank. The principal uncertainty associated with the calculated water usage is the uncertainty in the differential pressure transducer used on the inlet flow transducer, however, the uncertainties quoted in Table 2 result from consideration of propogation of all instrument errors involved. The "Value Assigned" column is based on a weighted average of the calculated and measured values of water used. The weighing function that was used attributes a weight inversely proportional to the percent uncertainty in a measurement except that negative values of water usage are set to zero. The "Value Assigned" column was then used as a basis for constructing the curves shown in Figure 4. The curves are based on a least squares fit of the data in Table 2 with three constraints levied upon the data.

The first constraint is that the driving force to transfer mass/evaporate water has the same shape as the saturation pressure of water as a function of temperature. The second constraint is that a single node lumped parameter model of the following form is a valid approximation to the behavior of the system being tested:

$$
H_{m} * A *\left(E_{s}-E_{b}\right)=W\left(E_{\text {out }}-E_{\text {in }}\right)
$$

Where: $\quad H_{m}$ Mass transport coefficient

$A^{m} \quad$ Area available for evaporation

$E_{s} \quad$ Surface moisture ratio

$\mathrm{E}_{\mathrm{b}} \quad$ BuTk moisture ratio

$W$ Airflow through dome space

$E_{\text {out }}$ Outlet moisture ratio 
Rev. 0

$$
\begin{gathered}
E_{\text {in }} \text { inlet moisture ratio } \\
E_{b}=E_{\text {out }} \text { is also applied as a condition to this equation. }
\end{gathered}
$$

The detailed results shown in Appendix $C$ support this assumption, since the moisture ratio measured at the tank exit is the same as that measured by the transducers internal to the tank.

The third constraint is that the mass transport coefficient is proportional to the $1 / 3$ power of the density difference.

$$
H_{m} \propto\left(\rho_{b}-\rho_{s}\right)^{k}
$$

where:

$$
\begin{aligned}
& \rho_{\mathrm{s}}=\text { Surface mixture density } \\
& \rho_{\mathrm{b}}=\text { Bulk mixture density }
\end{aligned}
$$

The experimental results shown in Figure 5 have been "scaled up" to the full size (75-foot diameter) tank and plotted in Figure 6 . These heat removal curves form the design basis for evaporative heat removal from the MWTF. The scaling was done based on the ratio of waste surface area to volumetric flow rate. Appendix $F$ contains a discussion of the issues associated with this scaling. Tests 2 and 4 were done to find out whether reduced headspace caused by filling the tank to the maximum allowable level will have an effect on the heat removal capabilities. Test 2 was run with a solution depth of 6 inches and Test 4 was run with a solution depth of 15.3 inches as shown in Table 1 . When the heat removal values are normal ized to the same flow value $(7.7 \mathrm{scfm})$ the latent heat removal are 130.6 $\mathrm{Btu} / \mathrm{hr}-\mathrm{ft}^{2}$ and $115.6 \mathrm{Btu} / \mathrm{hr}-\mathrm{ft}^{2}$ for tests 4 and 2, respectively. From this it can be seen that filling the tank to the maximum level will have no deleterious effect on latent heat removal. 
Figure 5. Test Results Compared to Correlations.

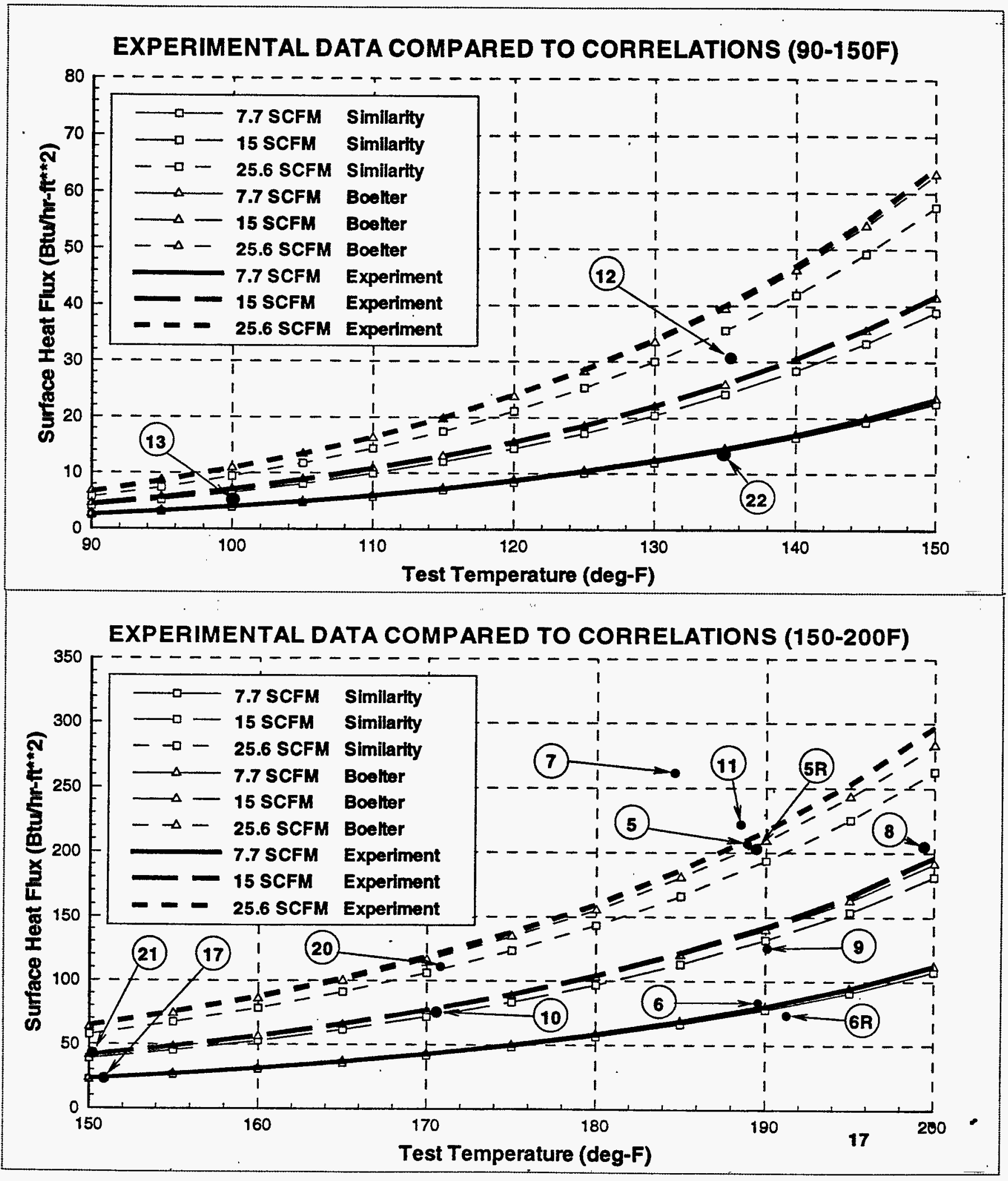


Figure 6. Recormended Design Values for MKTF.

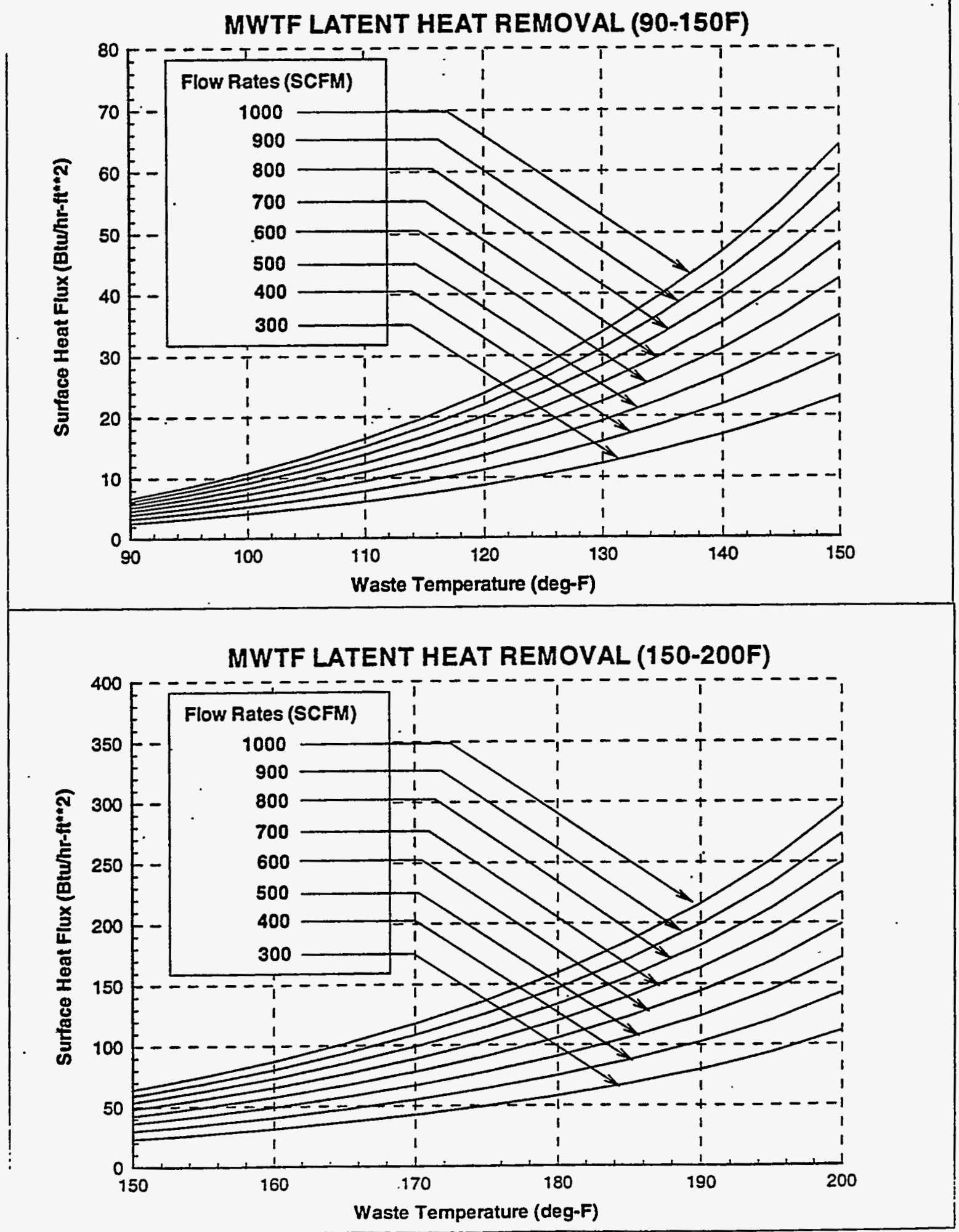


Table 2. Test Results in Chronological Order.

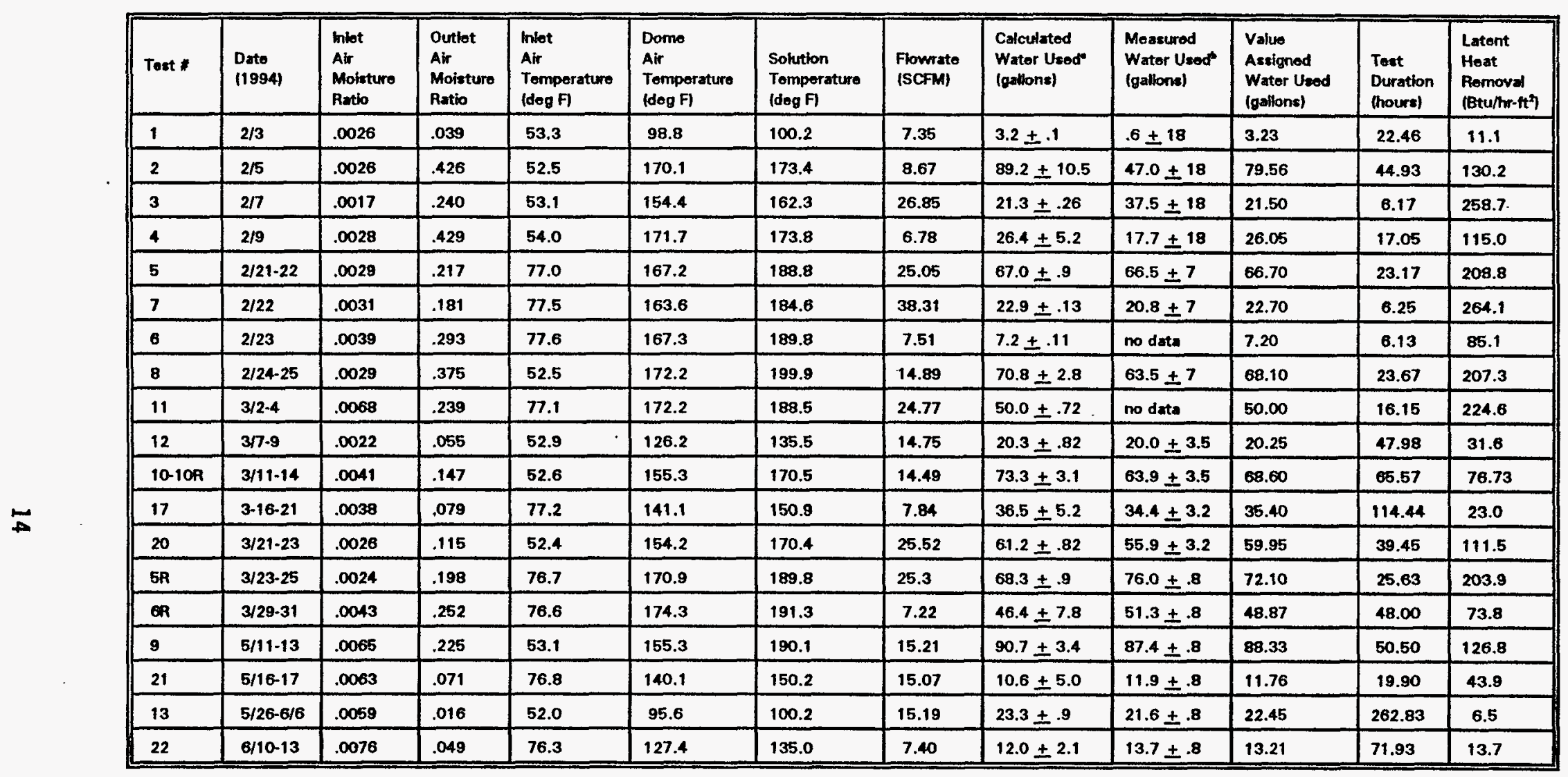

Calculated baced on flowmotors and tomp/humidity probes

- Measured bacod on makeup wator tanke 
WHC-SD-W236A-ER-009

Rev. 0

\subsection{References}

1. B. A. Crea, January 1994, Test Plan and Specification for Multifunction Waste Tank Facility (MWTF) Evaporative Heat Removal Tests, WHC-SD-W236ATP-004, Westinghouse Hanford Company, Richland, Washington.

2. E. R. Cramer, February 1994, Test Procedure for Multifunction Waste Tank Facility (MWTF) Evaporative Heat Removal Tests, WHC-SD-W236A-TC-001, Westinghouse Hanford Company, Richland, Washington.

3. Perry, Robert H. and Don Green, Perry's Chemical Engineers' Handbook, Sixth Edition, McGraw-Hi11, Inc., dated 1984.

4. Handbook of Chemistry and Physics, 55th Edition, CRC Press, 1974.

5. Boelter, L. M. K., et. al., Free Evaporation into air of water from a Free Horizontal Quiet Surface, Ind. Eng. Chem., Vol. 38, pp 596, 1946.

6. Shah, M. M., Estimating Evaporation from Horizontal Surfaces, ASHRAE Trans., Vol. 87, Pt. 1, pp.35, 1981.

7. Cramer, E. R., Multi-Function Waste Tank Facility Thermal Hydraulic Analysis for Title I Design, WHC-SD-W236A-ER-006, Rev. 0, Westinghouse Hanford Company, Richland, Washington.

8. Crea, B. A., 1994, MWTF Evaporation Test Lab Notebook, WHC-SD-W236A-TL-001, Rev. 0, Westinghouse Hanford Company, Richland, Washington. 


\section{HHC-SD-H236A-ER-009}

Rev. 0

\section{Appendix A. Vapor Pressure Measurements of Test Solutions.}


From: $\quad$ Chemical Engineering Laboratory

$8 A 400-94-039$

Phone: $\quad 373-5434$ S4-25

Date: November 22, 1994

Subject: VAPOR PRESSURE MEASUREMENTS ON CAUSTIC/SURROGATE WASTE SOLUTIONS WITH COTTRELL BOILING POINT APPARATUS

To:

T. B. HcCall HO-33
cc:
B. A. Crea
HO-33
M. J. Duchsherer S4-25
C. A. Hinman
M. J. Kupfer
HO-33
H. J. Schl iebe 7 A $\begin{array}{r}\mathrm{H} 5-46 \\ \mathrm{S4}-25\end{array}$
J. P. Sioughteff T6-07
CJB File/LB

References: (1) Internal Memo 8E130-94-058, C. J. Berglund to C. A. Hinman, "Vapor Pressure Measurements on Caustic/Surrogate Waste Solutions with Enhanced Test Apparatus", dated June 30, 1994.

(2) Experimental Physical Chemistry; Daniels, Williams, Bender, ATberty and Cornwe11; McGraw-Hi17 Book Company, Inc., 1962.

In an effort to improve on the results reported in reference 1 additional vapor pressure measurements were performed on the same test solutions, employing a more sophisticated glassware setup. The Cottrell boiling point apparatus described in reference 2 was designed to eliminate the effect of superheating when measuring the boiling points of solutions. This assembly is a catalog item from Fisher Scientific but they were out of stock and were having difficulty getting resupplied, so a set of dimensioned sketches were prepared based on the catalog iliustration and the Westinghouse giass shop fabricated the apparatus. Figure 1 in the Attachment is a fairly literal schematic diagram of the resulting assembly. As an indication of scale, the heating vessel is 50-millimeter giass tubing.

In use the apparatus is supported by a ring stand and clamps, with the heating vessel resting in a small heating mantle which is regulated by a variable transformer. The vacuum pump and digital electronic pressure gauge ("electronic manometer") are connected as shown in Figure 1 with flexible tubing. The heating vessel is filled with the test liquid to the level indicated in the figure. There are three small holes (approximately 5 millimeters in diameter) spaced around the circumference of the inner shroud and located about 3 centimeters above its lower rim; this equalizes pressures within the apparatus. A bleed valve on the vacuum pump was adjusted to yield the desired indicated absolute pressure in the apparatus, which typically fluctuated several tenths of a millimeter of mercury $(\mathrm{mm} \mathrm{Hg})$. The solution was heated and when it reached the boiling point vapor bubbles rising in the 
Page 2

November 22, 1994

recirculation risers capture small volumes of solution, resulting in a stream of vapor and solution impinging on the RTD temperature element. Presumably the boiling liquid will flash to equilibrium with the ambient pressure in the apparatus, thus subjecting the temperature element to the corresponding boiling temperature. This is obviously a dynamic situation and it is necessary that the flow of solution impinging on the temperature element be sustained, since the ambient temperature in the apparatus is dictated by solvent condensation (pure water, in this case) at that pressure. Thus there is potential for heat loss from the sensing portion of the temperature element to that area which is exposed to the ambient temperature, so the impinging solution must provide enough heat to the sensing portion to maintain the proper temperature. When a satisfactory recirculation flow was being maintained and the indicated temperature had stabilized the data were recorded and the internal pressure adjusted to the next desired value.

Several test runs were made with deionized (DI) water at intervals during this test effort to provide an ongoing informal verification of the pressure and temperature instrumentation calibrations. Interestingly, the performance of this apparatus with DI water at the lowest pressures (ergo, the lowest temperatures) was somewhat unsatisfactory, in that recirculation flow was quite erratic. The water would apparently superheat and finally vaporize too vigorousiy to develop good recirculation flow, and then the cycle would repeat. Nothing that was utilized as a "boiling chip" resulted in any improvement. As the pressure (and thus the boiling temperature) was increased the boiling did became more benign and recirculation was maintained. It seems likely that the viscosity and surface tension properties of water at the lower temperatures, in conjunction with the dimensions of the apparatus, were not conducive to yielding stable recirculation flow. Inasmuch as only the solvent was involved here the benefit of recirculation is not really required; the measured temperatures would be valid so long as enough vapor is generated to adequately heat the temperature element. The data from these runs are shown in Table 1 of the Attachment.

The test solutions displayed this phenomenon to a lesser degree so it was possible to achieve recirculation, albeit somewhat sluggish, at the lower pressures. This was probably due in part to the fact that the solutions, of course, boil at higher temperatures for a given pressure. Initially the test runs were started at the lowest absolute pressure desired (usuaily $65 \mathrm{~mm} \mathrm{Hg}$ ), but an alternative technique was employed for some of the tests in which the run was started at a higher boiling temperature $\left(70-80^{\circ} \mathrm{C}\right)$ to achieve a sustained recirculation flow, and then slowly reducing the pressure to the desired lower values so that boiling did not have to be initiated at a lower temperature. This procedure was marginally successful in improving boiling and recirculation performance.

Table 2 in the Attachment shows the vapor pressure/temperature data obtained with the Cottrell apparatus on the solutions that were employed for the work reported in reference 1; namely, a 30.5-percent sodium hydroxide ( $\mathrm{NaOH})$ solution, Test Solutions 5 and 6 (samples of 30.5-percent $\mathrm{NaOH}$ solution that had been used in tests by another engineering organization) and cc:waste (complexant concentrate) surrogate. In addition, a newly-prepared 10-molar $\mathrm{NaOH}$ solution ( 30.1 percent, $43 \mathrm{gms} \mathrm{NaOH} / 100 \mathrm{gms}$ water) was tested to offer a 
known reference solution. As seen from Table 2 the data from this fresh solution is quite consistent with the data from the 30.5 percent solution and Test Solution 6, while the Test Solution 5 results are displaced a degree or two high. The current specific gravities (SPG) of two of the test solutions were measured, weighing the amount of solution in a 250-milliliter volumetric flask and comparing it with the weight of DI water the flask held. Test Solution 5 gave a SPG of 1.350 and the SPG of Test Solution 6 was 1.330 .

In an effort to obtain additional insight into the quality of data generated with this apparatus a set of solutions was prepared to provide direct comparison with sodium hydroxide solution vapor pressure data in the Chemical Engineer's Handbook. Solutions were made up containing 20, 40 and 70 grams of sodium hydroxide per 100 milliliters of DI water. The boiling temperatures of these solutions were measured in the cottrell apparatus at internal pressures matching the data in the reference handbook. Table 3 in the Attachment 7 ists the values obtained along with the corresponding reference data. The temperatures for the 20 and $40 \mathrm{gram}$ solutions are higher than the reference data by one degree Celsius or less; the two lower temperatures for the 70 gram solution are sijightly lower than the reference values, probably because the recirculation flows with this higher concentration solution were irregular and sluggish due to the higher viscosity and did not adequately heat the temperature element.

As noted previousiy, the data from the 10-molar solution, the 30.5 percent solution, and Test Solution 6 are in quite good agreement, while Test Solution 5 routinely yielded temperatures between one and two degrees Celsius higher. This is consistent with Test Solution 5 showing a slightly higher SpG, which suggests a higher solution concentration. This same relationship was observed in the work reported in reference 1, but these latest temperatures are al1 about one degree lower. This would be consistent with temperature measurement in the Cottrell apparatus being less prone to sense solution superheat. In general the temperatures recorded were judged to be the result of good recirculation impingement on the temperature element and the DI water runs certainly indicate good instrument accuracy. Thus the relatively larger disparity (compared with the DI water results) between the reference data and the observed results with the specifically-matching test solutions is somewhat disconcerting. And the apparent high-bias of the temperatures suggests superheating, which seems inconceivable in the Cottrell apparatus. Hopefulty the potential uncertainty in this vapor pressure data does not significantiy impact the ultimate application of this information.

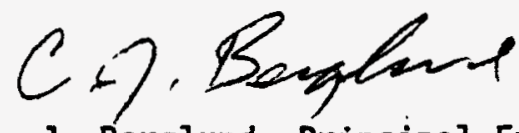

C. J. Berglund, Principal Engineer

Chemical Engineering Laboratory

$c j b$

Attachment 


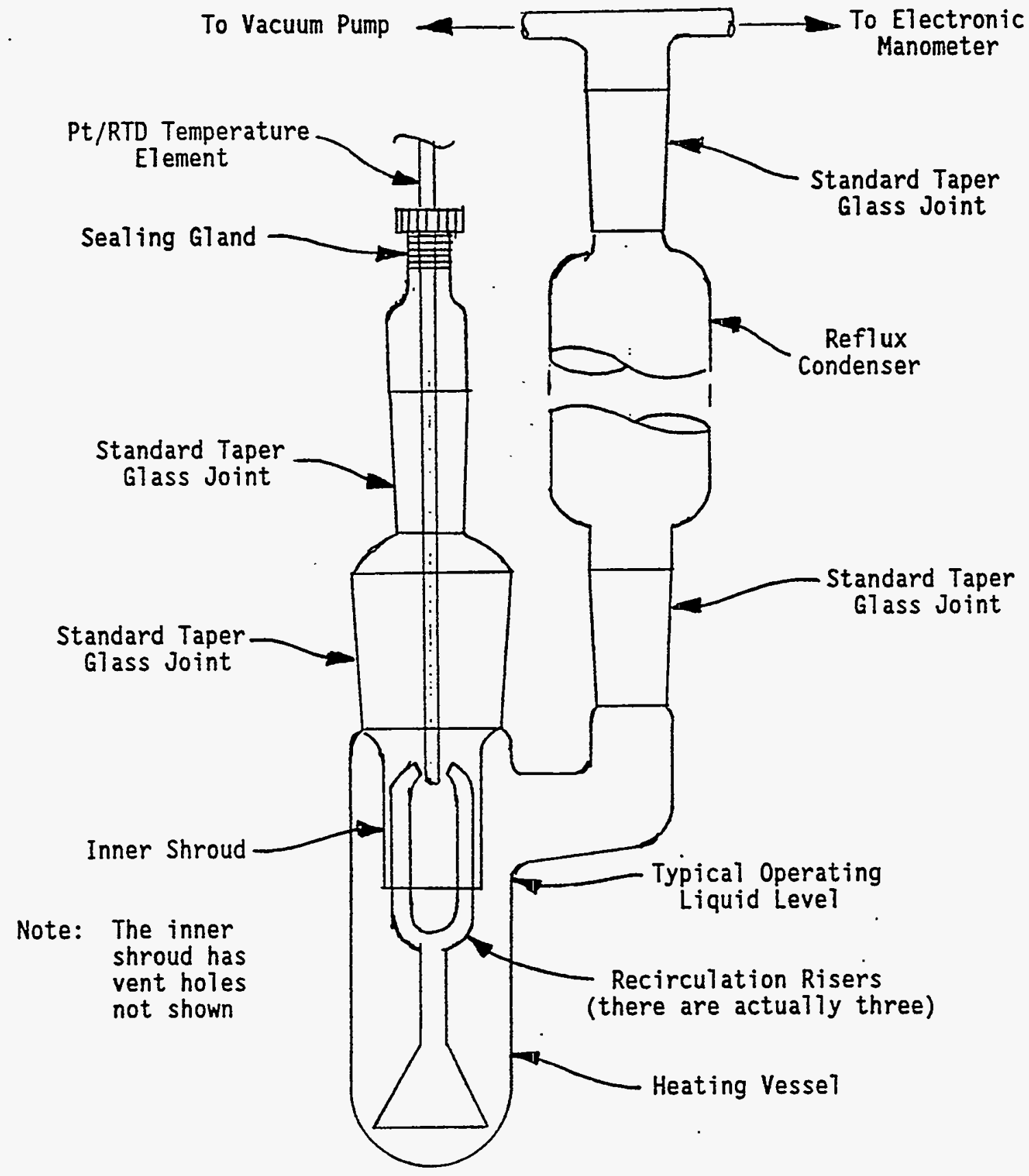

Figure 1. Cottrell Boiling Point Apparatus 
* * * TABLE 1. DI WATER VAPOR PRESSURE DATA WITH COTTRELL APPARATUS * * *

$\begin{array}{cccccc}\begin{array}{c}\text { ABSOLUTE } \\ \text { PRESSURE } \\ \text { mm Hg }\end{array} & \text { Handbook } & \text { oct } 17 & \text { Oct } 20 & \text { Oct } 25 & \text { Nov 1,7 } \\ 65 & 43.1 & 43.2 & 43.2 & -- & \\ 80 & 47.1 & 47.2 & 47.1 & 47.2 & \\ 81 & 47.3 & & & & .46 .9 \\ 94 & 50.3 & & & & 50.4 \\ 100 & 51.6 & 51.7 & 51.6 & 51.8 & \\ 120.5 & 55.4 & & & & 55.6 \\ 150 & 60.1 & 60.2 & 60.1 & 60.3 & \\ 200 & 66.5 & 66.6 & 66.4 & 66.6 & \\ 202 & 65.7 & & & & 66.8 \\ 231 & 69.7 & & & & 69.8 \\ 250 & 71.6 & 71.6 & 71.7 & 71.9 & \\ 288.5 & 75.0 & & & & 74.9 \\ 300 & 75.9 & 75.9 & 75.9 & 76.1 & \\ 400 & 83.0 & 83.1 & 82.9 & 83.3 & \\ 450 & 85.9 & & & & 85.9 \\ 500 & 88.7 & 88.7 & 88.6 & 88.9 & \\ 600 & 93.5 & 93.6 & 93.3 & 93.6 & \\ 621 & 94.4 & & & & 94.7 \\ 697 & 97.6 & 97.4 & 97.5 & 97.7 & \\ & & & & & \end{array}$

Note: The DI water "Handbook" data is from the Handbook of Chemistry and Physics, Thirty-third Edition, Chemical Rubber Publishing Company, 1951. 
* * * TABLE 2. VAPOR PRESSURE DATA ON TEST SOLUTIONS IN COTTRELL APPARATUS * * *

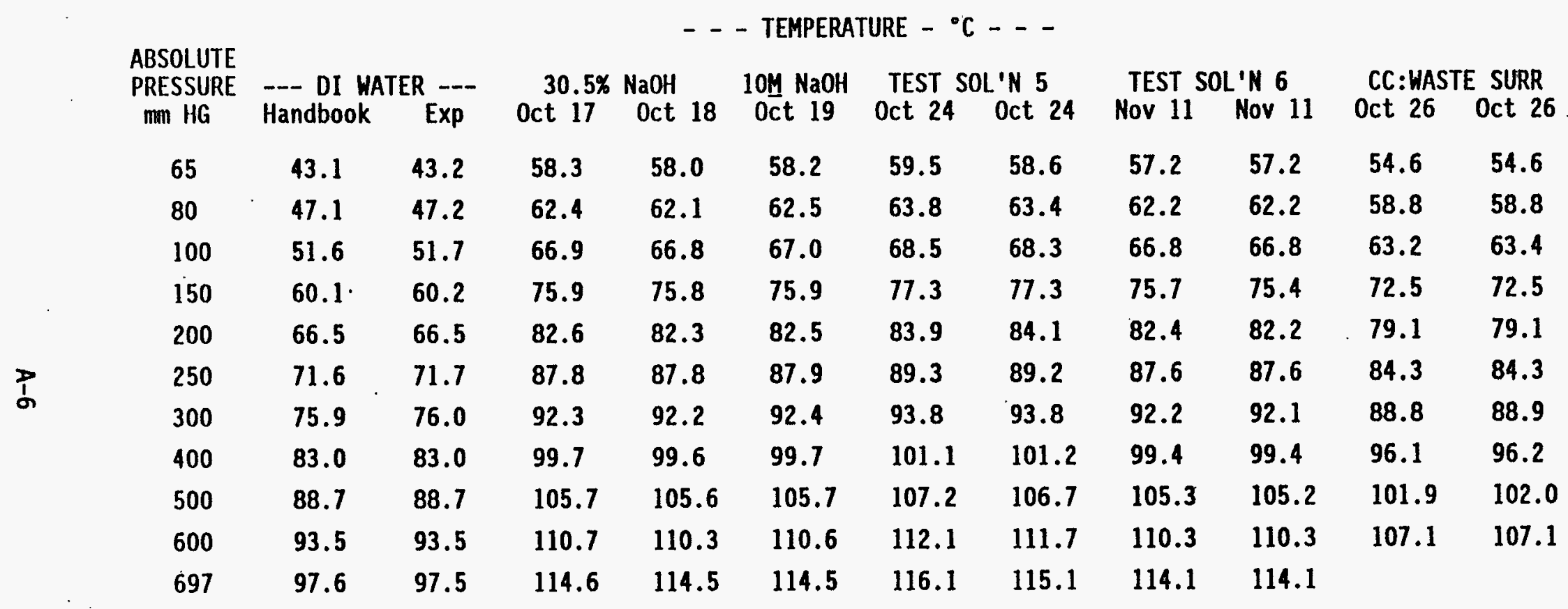

Note: The DI water experimental data ("Exp") are mean values of the test data shown in Table 1. 


\section{* * table 3. VÁPor PRESSURE daTA on reference solutions}

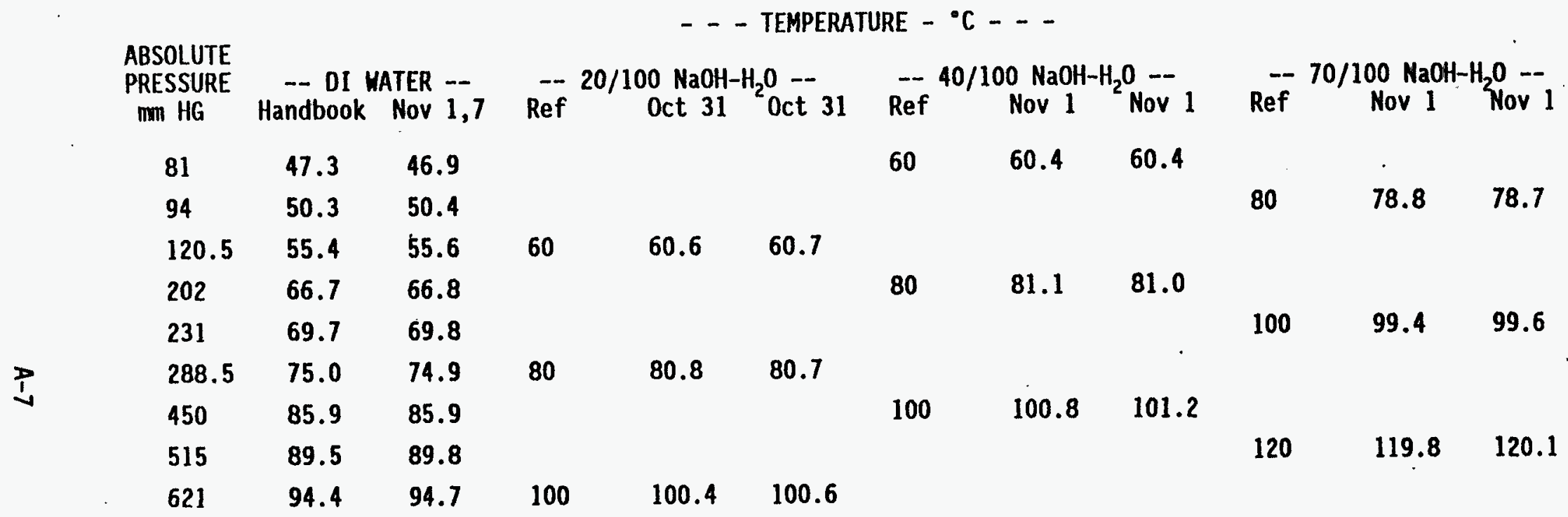

Notes: $20 / 100 \mathrm{NaOH}-\mathrm{H}_{2} \mathrm{O}$ means $20 \mathrm{gms} \mathrm{NaOH}$ dissolved in $100 \mathrm{gms} \mathrm{H}_{2} \mathrm{O}$, etc.

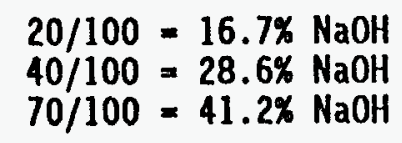

"Ref" is the temperature at which the specified $\mathrm{NaOH}$ solution has the corresponding vapor pressure shown in the ABSOLUTE PRESSURE column, per $\mathrm{NaOH}-\mathrm{H}_{2} \mathrm{O}$ vapor pressure/temperature data from the Chemical Engineers' Handbook, Third Edition, McGraw-Hil1 Book Company, Inc., 1950. 
WHC-SD-W236A-ER-009

Rev. 0

Appendix B. Instrument List. 


\begin{tabular}{|c|c|c|c|c|c|}
\hline $\begin{array}{c}\text { Instrument/ } \\
\text { Variable }\end{array}$ & Description/Location & Function & $\begin{array}{c}\text { Manufacture/ } \\
\text { Mode1 }\end{array}$ & Accuracy & $\begin{array}{l}\text { Calibration } \\
\text { lab code \# }\end{array}$ \\
\hline $\mathrm{TCl}$ & $\begin{array}{l}\text { Thermocouple teed into } \\
\text { circulation heater } \\
\text { output }\end{array}$ & $\begin{array}{l}\text { Control input for } \\
\text { circulation heater } \\
\text { temperature controller }\end{array}$ & $\begin{array}{l}\text { Type K } \\
\text { thermocouple }\end{array}$ & $\pm 2^{\circ} \mathrm{F}$ & $\begin{array}{l}\text { Used as } \\
\text { Received }\end{array}$ \\
\hline TC2 & $\begin{array}{l}\text { Thermocouple internal } \\
\text { to circulation heater }\end{array}$ & $\begin{array}{l}\text { Independent over } \\
\text { temperature cutout for } \\
\text { circulation heater } \\
\text { controller }\end{array}$ & $\begin{array}{l}\text { Type K } \\
\text { thermocoup } 7 e\end{array}$ & $\pm 2^{\circ} \mathrm{F}$ & $\begin{array}{l}\text { Used as } \\
\text { Received }\end{array}$ \\
\hline TC3 & $\begin{array}{l}\text { Thermocouple in } \\
\text { solution at center of } \\
\text { tank }\end{array}$ & Solution temp, data & $\begin{array}{l}\text { Type K } \\
\text { thermocouple }\end{array}$ & $\pm 2^{\circ} \mathrm{F}$ & $\begin{array}{l}\text { Used as } \\
\text { Received }\end{array}$ \\
\hline TC4 & $\begin{array}{l}\text { Thermocouple in } \\
\text { solution at center of } \\
\text { tank }\end{array}$ & Solution temp, data & $\begin{array}{l}\text { Type K } \\
\text { thermocouple }\end{array}$ & $\pm 2{ }^{\circ} \mathrm{F}$ & $\begin{array}{l}\text { Used as } \\
\text { Received }\end{array}$ \\
\hline TC5 & $\begin{array}{l}\text { Thermocouple in tank } \\
\text { solution at radius of } \\
\text { vent outlet and } \\
\text { displaced }-90^{\circ}\end{array}$ & Solution temp, data & $\begin{array}{l}\text { Type K } \\
\text { thermocouple }\end{array}$ & $\pm 2^{\circ} \mathrm{F}$ & $\begin{array}{l}\text { Used as } \\
\text { Received }\end{array}$ \\
\hline TC6 & $\begin{array}{l}\text { Thermocouple in tank } \\
\text { solution at radius of } \\
\text { vent outlet and } \\
\text { displaced }+90^{\circ}\end{array}$ & Solution temp, data & $\begin{array}{l}\text { Type K } \\
\text { thermocouple }\end{array}$ & $\pm 2^{\circ} \mathrm{F}$ & $\begin{array}{l}\text { Used as } \\
\text { Received }\end{array}$ \\
\hline TC7 & $\begin{array}{l}\text { Thermocouple on top of } \\
\text { tank under insulating } \\
\text { rubber }\end{array}$ & $\begin{array}{l}\text { Dome/head temperature, } \\
\text { data }\end{array}$ & $\begin{array}{l}\text { Type K } \\
\text { thermocouple }\end{array}$ & $\pm 2{ }^{\circ} \mathrm{F}$ & $\begin{array}{l}\text { Used as } \\
\text { Received }\end{array}$ \\
\hline TC8 & $\begin{array}{l}\text { Thermocouple on sloped } \\
\text { part of tank head under } \\
\text { insulating rubber }\end{array}$ & $\begin{array}{l}\text { Dome/head temperature, } \\
\text { data }\end{array}$ & $\begin{array}{l}\text { Type K } \\
\text { thermocouple }\end{array}$ & $\pm 2^{\circ} \mathrm{F}$ & $\begin{array}{l}\text { Used as } \\
\text { Received }\end{array}$ \\
\hline P1 & $\begin{array}{l}\text { Inlet air static } \\
\text { pressure }\end{array}$ & $\begin{array}{l}\text { Ambient absolute air } \\
\text { pressure, data }\end{array}$ & $\begin{array}{l}\text { MKS Baratron } \\
222 \text { BHS } \\
1000 \text { Torr } \\
\end{array}$ & $\begin{array}{l} \pm .5 \% \\
\text { Reading }\end{array}$ & $\begin{array}{l}679-80-02- \\
024\end{array}$ \\
\hline DP1 & $\begin{array}{l}\text { Inlet air differential } \\
\text { pressure }\end{array}$ & $\begin{array}{l}\text { Differential pressure } \\
\text { from the inlet Venturi } \\
\text { flow meter, data }\end{array}$ & $\begin{array}{l}\text { MKS Baratron } \\
223 \mathrm{~B} \\
\pm 0-5 \text { in } / \mathrm{H}_{2} \mathrm{O}\end{array}$ & $\begin{array}{l} \pm .5 \% \\
\text { Füili } \\
\text { Scale }\end{array}$ & $\begin{array}{l}679-80-02- \\
022\end{array}$ \\
\hline
\end{tabular}




\begin{tabular}{|c|c|c|c|c|c|}
\hline $\begin{array}{c}\text { Instrument/ } \\
\text { Variable }\end{array}$ & Description/Location & Function & $\begin{array}{c}\text { Manufacture/ } \\
\text { Model }\end{array}$ & Accuracy & $\begin{array}{l}\text { Cal ibration } \\
\text { lab code \# }\end{array}$ \\
\hline FLOWIN & $\begin{array}{l}\text { Inlet air flow venturi } \\
\text { meter }\end{array}$ & $\begin{array}{l}\text { Mass flow rate of the } \\
\text { inlet air derived } \\
\text { from: DP1, RTD1, RH1. } \\
\text { computed value }\end{array}$ & $\begin{array}{l}\text { Flow-Dyne } \\
\text { Engineering } \\
\text { VP0150979-PVC } \\
\text {.979" Dia. } \\
\text { throat } \\
\end{array}$ & $N / A$ & $\begin{array}{l}\text { Used as } \\
\text { Received }\end{array}$ \\
\hline $\mathrm{DP2}$ & $\begin{array}{l}\text { Outlet air differential } \\
\text { pressure }\end{array}$ & $\begin{array}{l}\text { Differential pressure } \\
\text { from the pitot/static } \\
\text { section at the outlet }\end{array}$ & $\begin{array}{l}\text { MKS Baratron } \\
223 \mathrm{BD} \\
\pm 0-1 \text { torr } \\
\end{array}$ & $\begin{array}{l} \pm .5 \% \\
\text { Fuil } \\
\text { Scale } \\
\end{array}$ & $\begin{array}{l}679-80-02- \\
025\end{array}$ \\
\hline FLOWOUT & $\begin{array}{l}\text { Outlet air flow } \\
\text { Pitot/static section }\end{array}$ & $\begin{array}{l}\text { Mass flow rate of the } \\
\text { outlet a ir derived } \\
\text { from: DP2, RTD4, RH4. } \\
\text { computed value }\end{array}$ & $\begin{array}{l}\text { Air Monitor } \\
\text { Corp LO-FLO } \\
0-50 \text { SCFM }\end{array}$ & $N / A$ & $\begin{array}{l}\text { Used as } \\
\text { Received }\end{array}$ \\
\hline RTD1/Tempin & $\begin{array}{l}\text { Inlet air temperature } \\
\text { in plywood box } \\
\text { surrounding inlet } \\
\text { flowmeter }\end{array}$ & $\begin{array}{l}\text { Inlet air dry bulb } \\
\text { temp, data }\end{array}$ & $\begin{array}{l}\text { Vaisala HMD } \\
20 Y B\end{array}$ & $\pm .2{ }^{\circ} \mathrm{C}$ & $\begin{array}{l}679-32-03- \\
006\end{array}$ \\
\hline RTD2/Temp2 & $\begin{array}{l}\text { Tank Vapor space air } \\
\text { temperature } 12 " \text { above } \\
\text { liquid surface, center } \\
\text { of tank }\end{array}$ & $\begin{array}{l}\text { Vapor space air dry } \\
\text { bulb temperature, data }\end{array}$ & $\begin{array}{l}\text { Vaisala HMP } \\
135 Y\end{array}$ & $\pm .2{ }^{\circ} \mathrm{C}$ & $\begin{array}{l}679-32-07- \\
003\end{array}$ \\
\hline RTD3/Temp3 & $\begin{array}{l}\text { Tank Vapor space air } \\
\text { temperature } \text { 6" above }^{\prime \prime} \\
\text { liquid surface, center } \\
\text { of tank }\end{array}$ & $\begin{array}{l}\text { Vapor space air dry } \\
\text { bulb temperature, data }\end{array}$ & $\begin{array}{l}\text { Vaisala HMP } \\
135 Y\end{array}$ & $\pm .2{ }^{\circ} \mathrm{C}$ & $\begin{array}{l}679-32-07- \\
002\end{array}$ \\
\hline RTD4/Tempout & $\begin{array}{l}\text { Tank Outlet dry bulb } \\
\text { air temperature, teed } \\
\text { into air outlet line } \\
\text { directly above tank }\end{array}$ & $\begin{array}{l}\text { Outlet air dry bulb } \\
\text { temperature, data }\end{array}$ & $\begin{array}{l}\text { Vaisala HMP } \\
135 Y\end{array}$ & $\pm .2{ }^{\circ} \mathrm{C}$ & $\begin{array}{l}679-32-01- \\
004\end{array}$ \\
\hline RH1/Epsin & $\begin{array}{l}\text { Inlet air relative } \\
\text { humidity. Probe in } \\
\text { plywood box surrounding } \\
\text { inlet flowmeter. }\end{array}$ & $\begin{array}{l}\text { Relative humidity post } \\
\text { processed with Tempin } \\
\text { to give inlet moisture } \\
\text { ratio. data, computed } \\
\text { value }\end{array}$ & $\begin{array}{l}\text { Vaisala HMD } \\
20 Y B\end{array}$ & $\pm 2 \%$ R.H. & $\begin{array}{l}679-32-03- \\
006\end{array}$ \\
\hline
\end{tabular}




\begin{tabular}{|c|c|c|c|c|c|}
\hline $\begin{array}{c}\text { Instrument/ } \\
\text { Variable }\end{array}$ & Description/Location & Function & $\begin{array}{c}\text { Manufacture/ } \\
\text { Mode1 }\end{array}$ & Accuracy & $\begin{array}{l}\text { Calibration } \\
\text { lab code \# }\end{array}$ \\
\hline RH2/Eps2 & $\begin{array}{l}\text { Tank Vapor space air } \\
\text { reTative humidity } \sim 12 " \\
\text { above liquid surface, } \\
\text { center of tank }\end{array}$ & $\begin{array}{l}\text { Relative humidity } \\
\text { post-processed with } \\
\text { Temp2 to give moisture } \\
\text { ratio. data, computed } \\
\text { value }\end{array}$ & $\begin{array}{l}\text { Vaisala HMP } \\
\text { l35Y }\end{array}$ & $\begin{array}{l} \pm 2 \% \text { R.H. } \\
0-90 \% \\
\pm 3 \% \text { R.H. } \\
90-100 \%\end{array}$ & $\begin{array}{l}679-32-01- \\
003\end{array}$ \\
\hline RH3/Eps3 & $\begin{array}{l}\text { Tank Vapor space air } \\
\text { relative humidity }{ }^{\prime \prime} \\
\text { above liquid surface, } \\
\text { center of tank }\end{array}$ & $\begin{array}{l}\text { Relative humidity } \\
\text { post-processed with } \\
\text { Temp } 3 \text { to give moisture } \\
\text { ratio. data, computed } \\
\text { value }\end{array}$ & $\begin{array}{l}\text { Vaisala HMP } \\
135 Y\end{array}$ & $\begin{array}{l} \pm 2 \% \text { R.H. } \\
0-90 \% \\
\pm 3 \% \text { R.H. } \\
90-100 \%\end{array}$ & $\begin{array}{l}679-32-01- \\
002\end{array}$ \\
\hline RH4/EPSOUT & $\begin{array}{l}\text { Tank outlet relative } \\
\text { humidity. Probe is } \\
\text { teed into air outlet } \\
\text { line directly above } \\
\text { tank }\end{array}$ & $\begin{array}{l}\text { Relative humidity } \\
\text { post-processed with } \\
\text { Tempout to give } \\
\text { moisture ratio. data, } \\
\text { computed value }\end{array}$ & $\begin{array}{l}\text { Vaisala HMP } \\
\text { 135Y }\end{array}$ & $\begin{array}{l} \pm 2 \% \text { R.H. } \\
0-90 \% \\
\pm 3 \% \text { R.H. } \\
90-100 \%\end{array}$ & $\begin{array}{l}679-32-01- \\
004\end{array}$ \\
\hline EPSOURC & $\begin{array}{l}\text { Moisture ratio at } \\
\text { simulant surface, based } \\
\text { on simulant temp and } \\
\text { vapor pressure } \\
\text { reduction to } 55 \% \text { of } \\
\text { water }\end{array}$ & $\begin{array}{l}\text { Provide a measure of } \\
\text { the driving potential } \\
\text { available for } \\
\text { evaporation }\end{array}$ & derived value & $N / A$ & $N / A$ \\
\hline
\end{tabular}


WHC-SD-H236A-ER-009

Rev. $O$

Appendix C. Test Data.

$c-i$ 


\section{RTD Temperatures (test 1)}

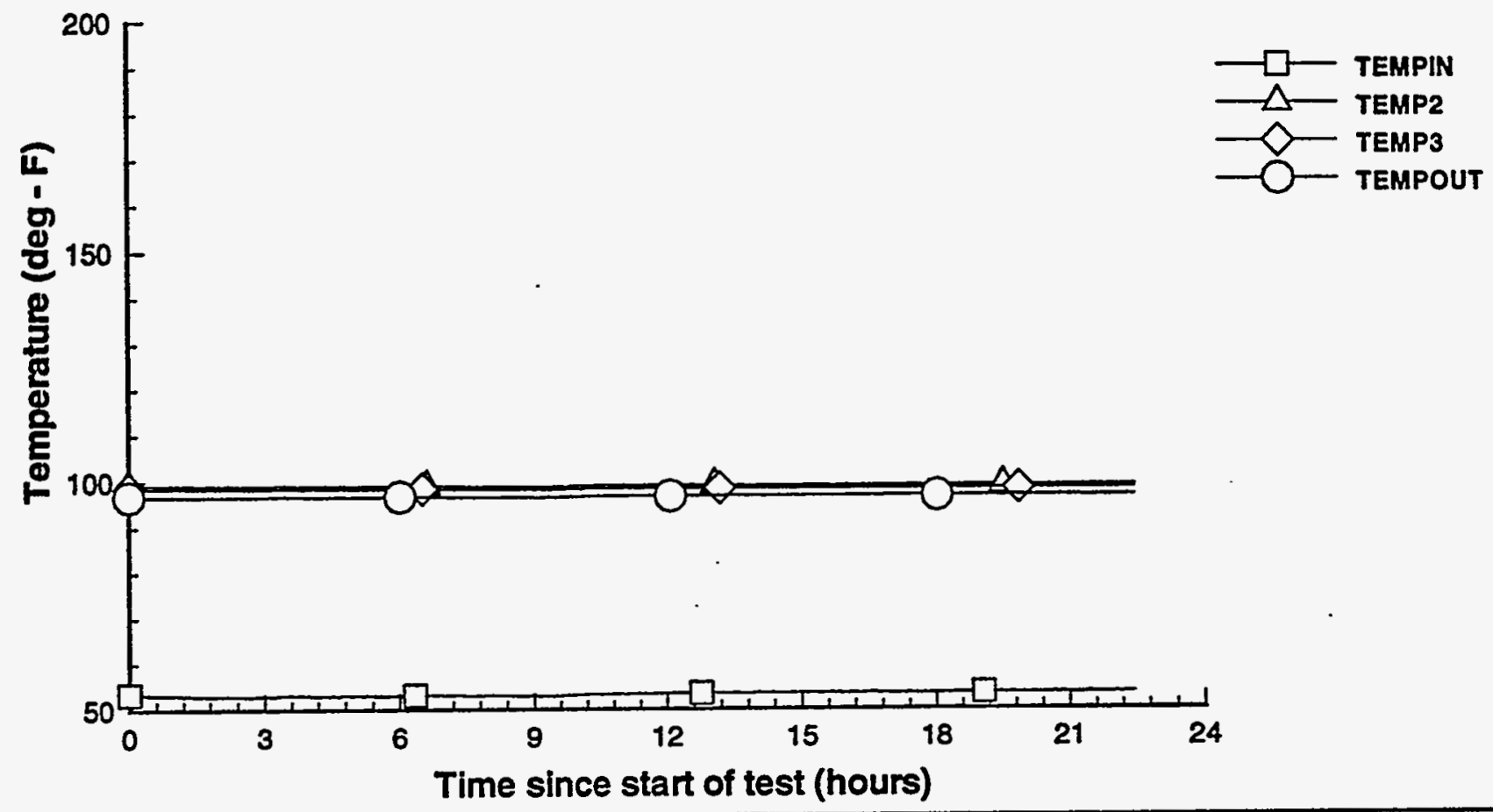

Vapor Space Air Flow (test 1)

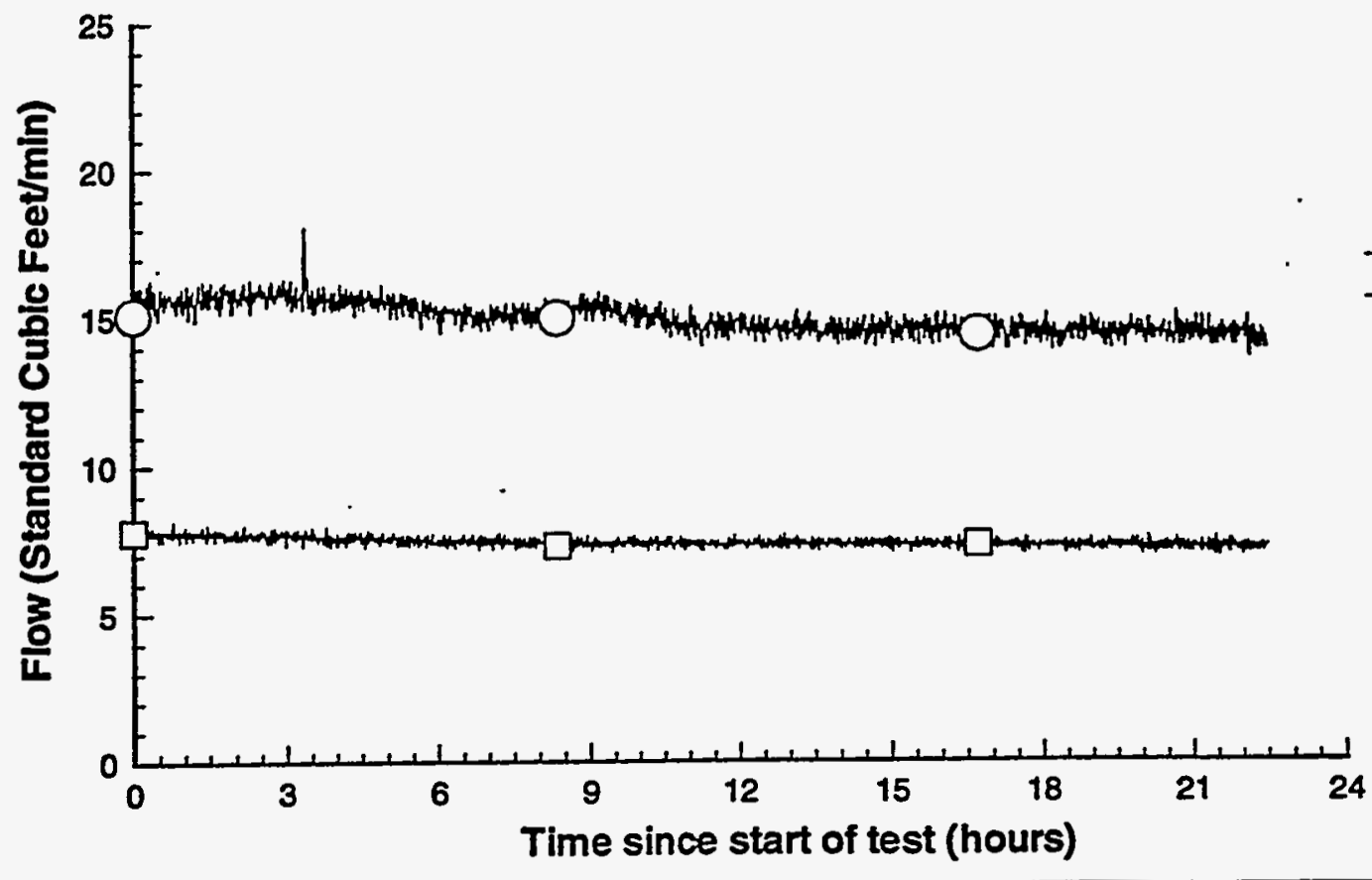

C-1 


\section{Thermocouple Temperatures (test 1)}
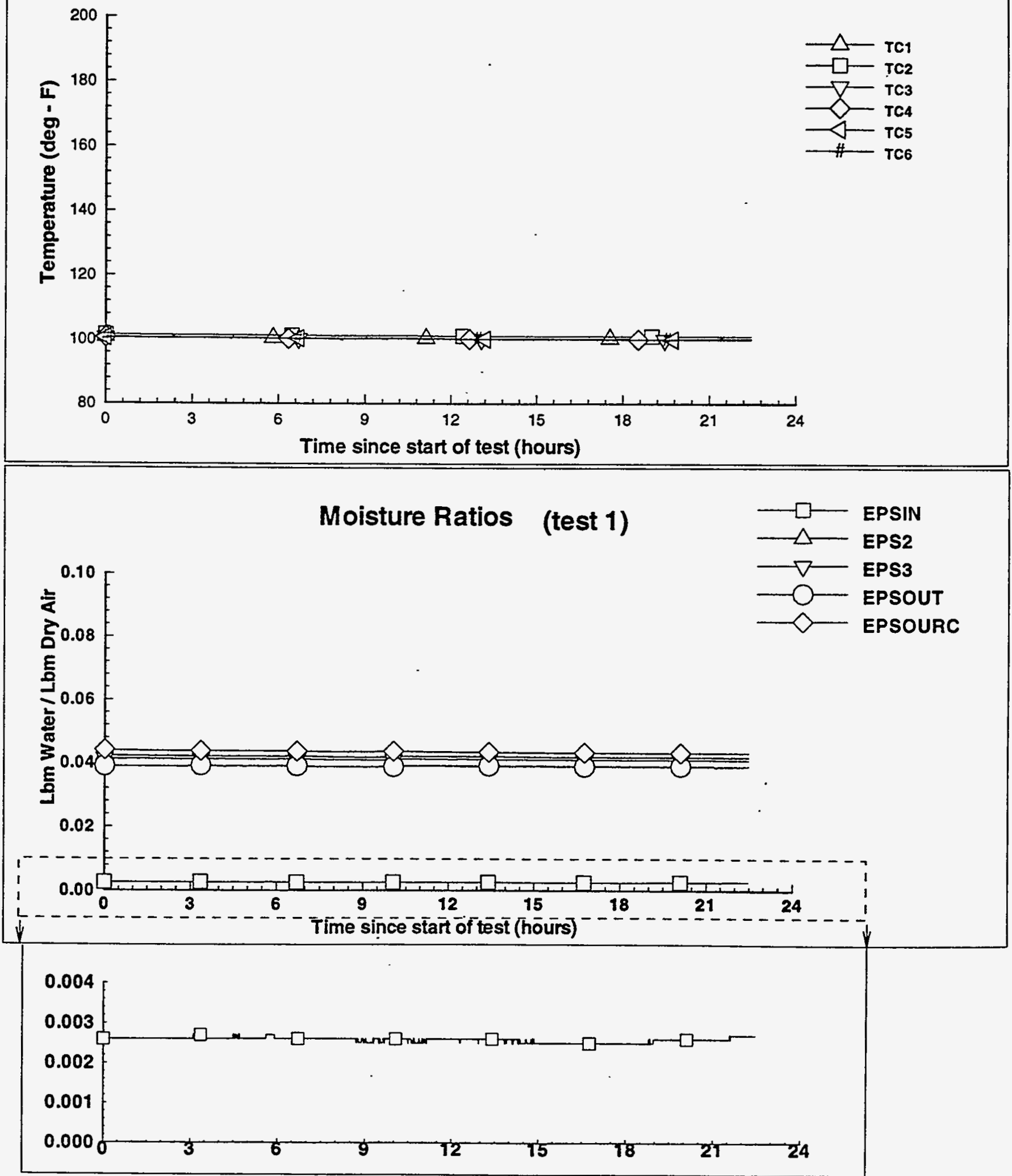


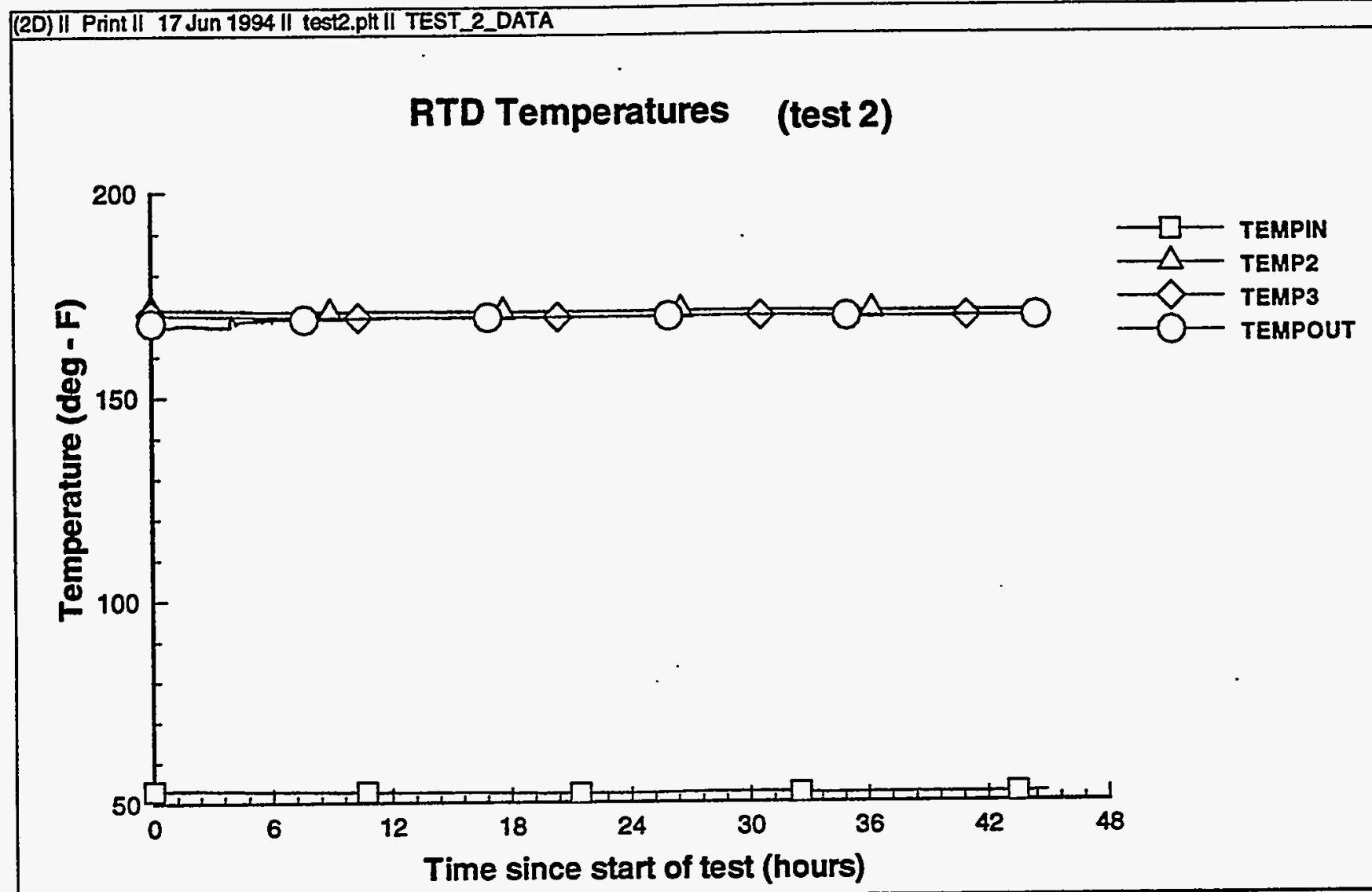

\section{Vapor Space Air Flow (test 2)}

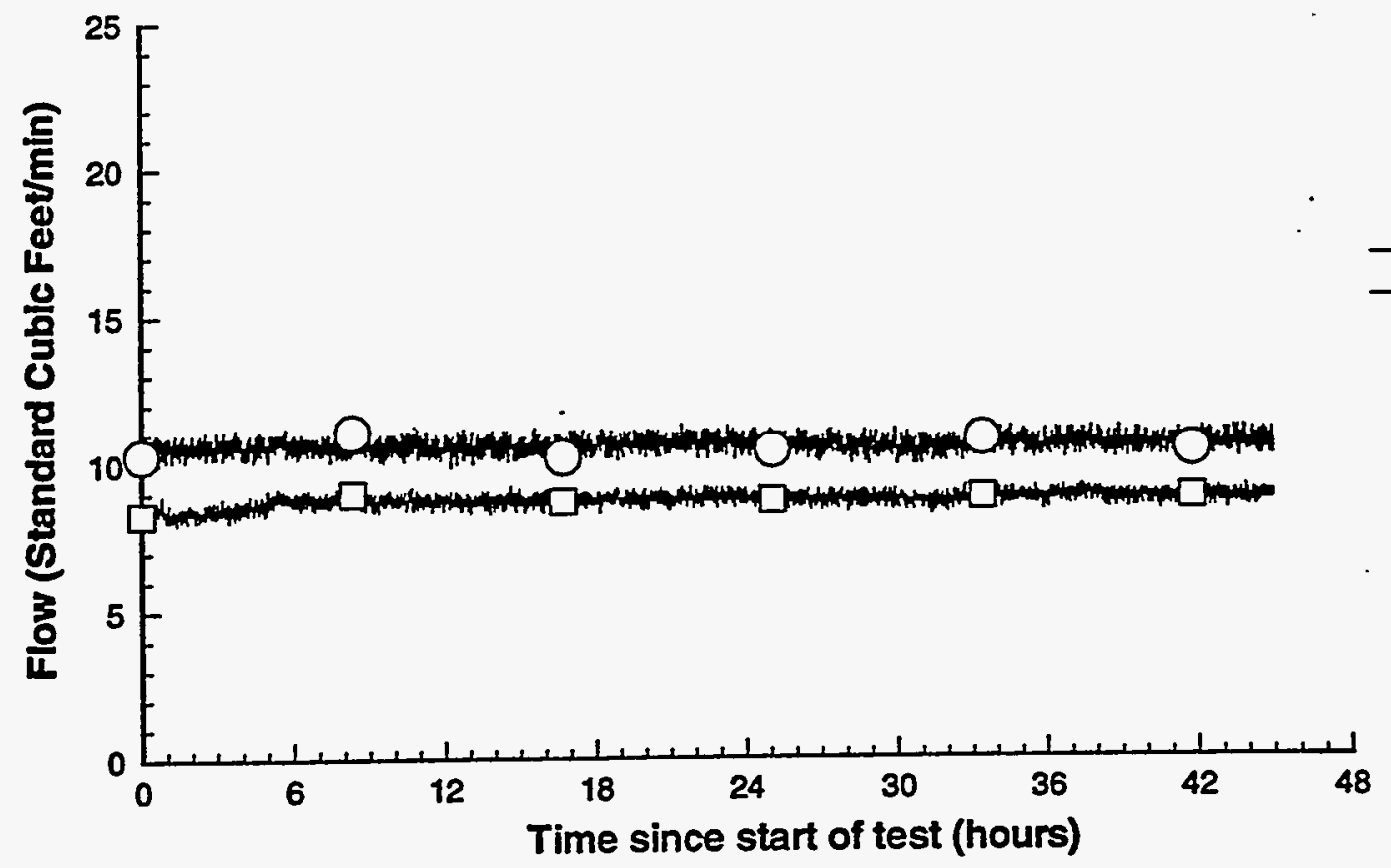


RTD Temperatures (test 2)
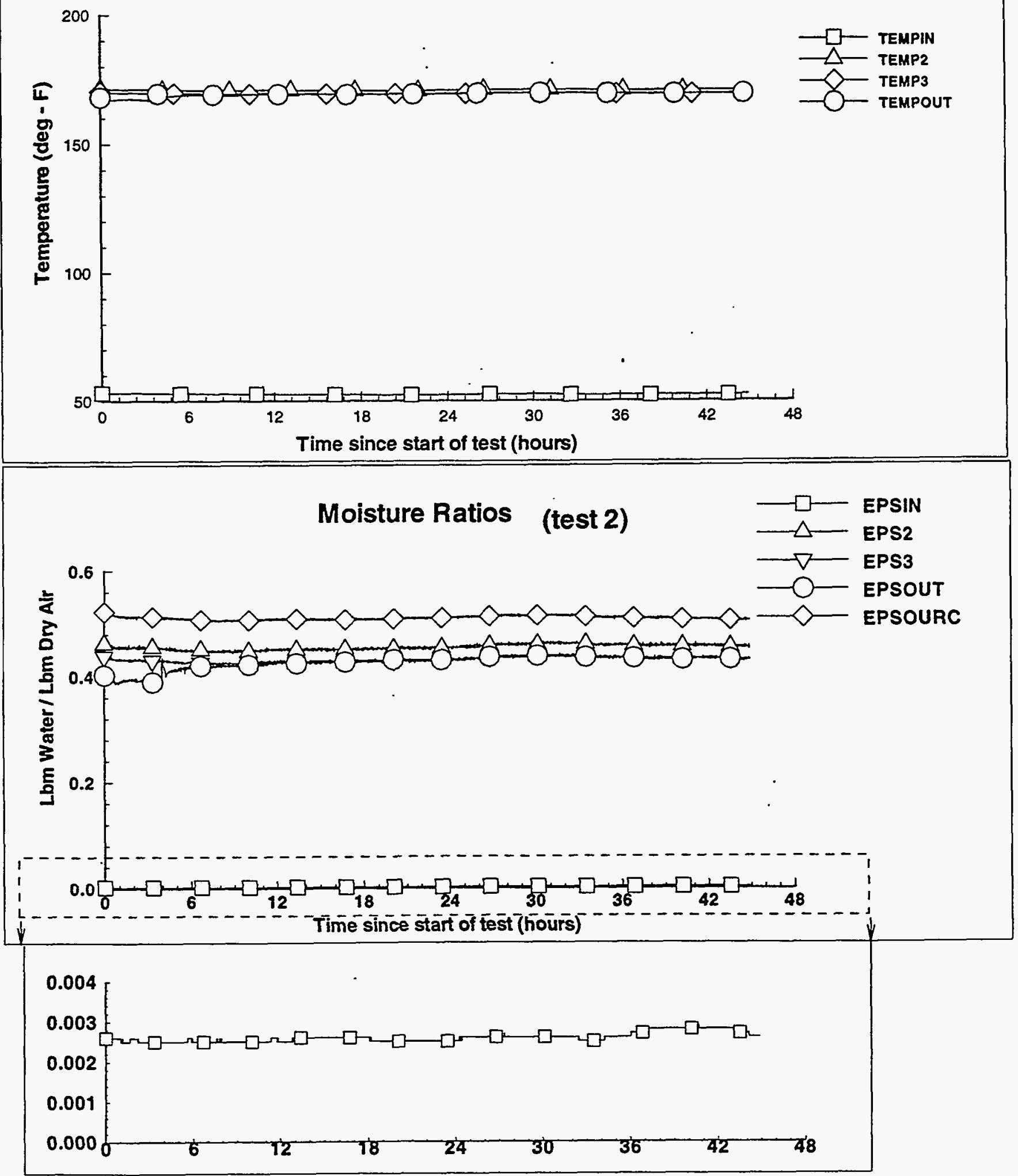
WHC-SD-W236A-ER-009

Rev. 0

\section{RTD Temperatures (test 3)}

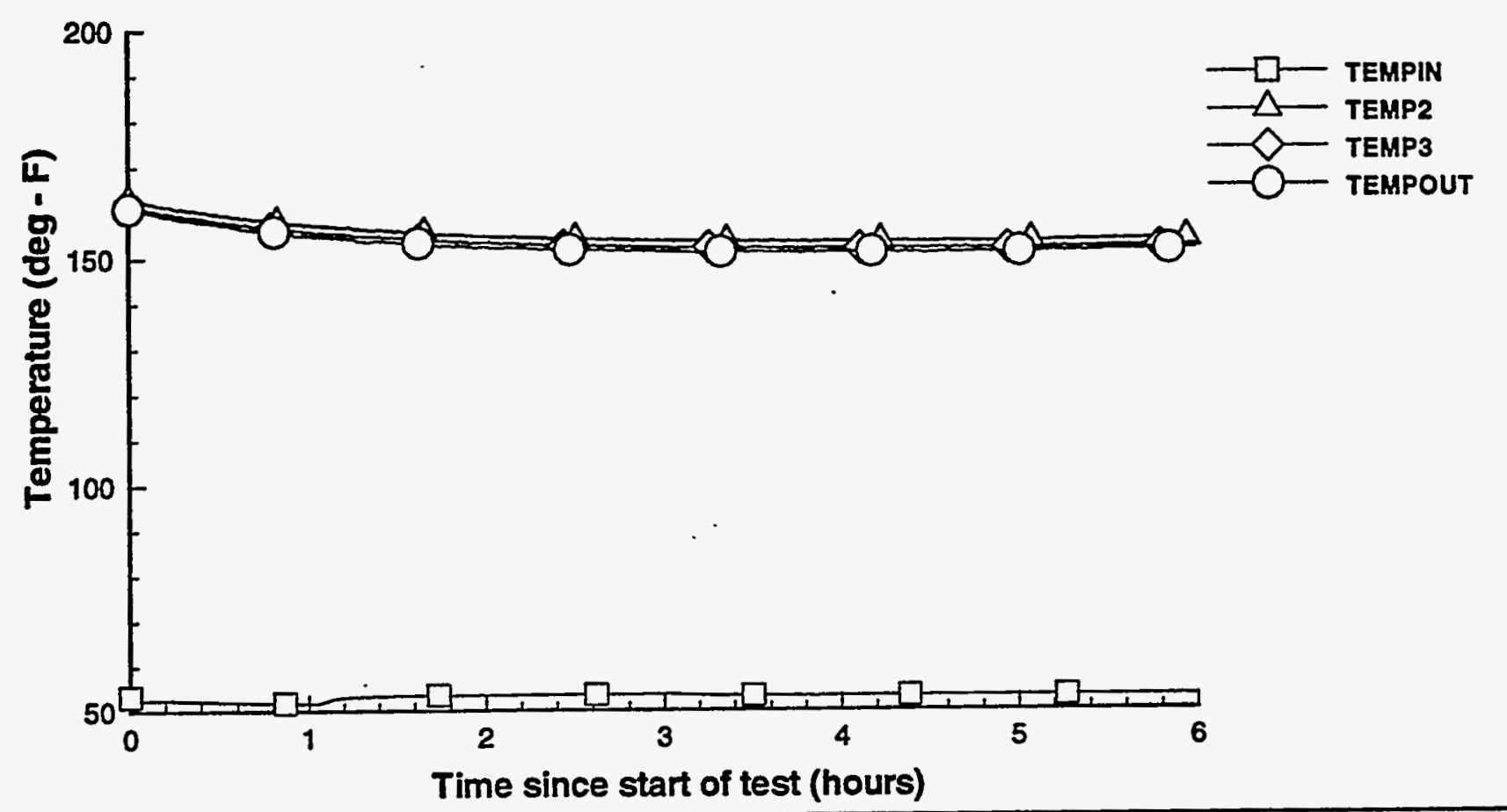

Vapor Space Air Flow (test 3)

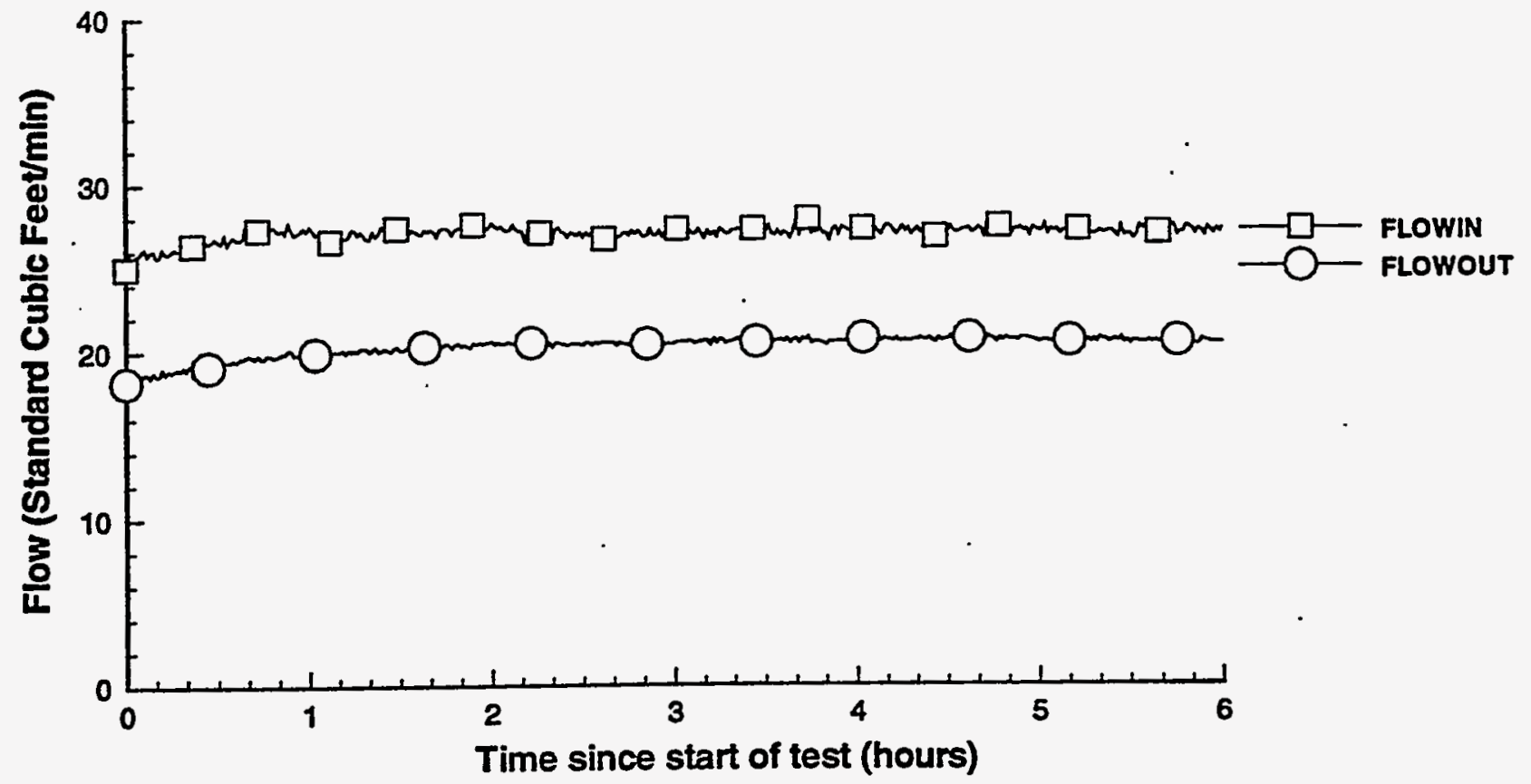

C-5 
HHC-SD-W236A-ER-009

Rev. 0

(2D) || Print I| 19 Aug 1994 || test3.pH || TEST_3_DATA

Thermocouple Temperatures

(test 3)
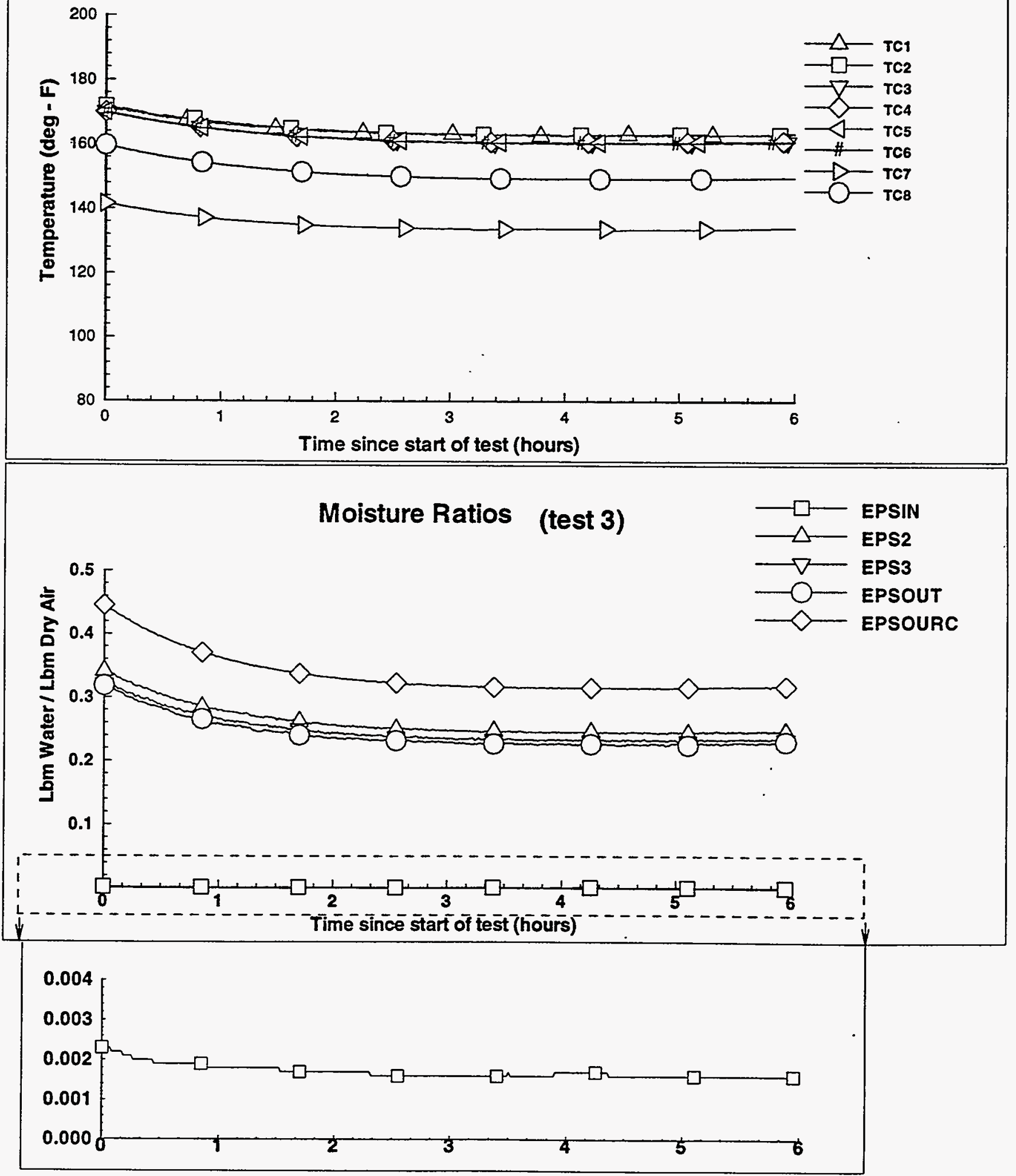

C-6 
WHC-SD-W236A-ER-009

Rev. 0

RTD Temperatures (test 4)

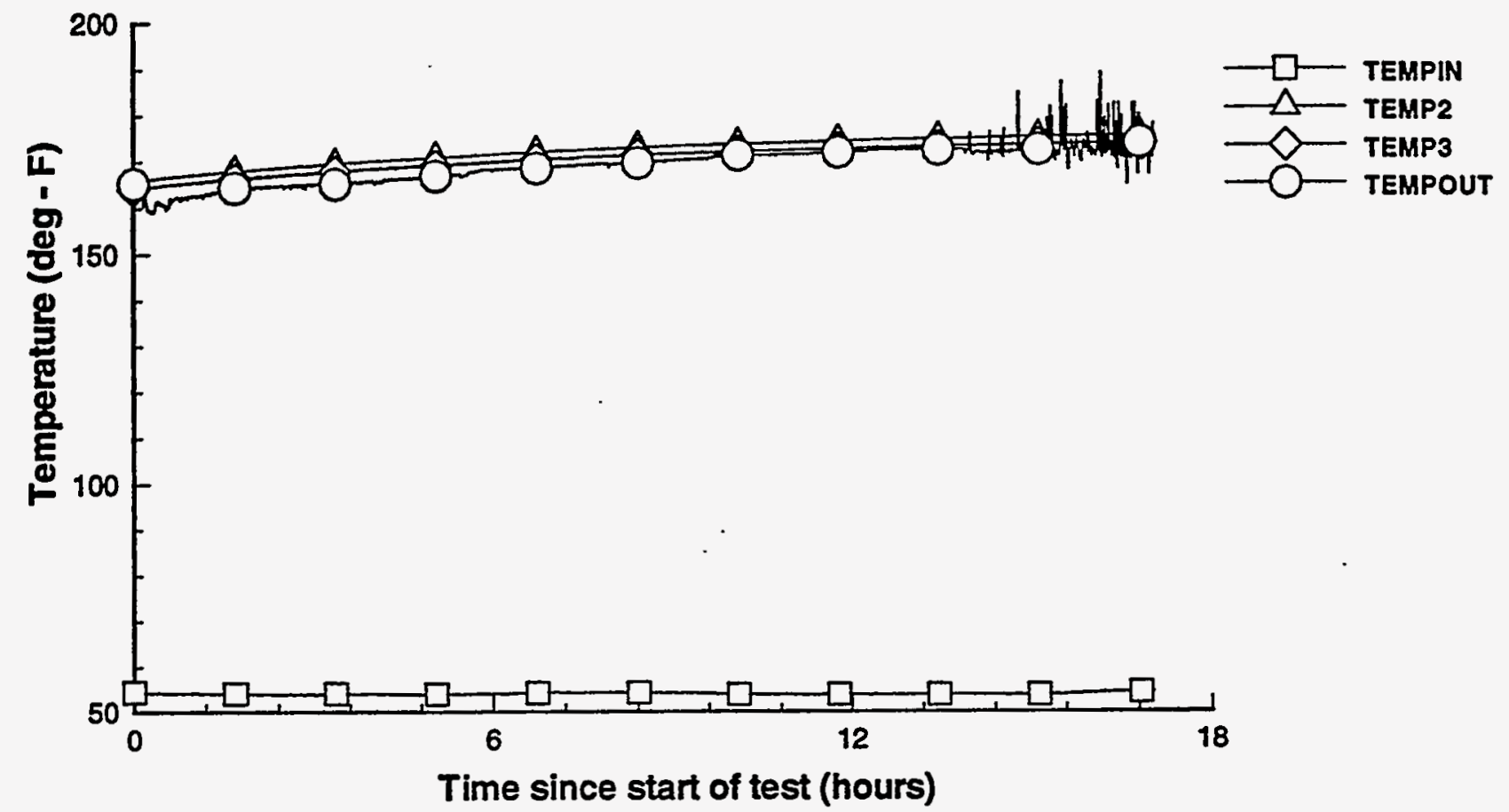

Vapor Space Air Flow (test 4)

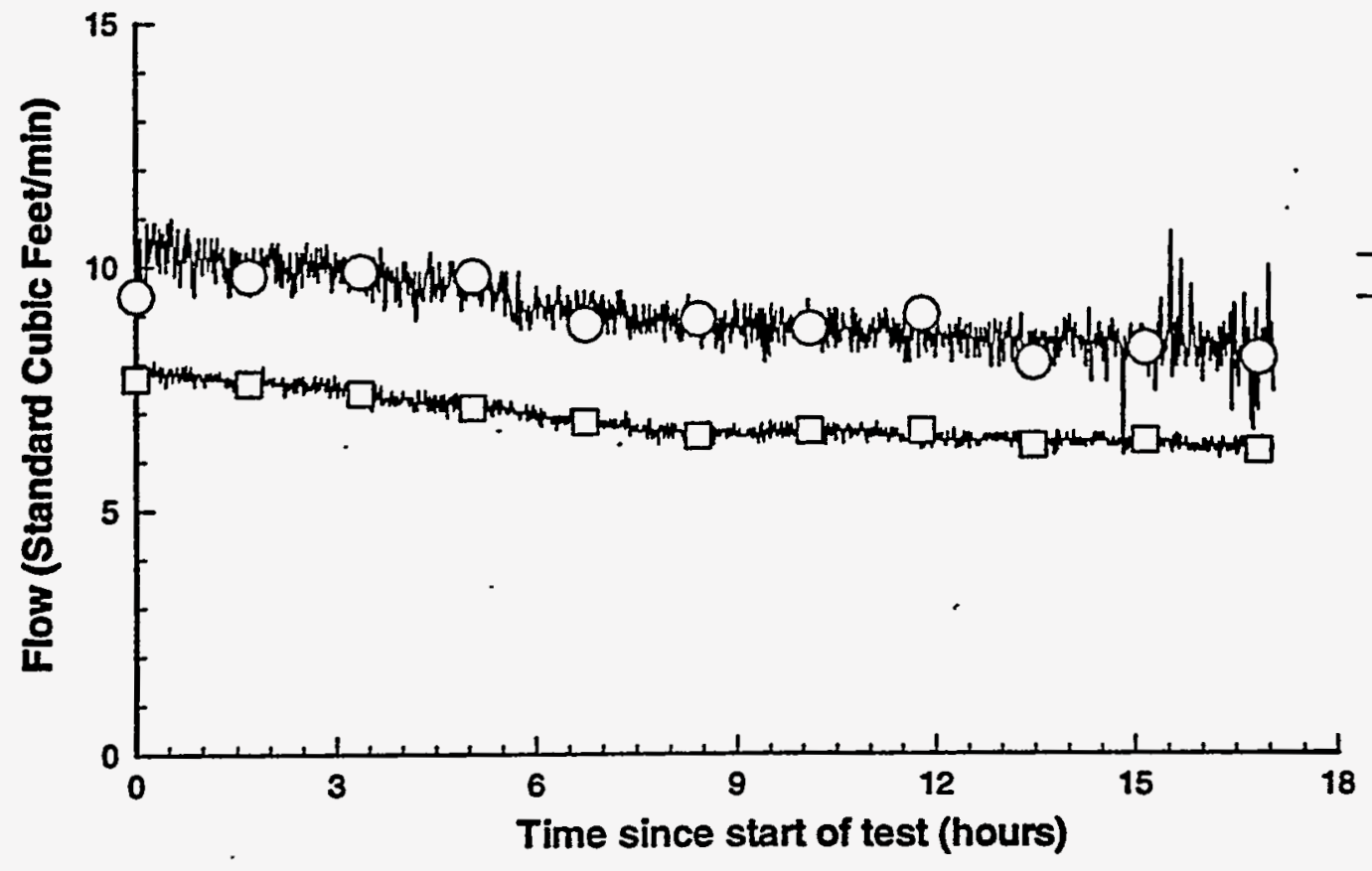


WHC-SD-W236A-ER-009

Rev. 0

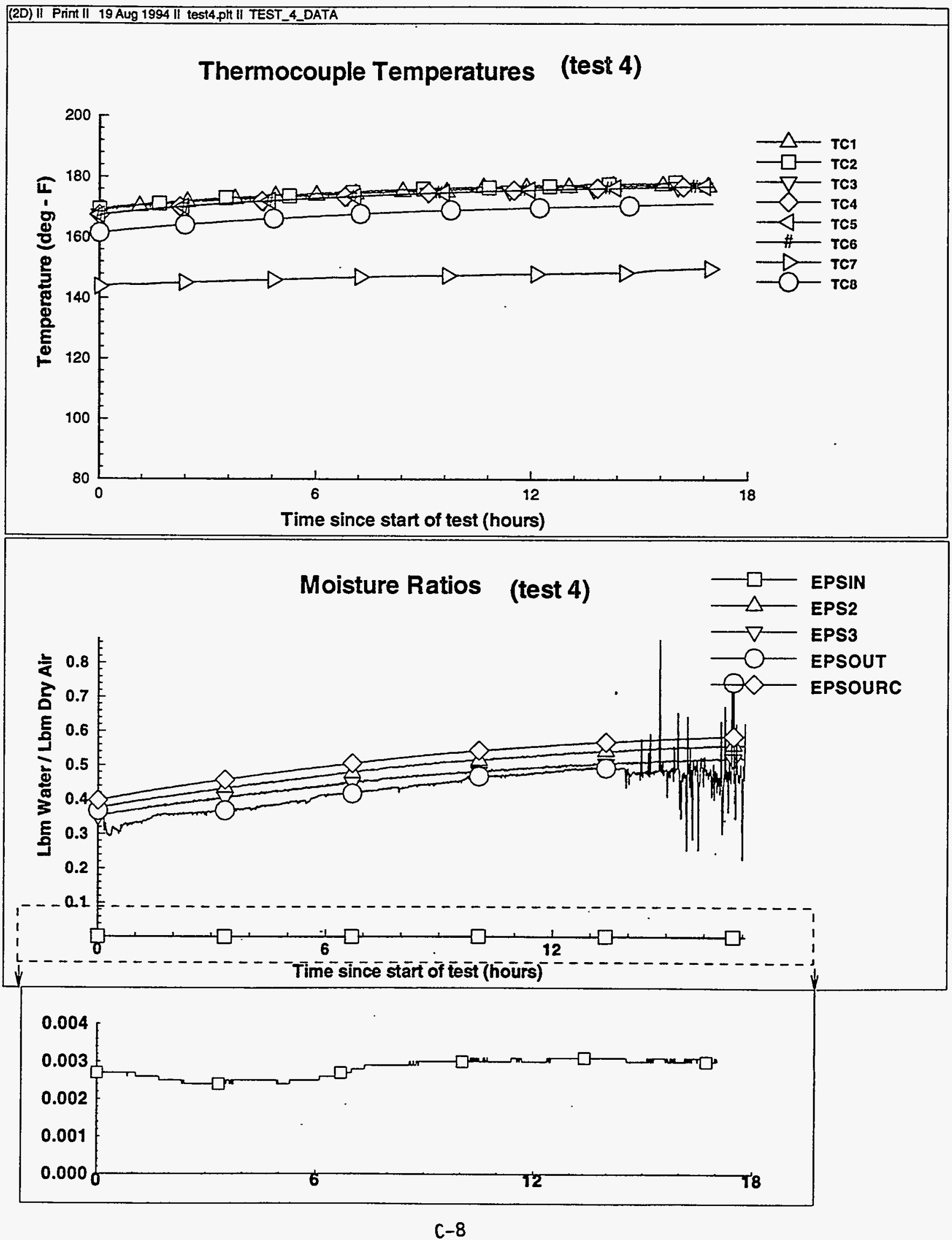




\section{RTD Temperatures (test 5)}

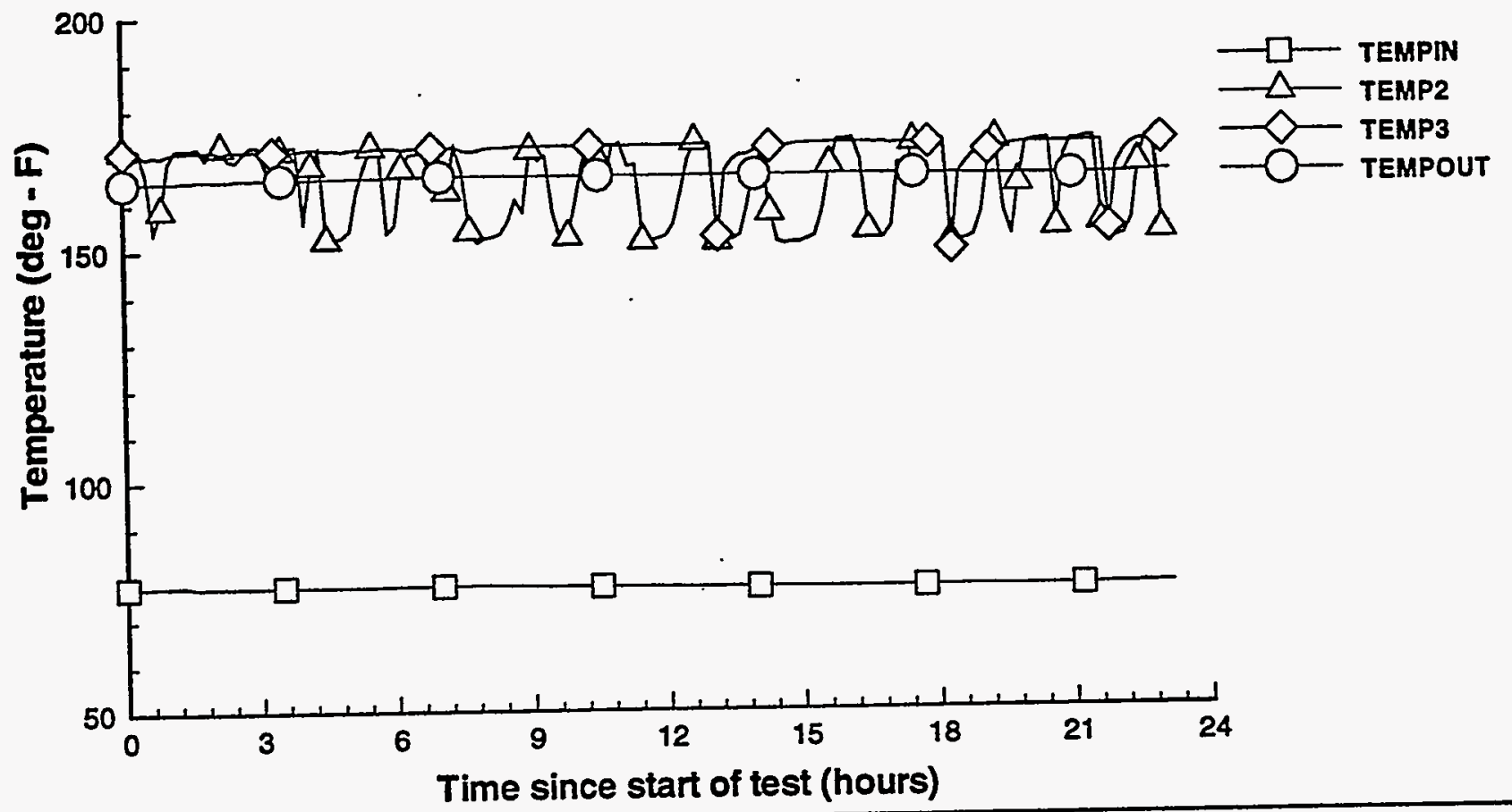

Vapor Space Air Flow (test 5)

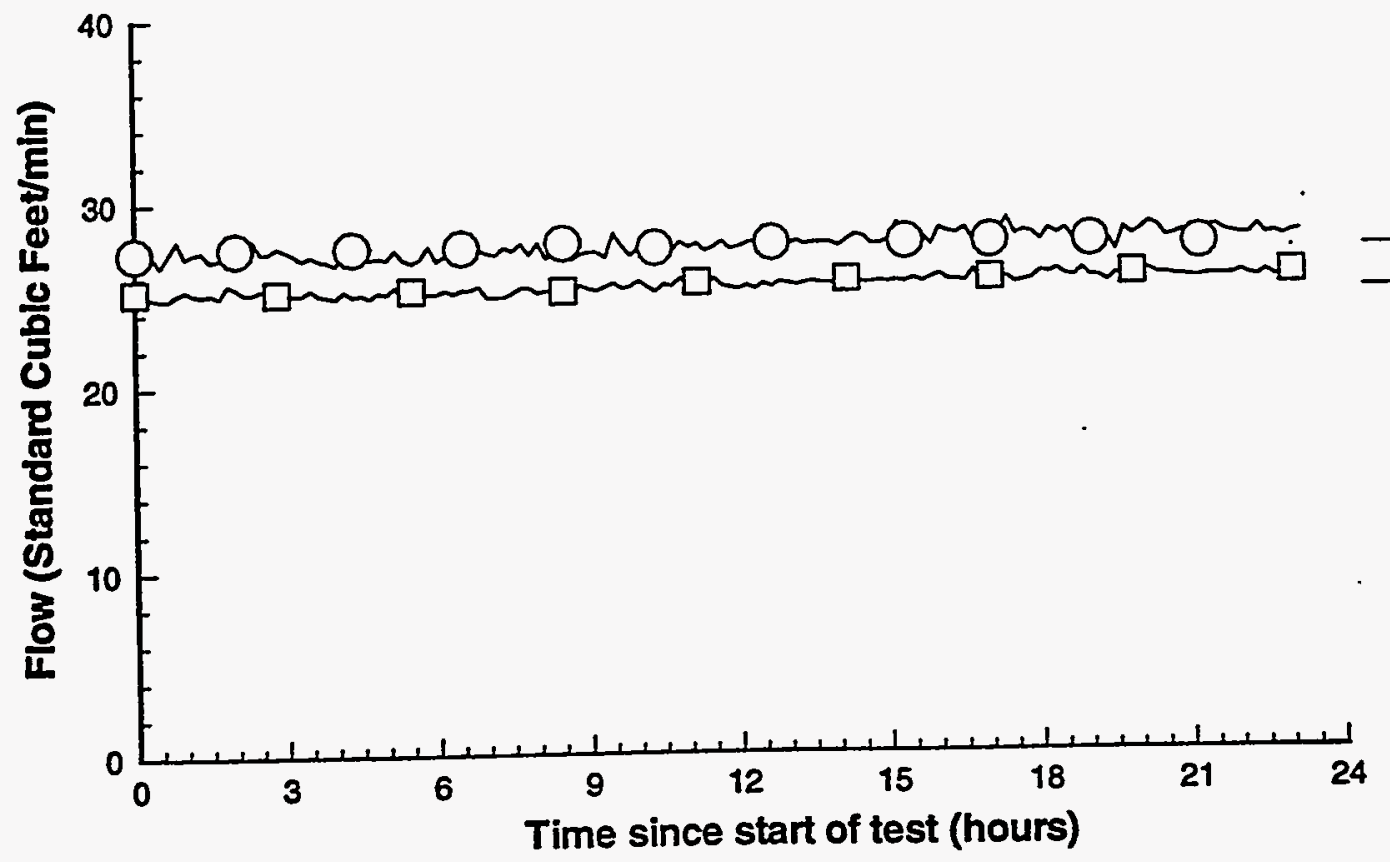


WHC-SD-W236A-ER-009

Rev. 0

(2D) II Print II 19Aug 1994 II test5.pIt II TEST_5_DATA

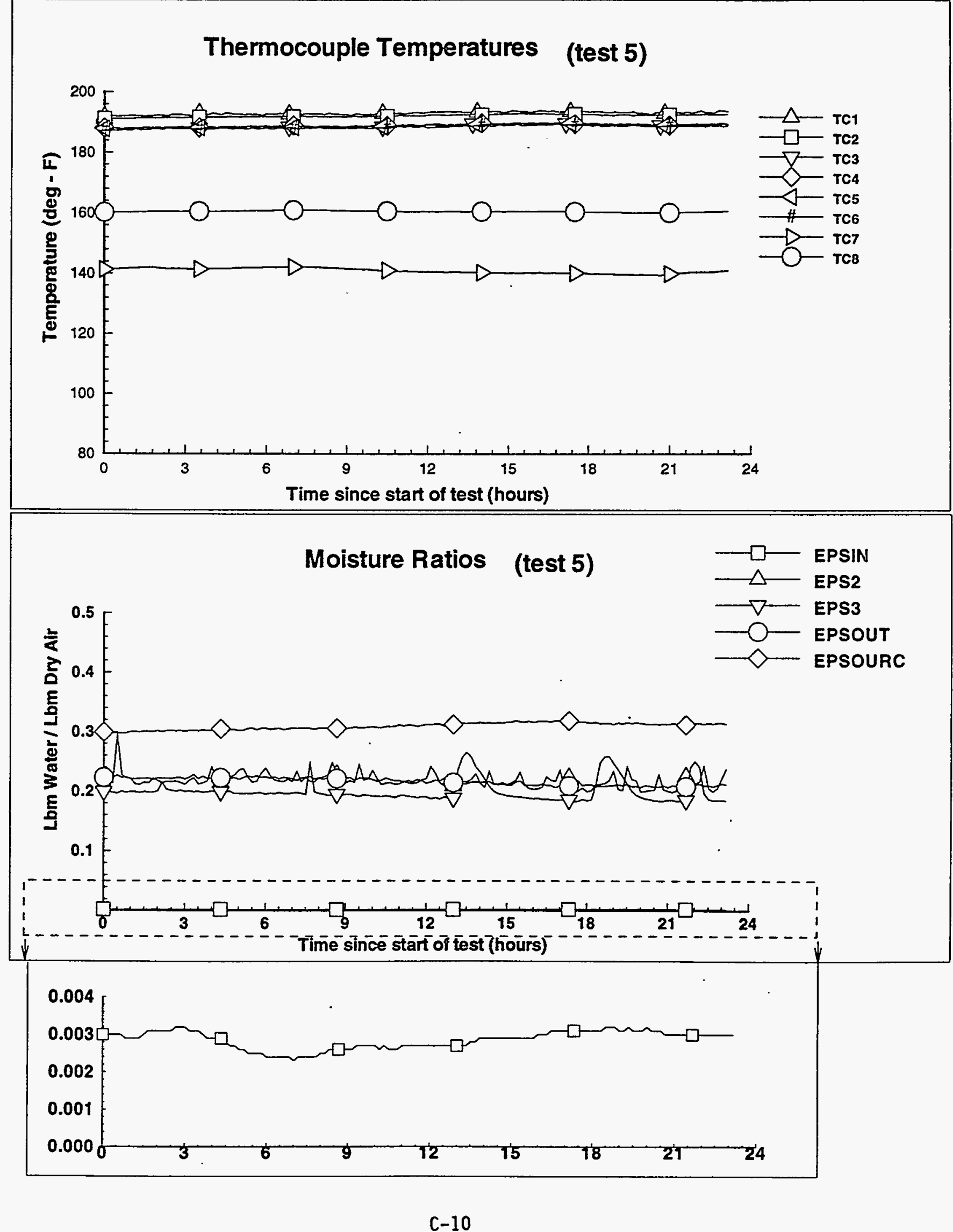


RTD Temperatures (test 5R)

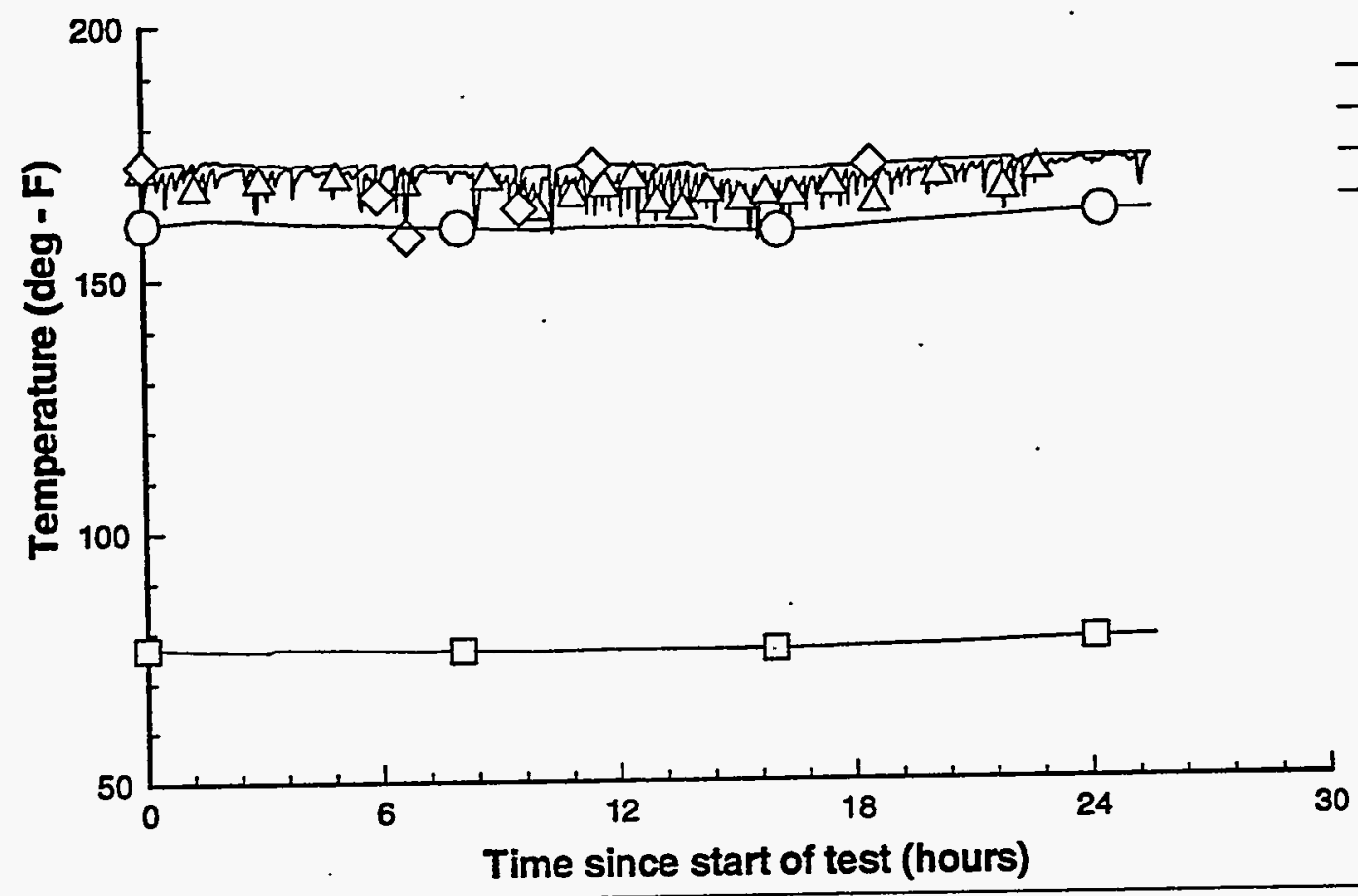

Vapor Space Air Flow (test 5R)

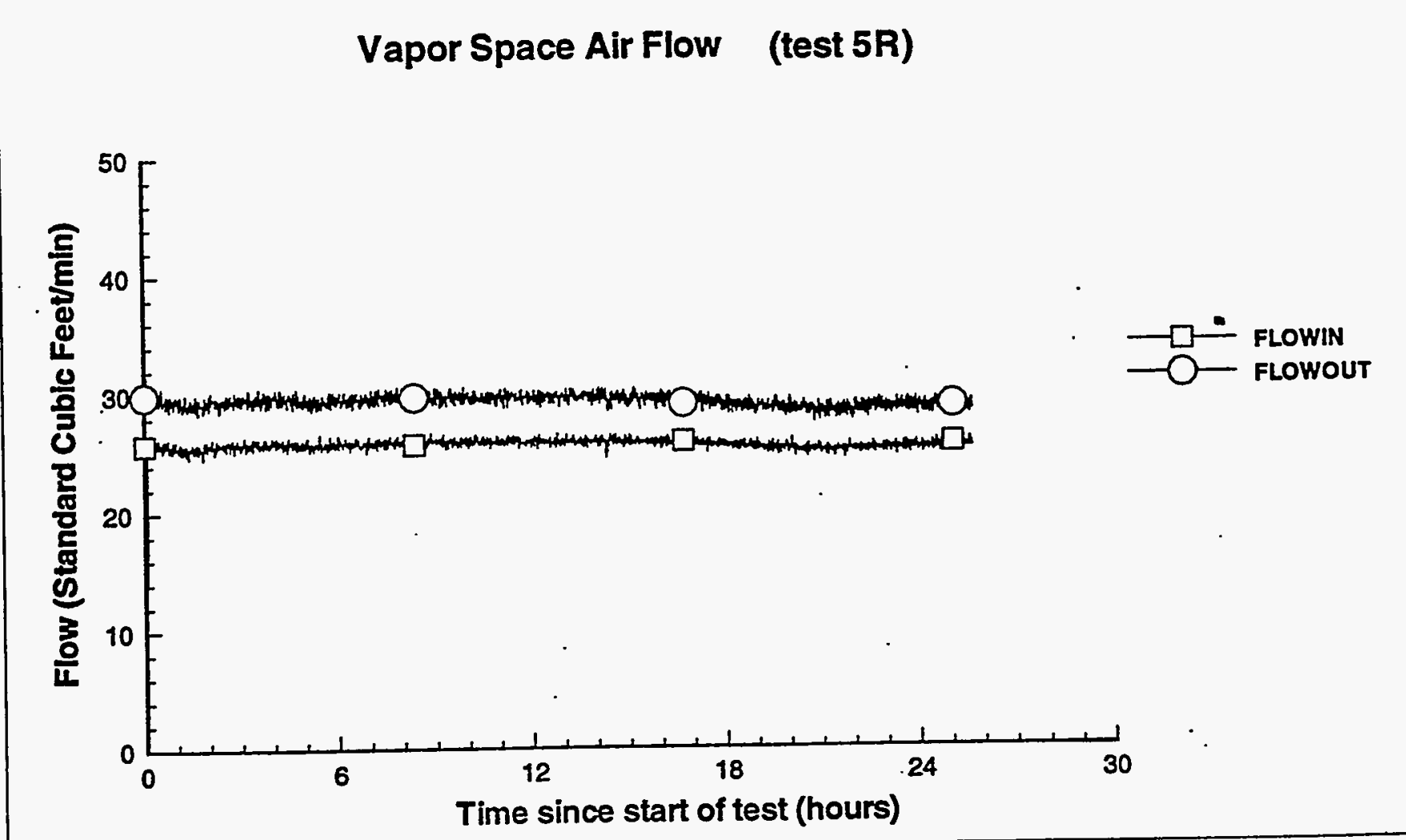

C-11 


\section{Thermocouple Temperatures (test 5R)}
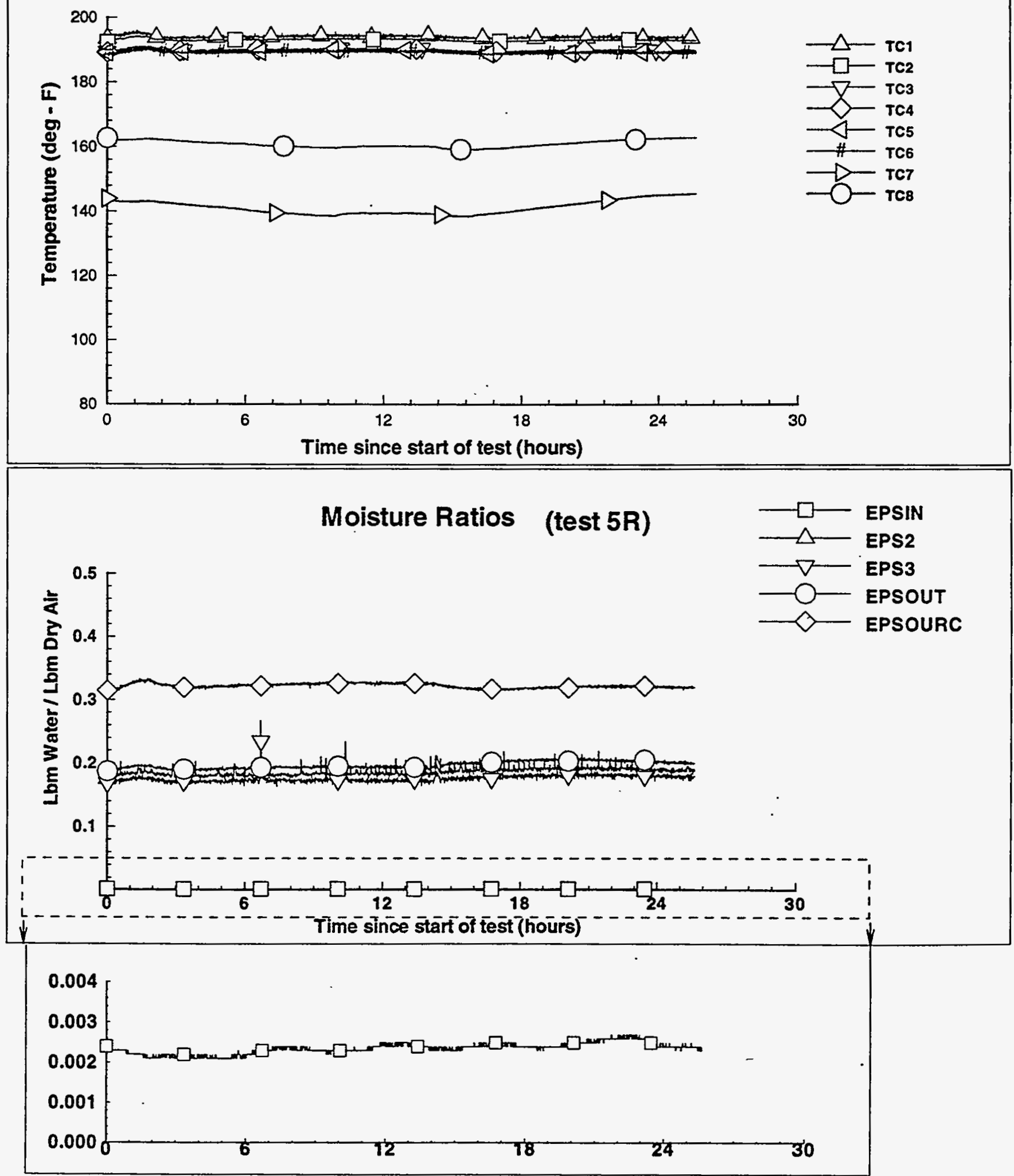


\section{RTD Temperatures (test 6)}

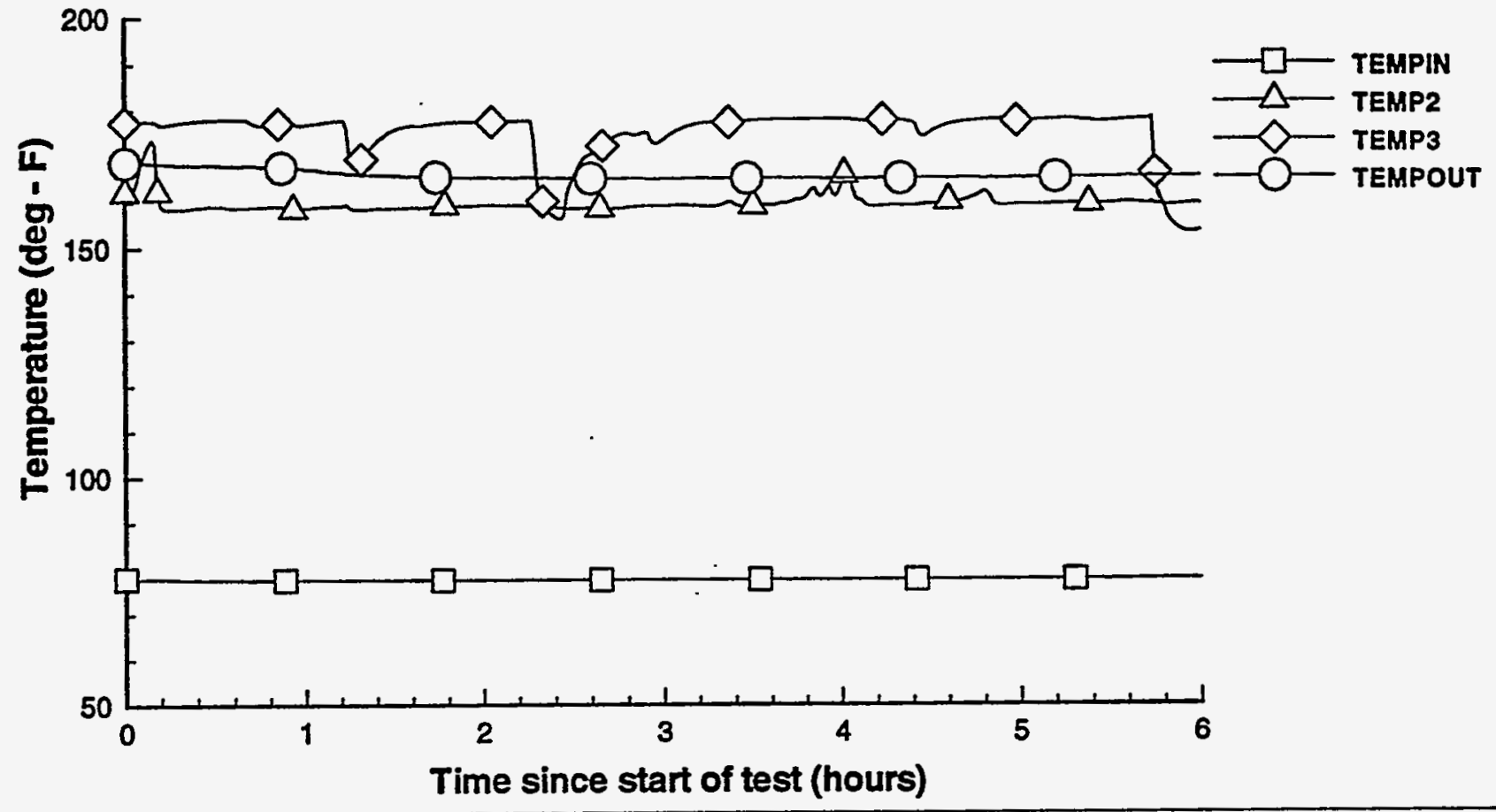

Vapor Space Air Flow (test 6)

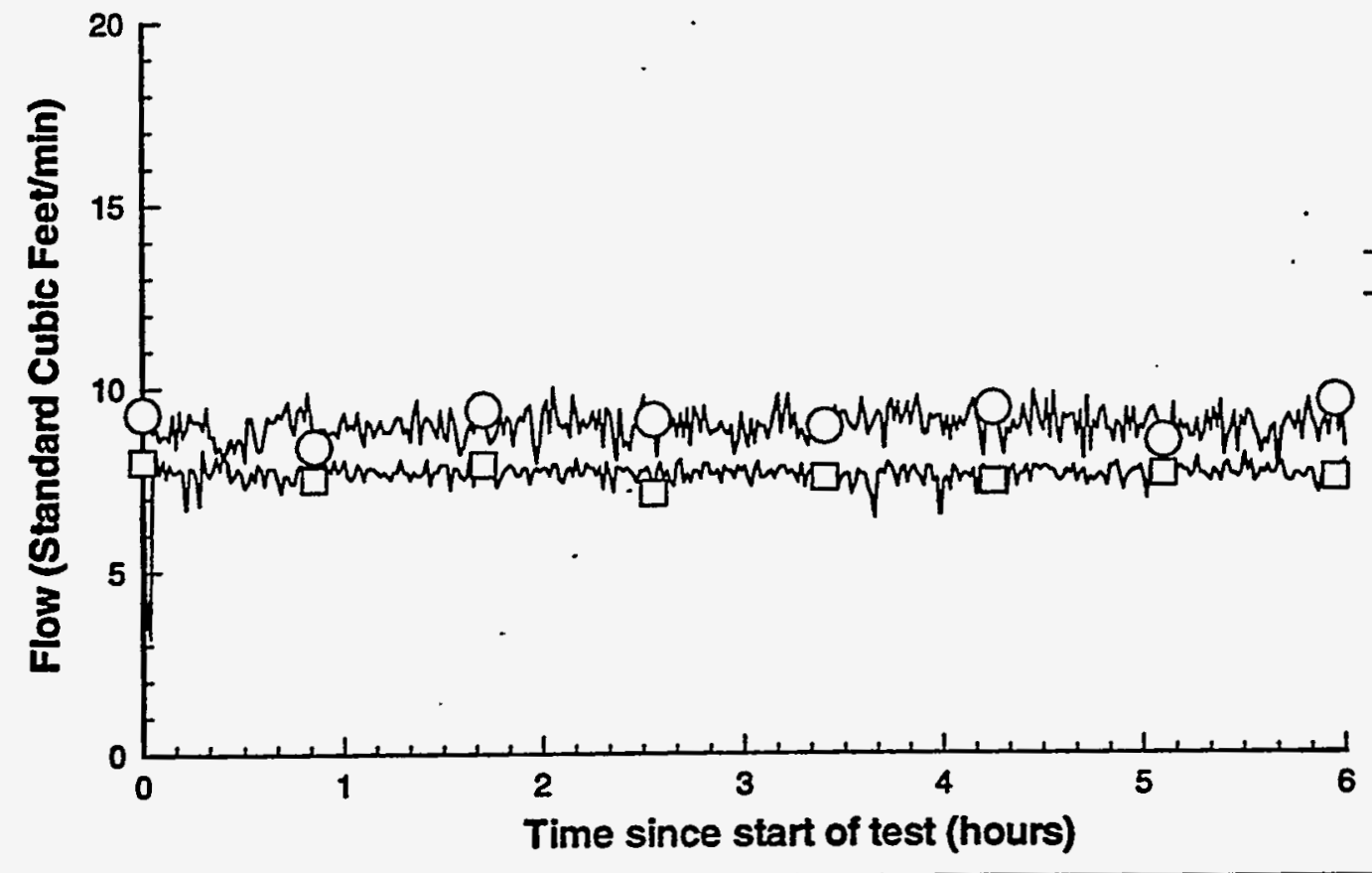


WHC-SD-W236A-ER-009

Rev. 0

(2D) II Print II 19 Aug 1994 II test6.pH II TEST_6_DATA

Thermocouple Temperatures (test 6)
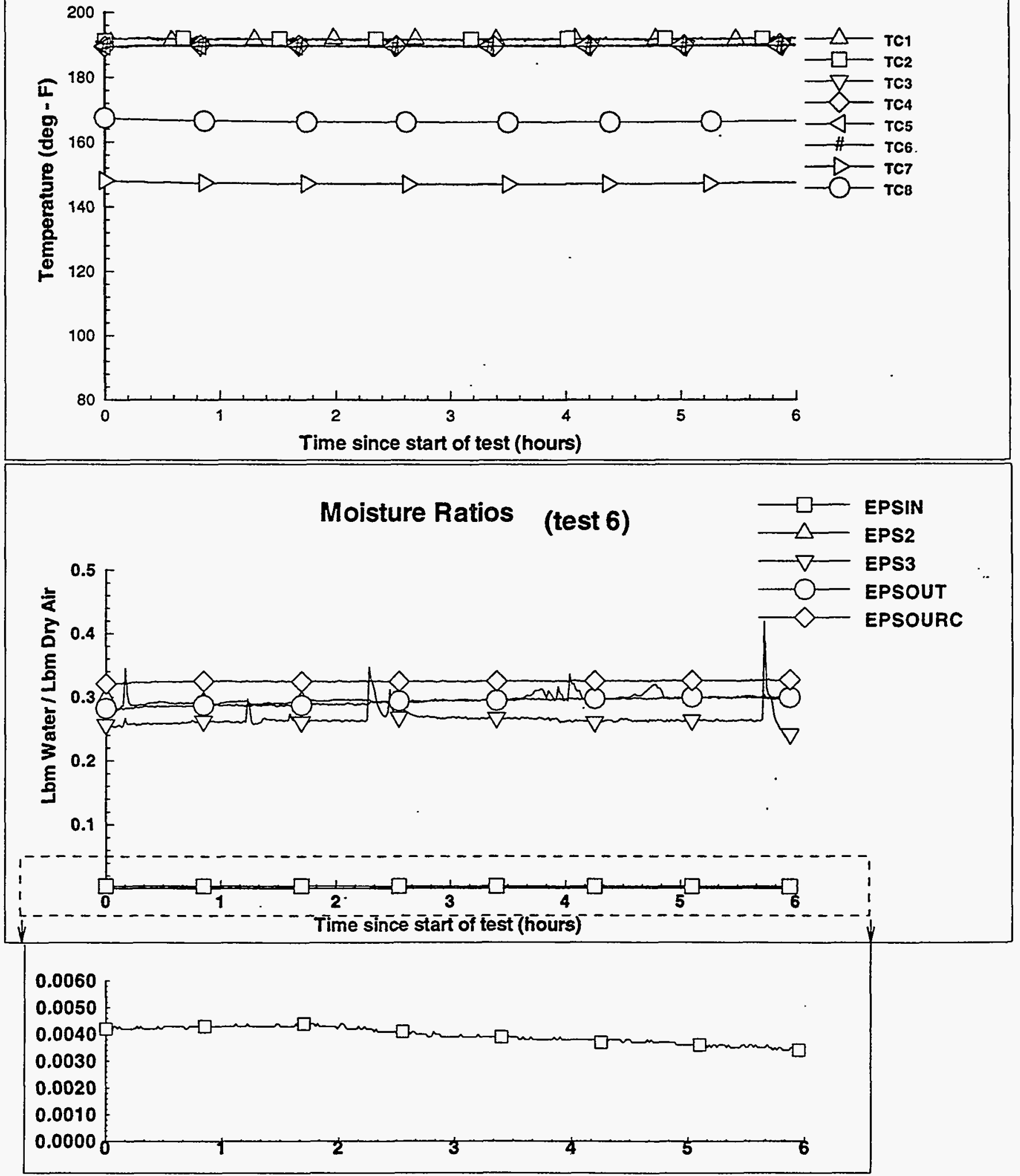


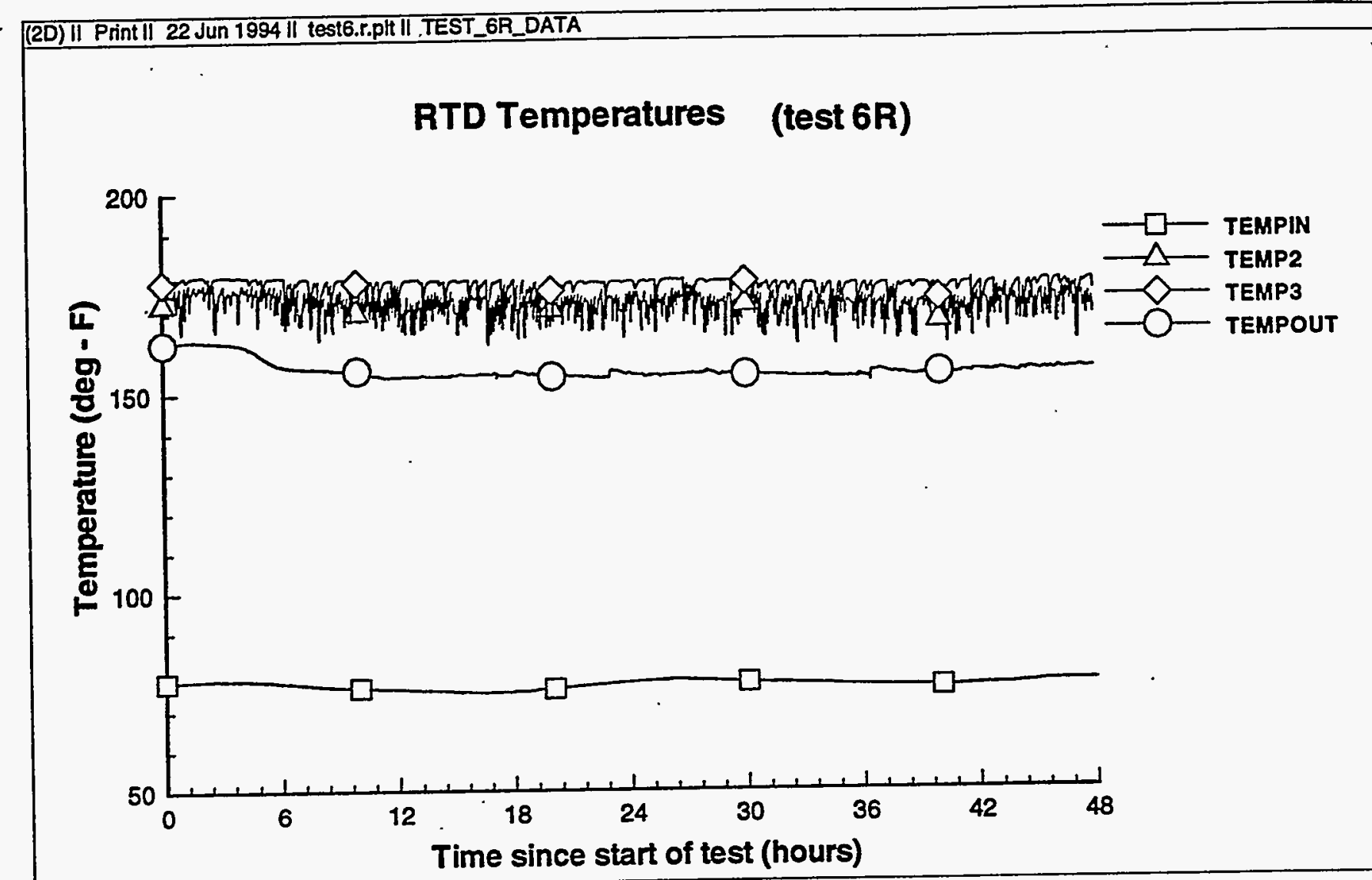

Vapor Space Air Flow (test 6R)

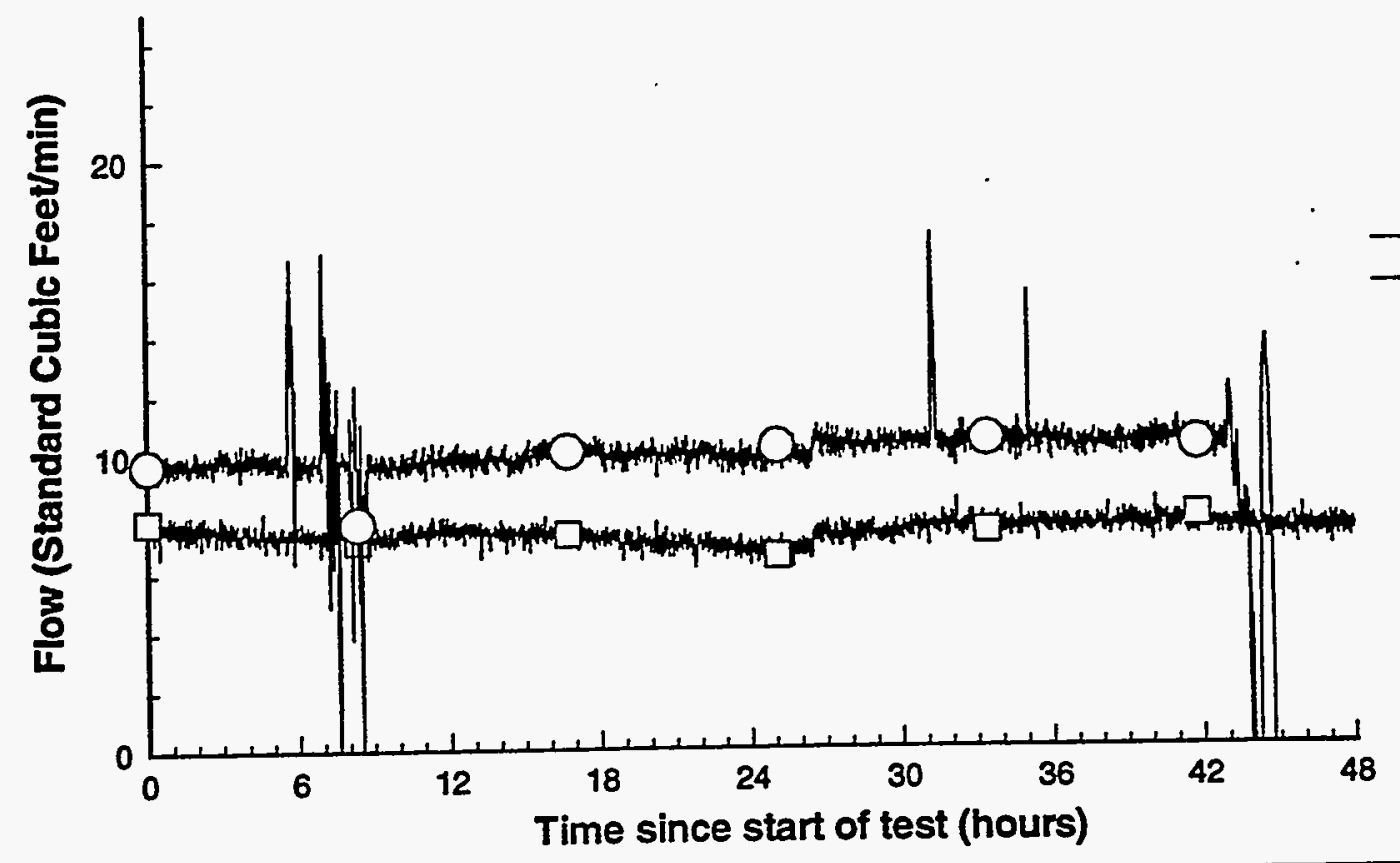




\section{HHC-SD-W236A-ER-009 \\ Rev. 0}
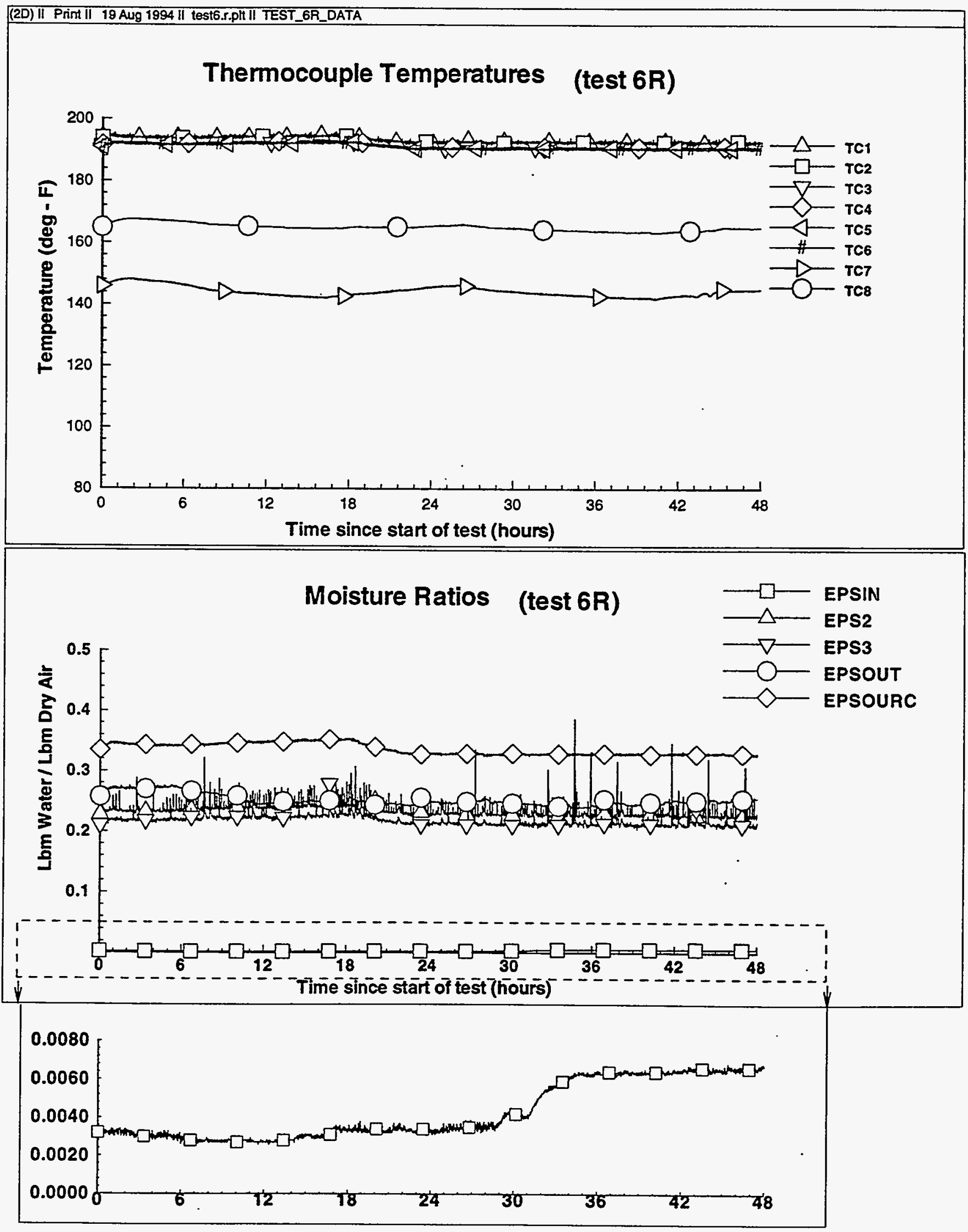


\section{RTD Temperatures (test 7)}

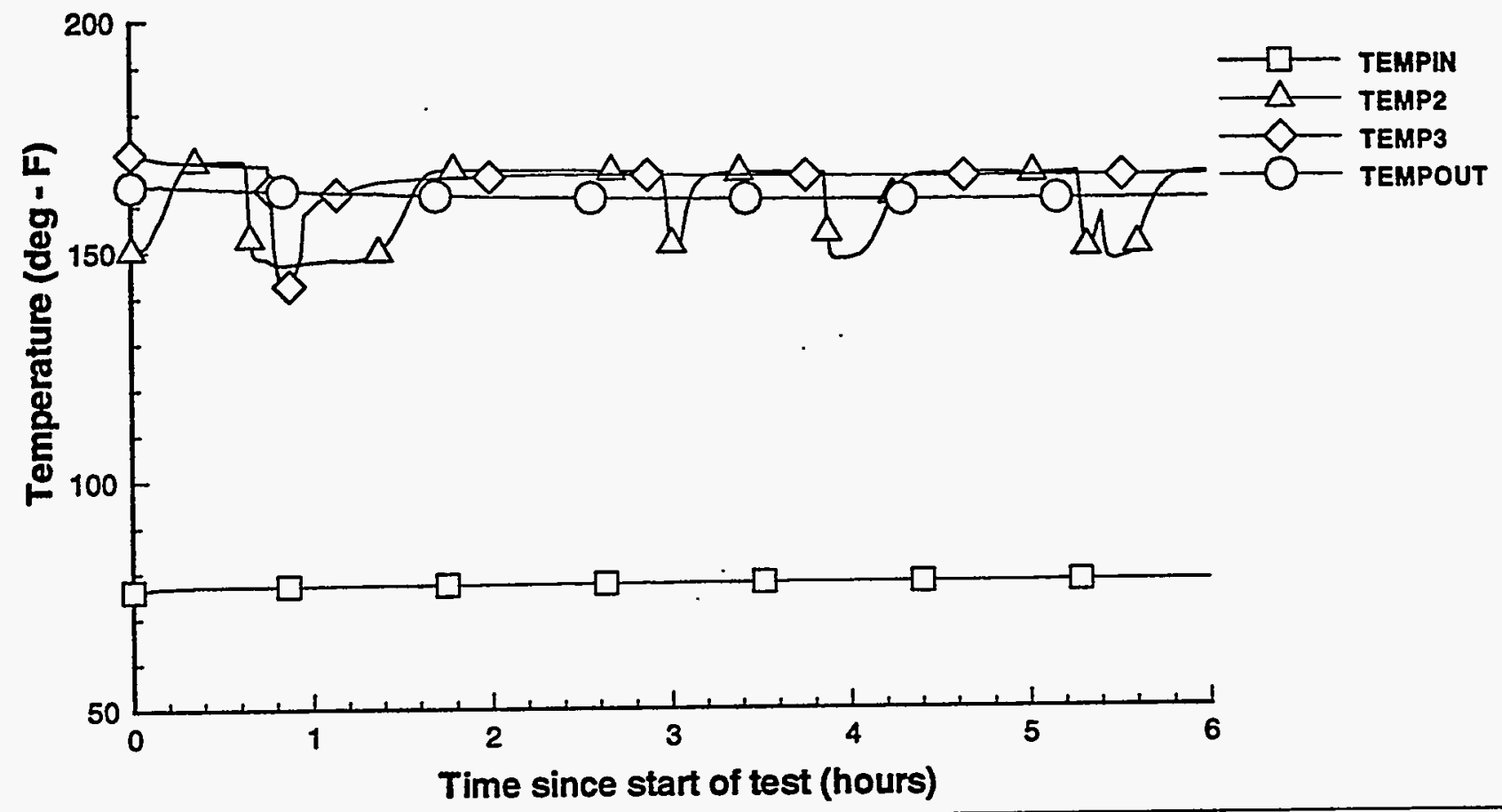

Vapor Space Air Flow (test 7)

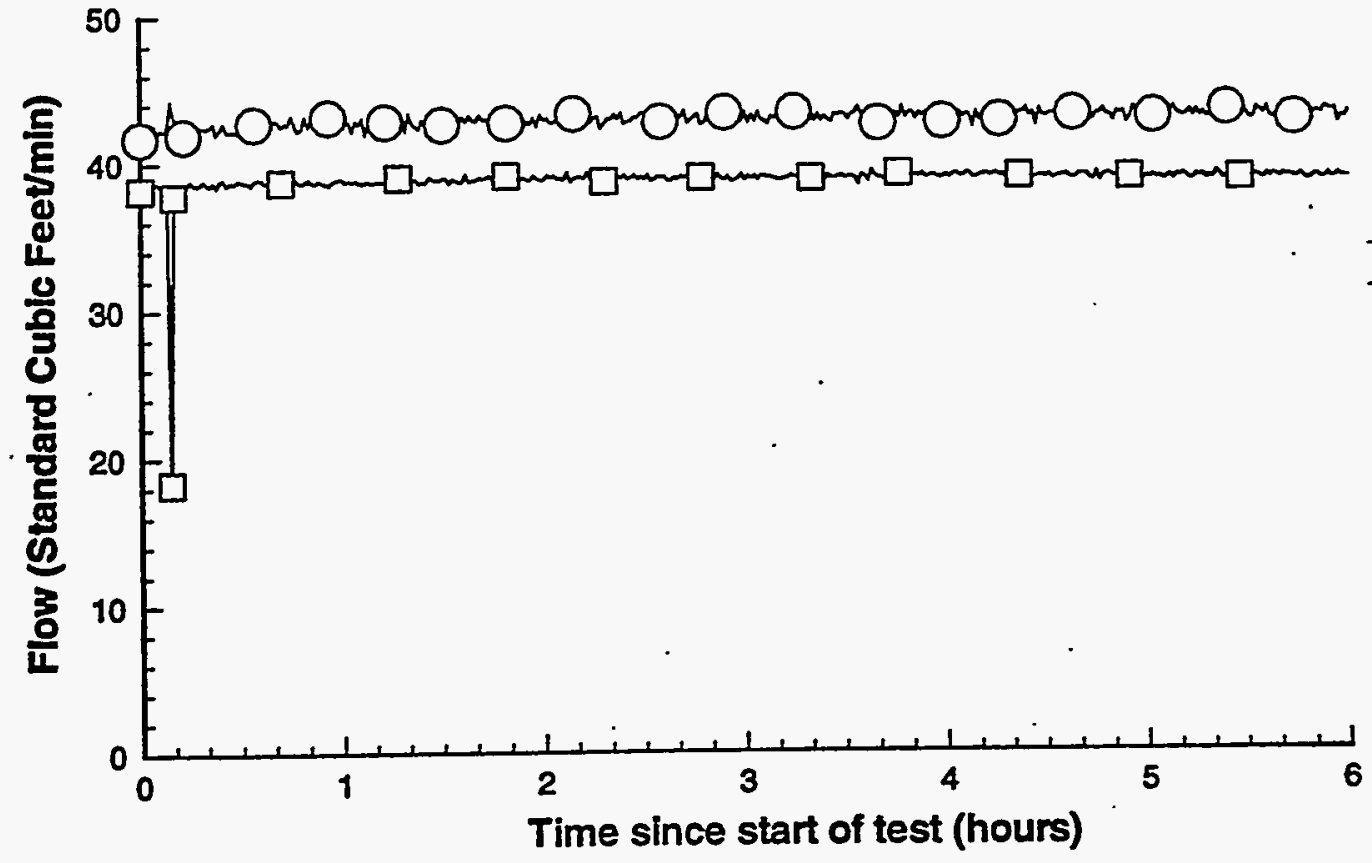


WHC-SD-W236A-ER-009

Rev. 0
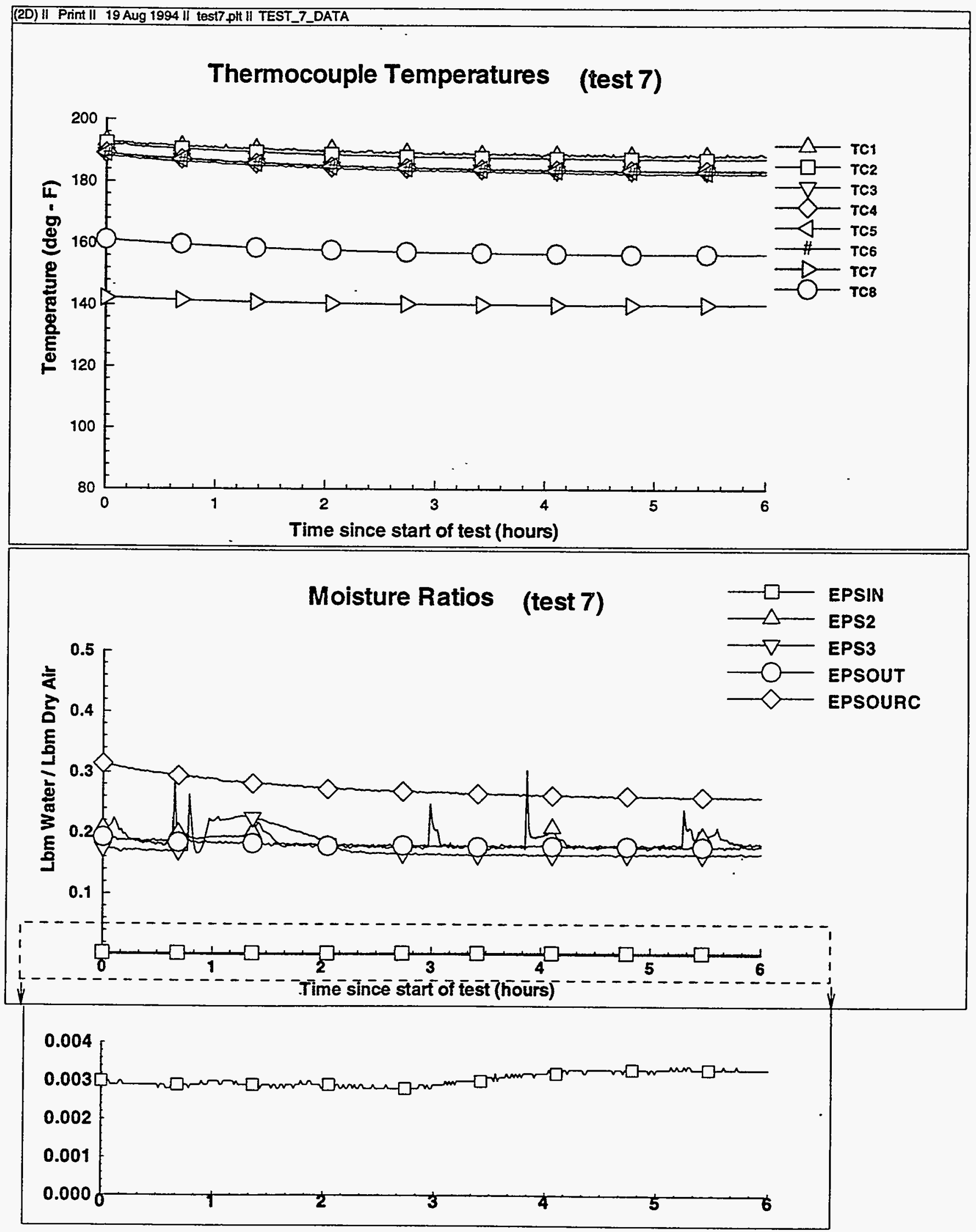
WHC-SD-W236A-ER-009

Rev. 0

RTD Temperatures (test 8)

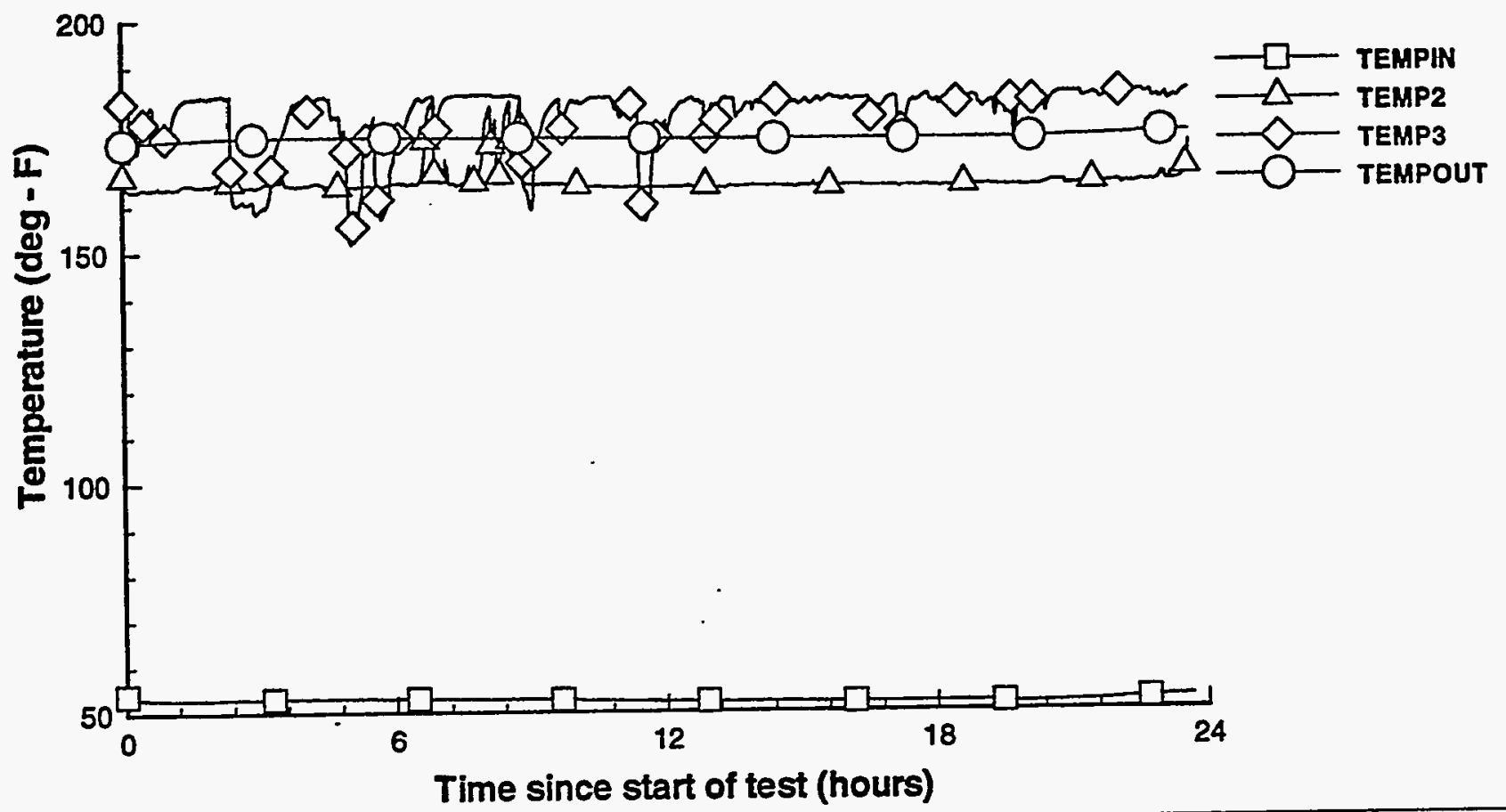

Vapor Space Air Flow (test 8)

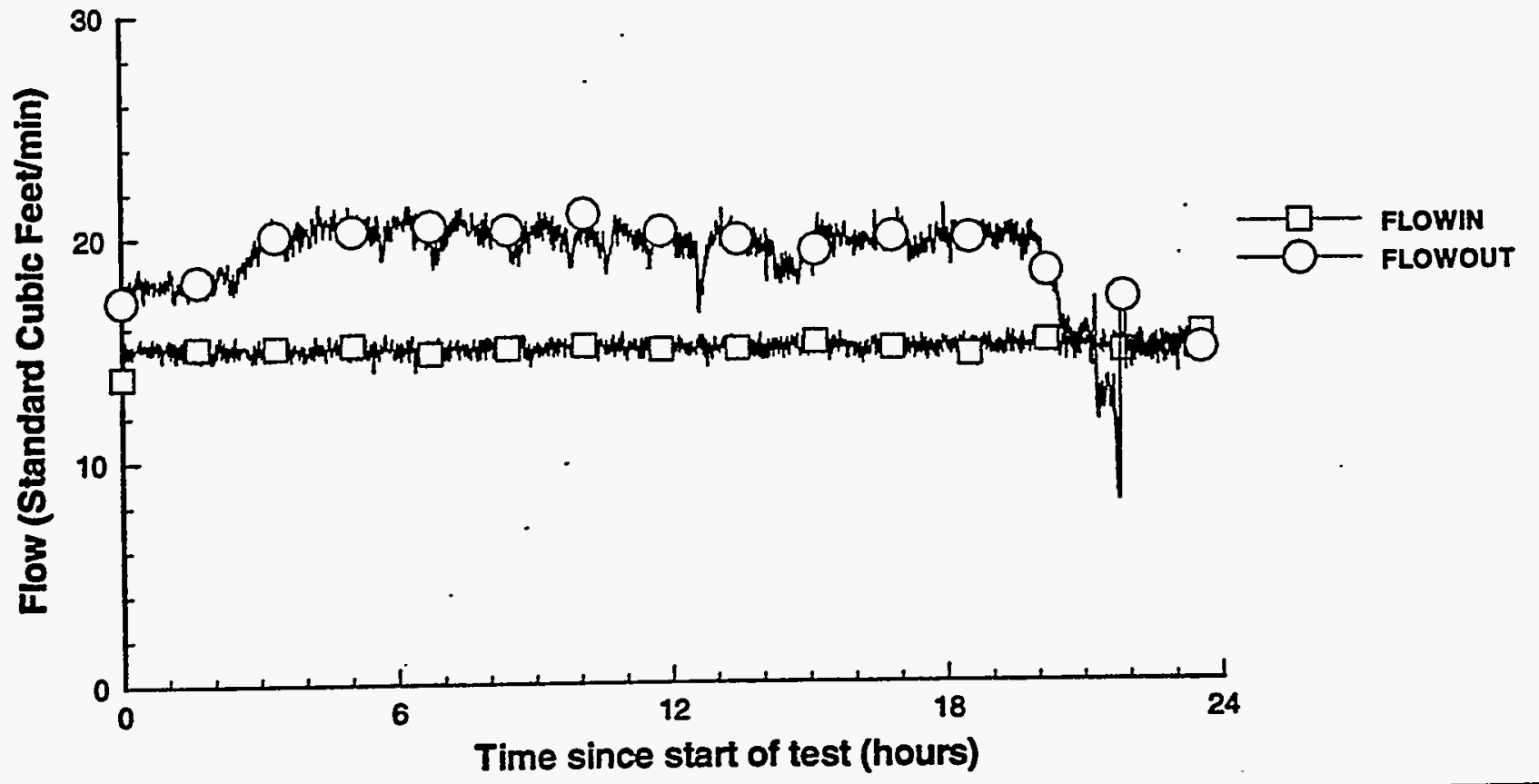



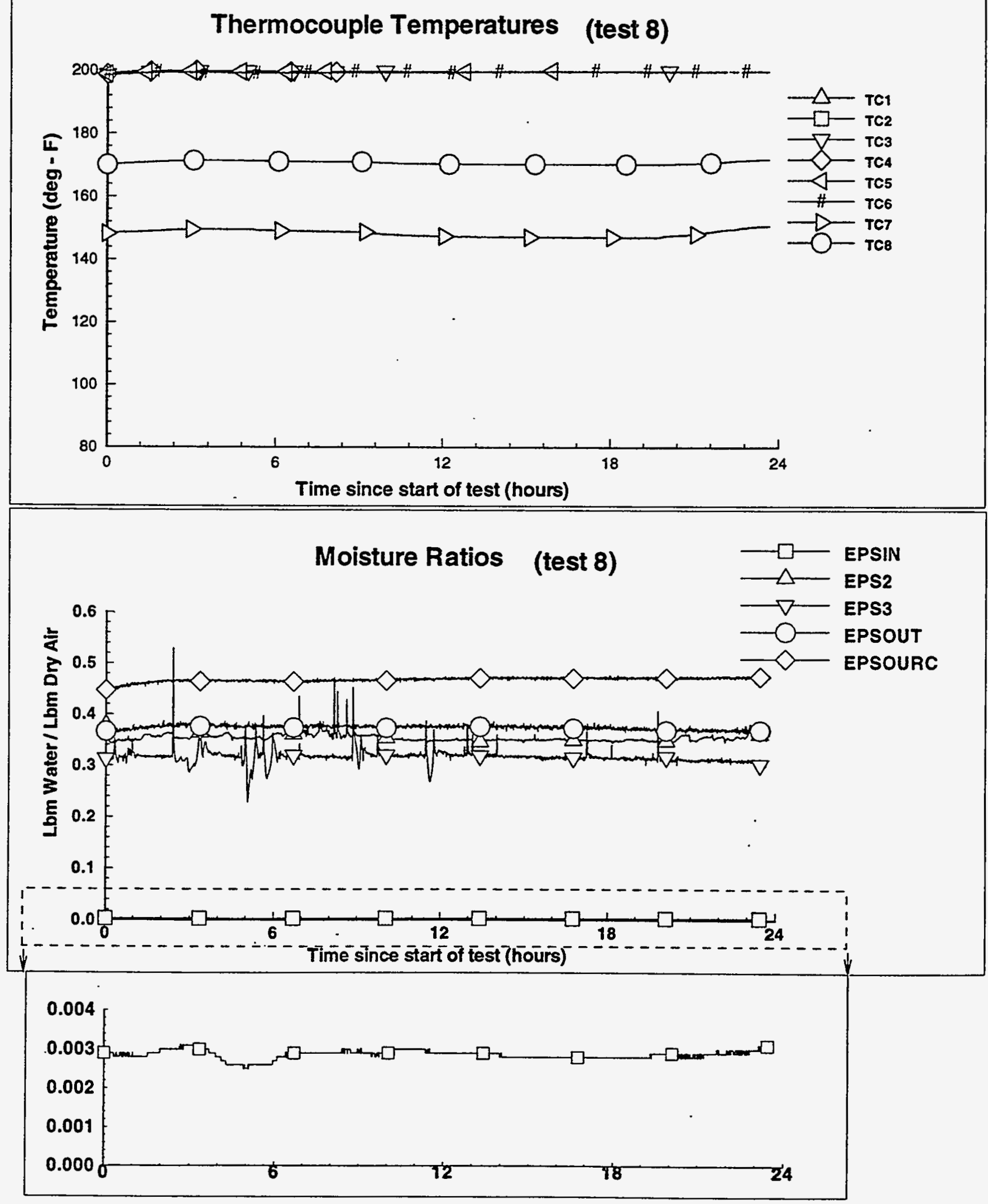


\section{RTD Temperatures (test 9)}

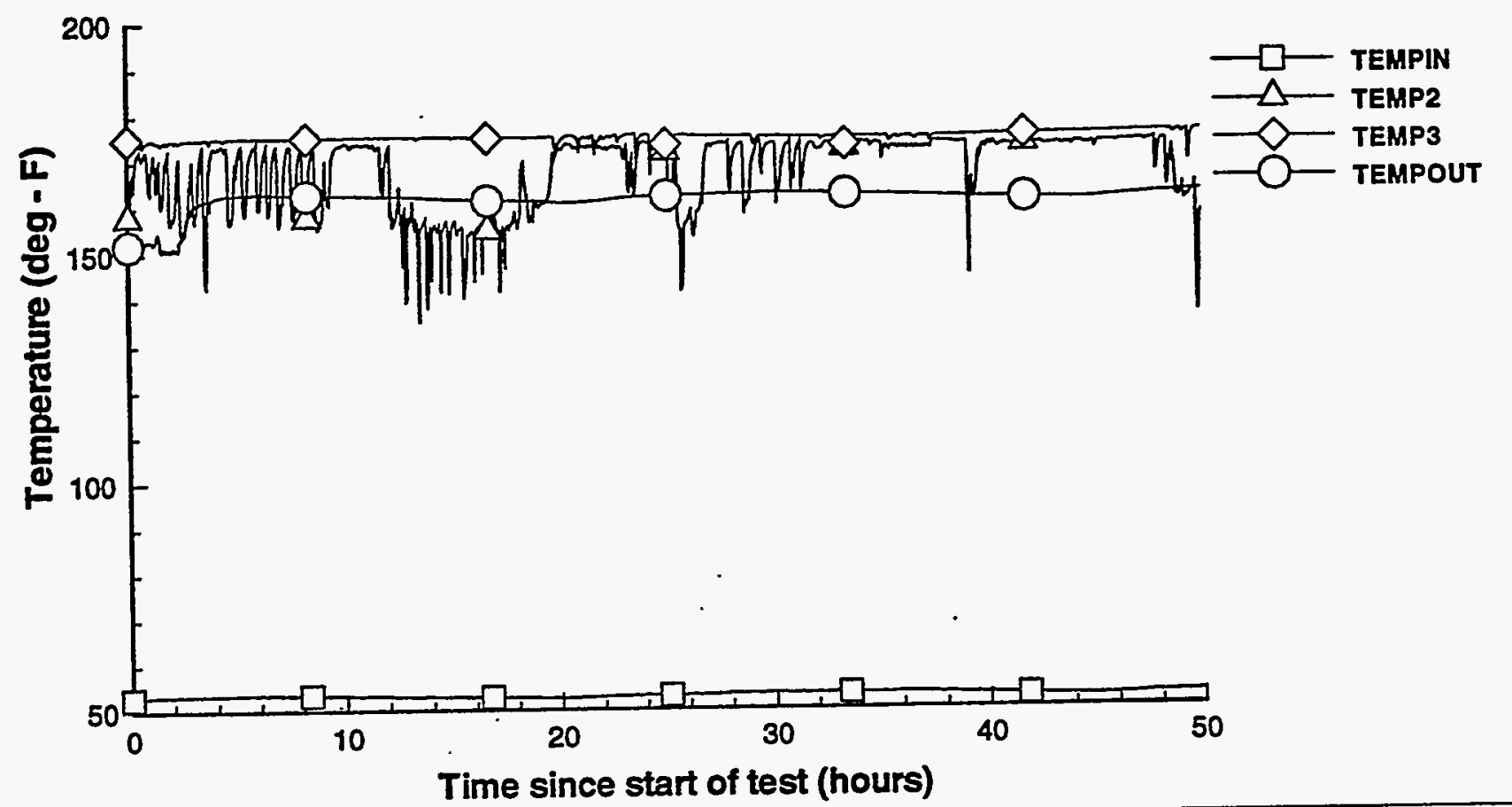

\section{Vapor Space Air Flow (test 9)}

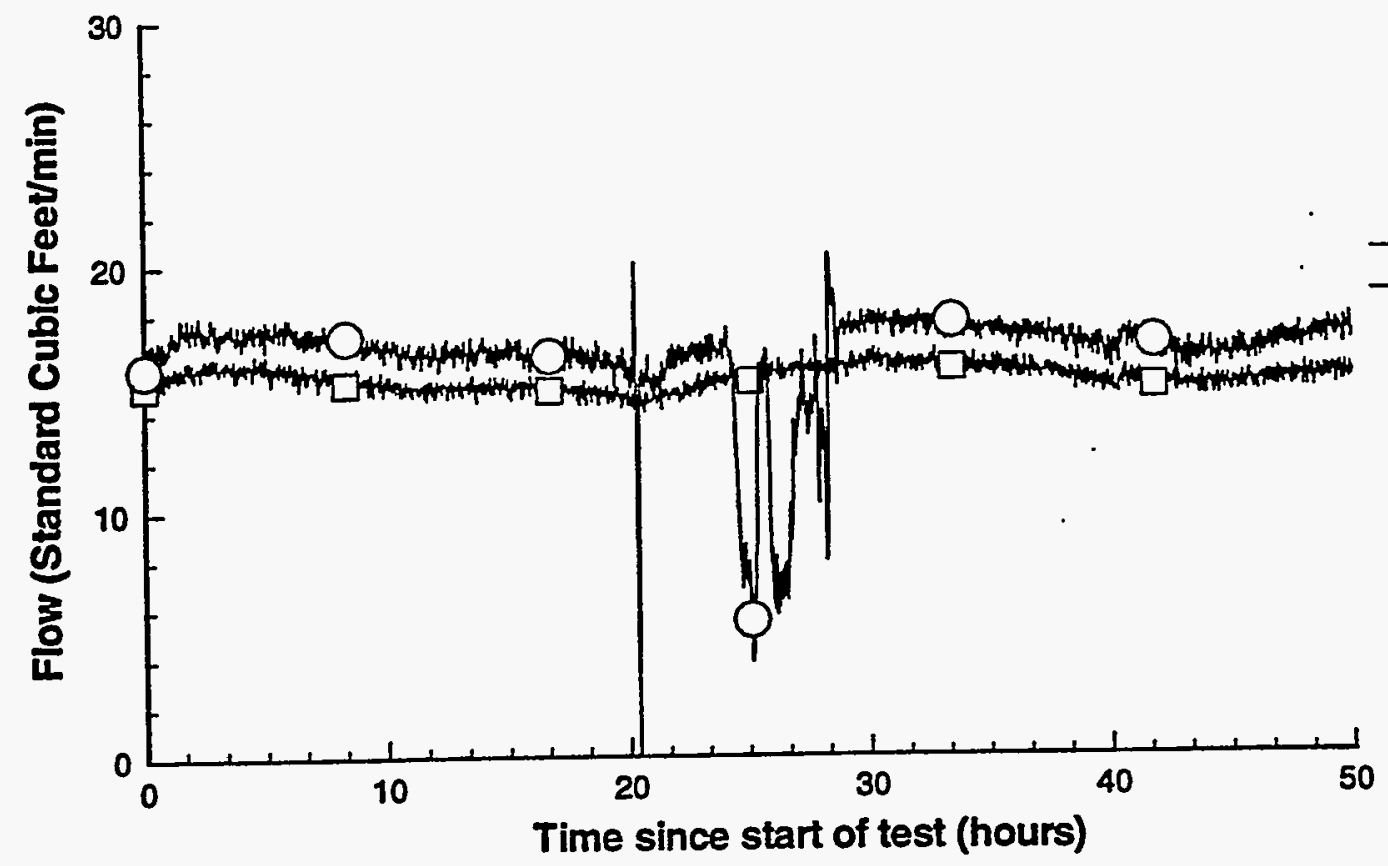


WHC-SD-W236A-ER-009

Rev. 0

(2D) II Print II 19 Aug 1994 || test9.plt II TEST_9_DATA

\section{Thermocouple Temperatures (test 9)}
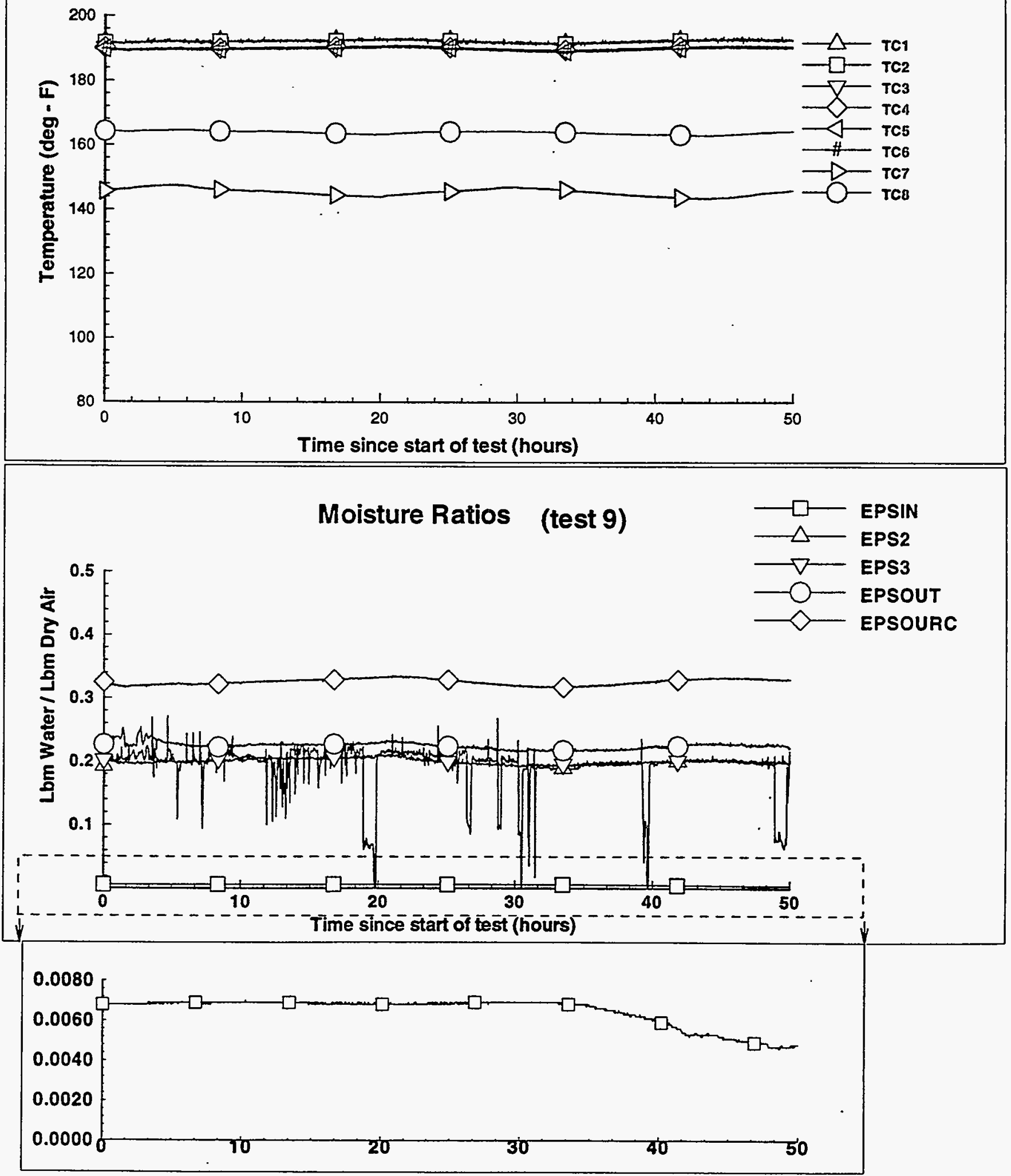


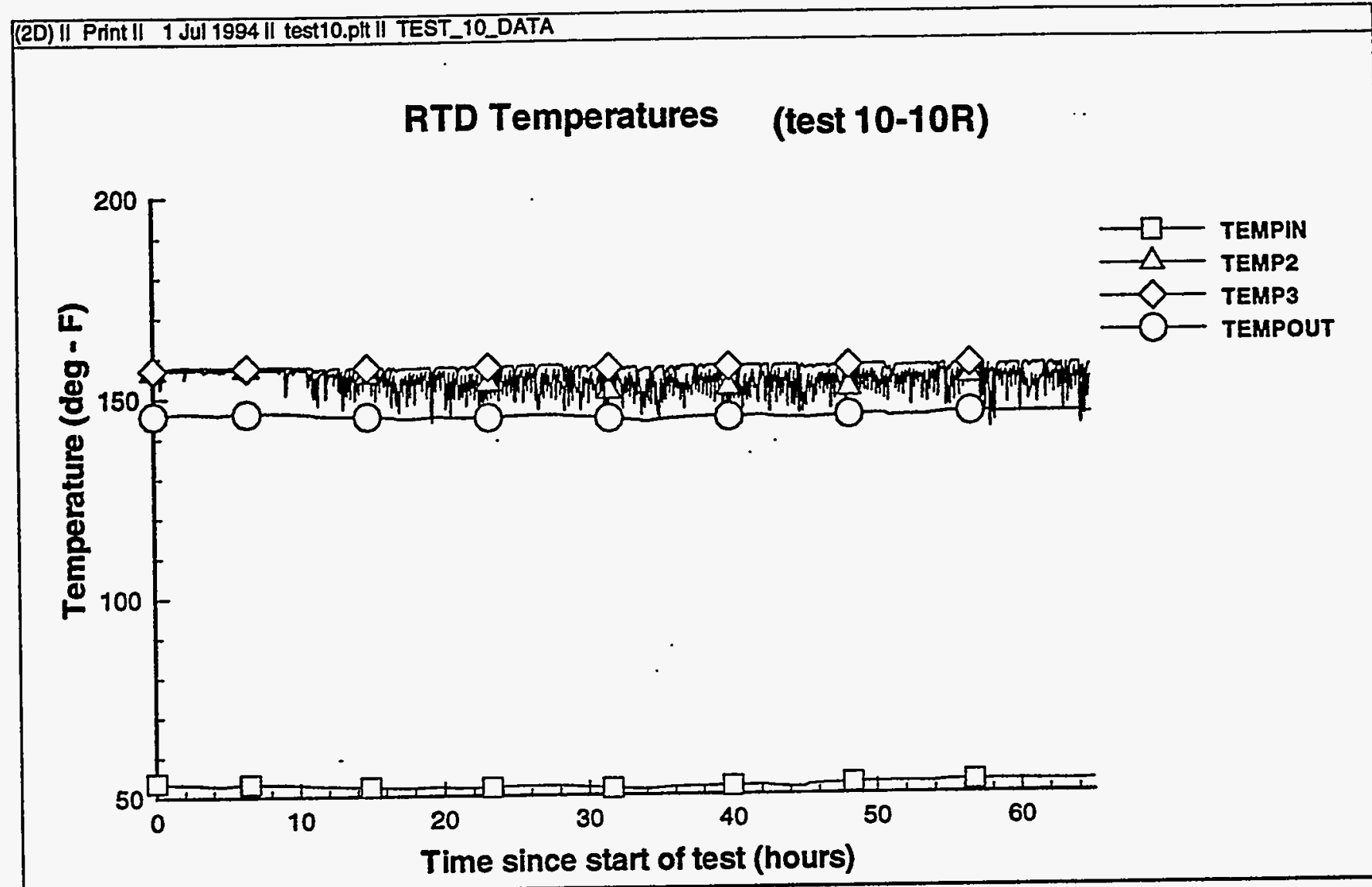

Vapor Space Air Flow (test 10-10R)

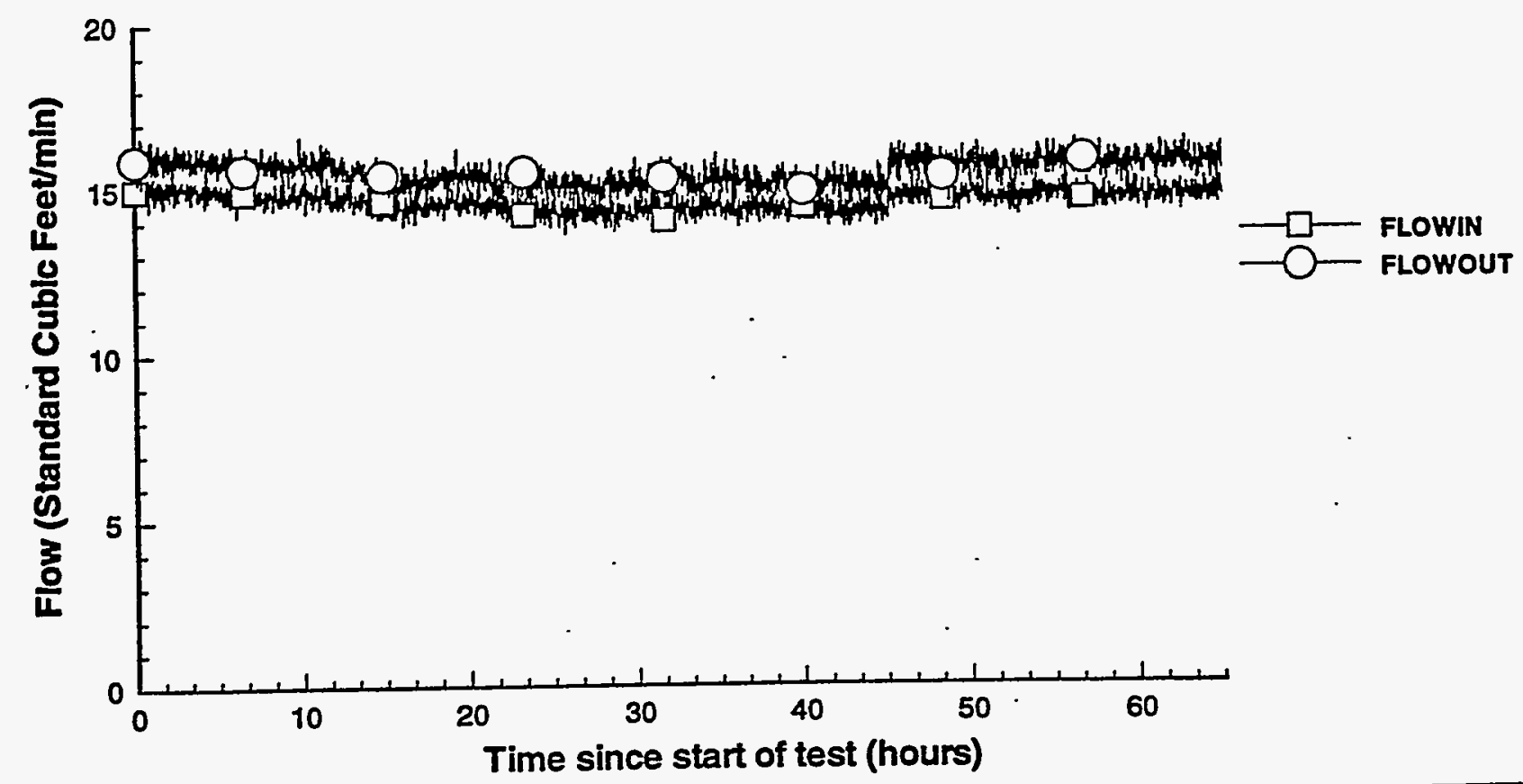




\section{Thermocouple Temperatures (test 10-10R)}
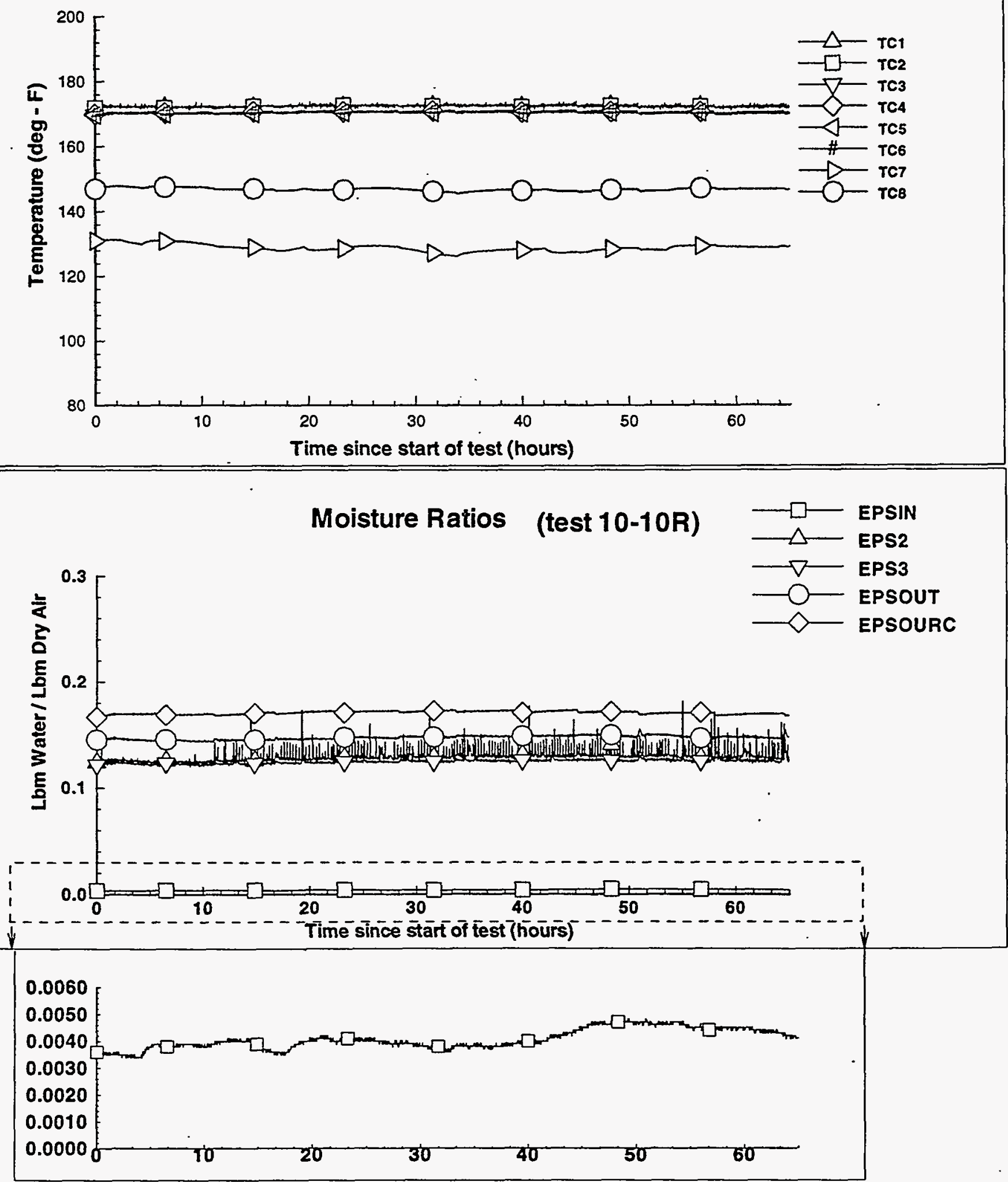


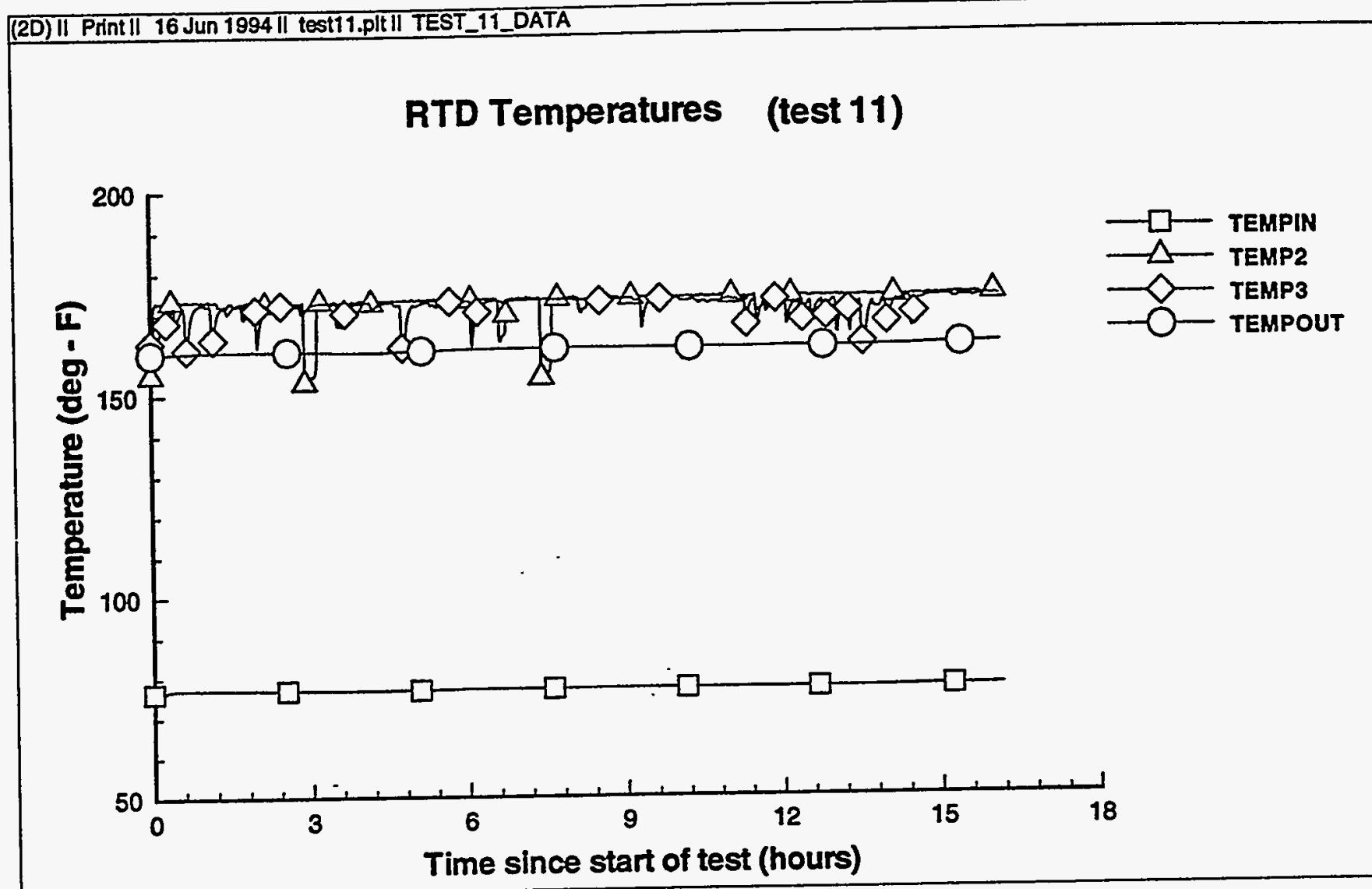

Vapor Space Air Flow (test 11)

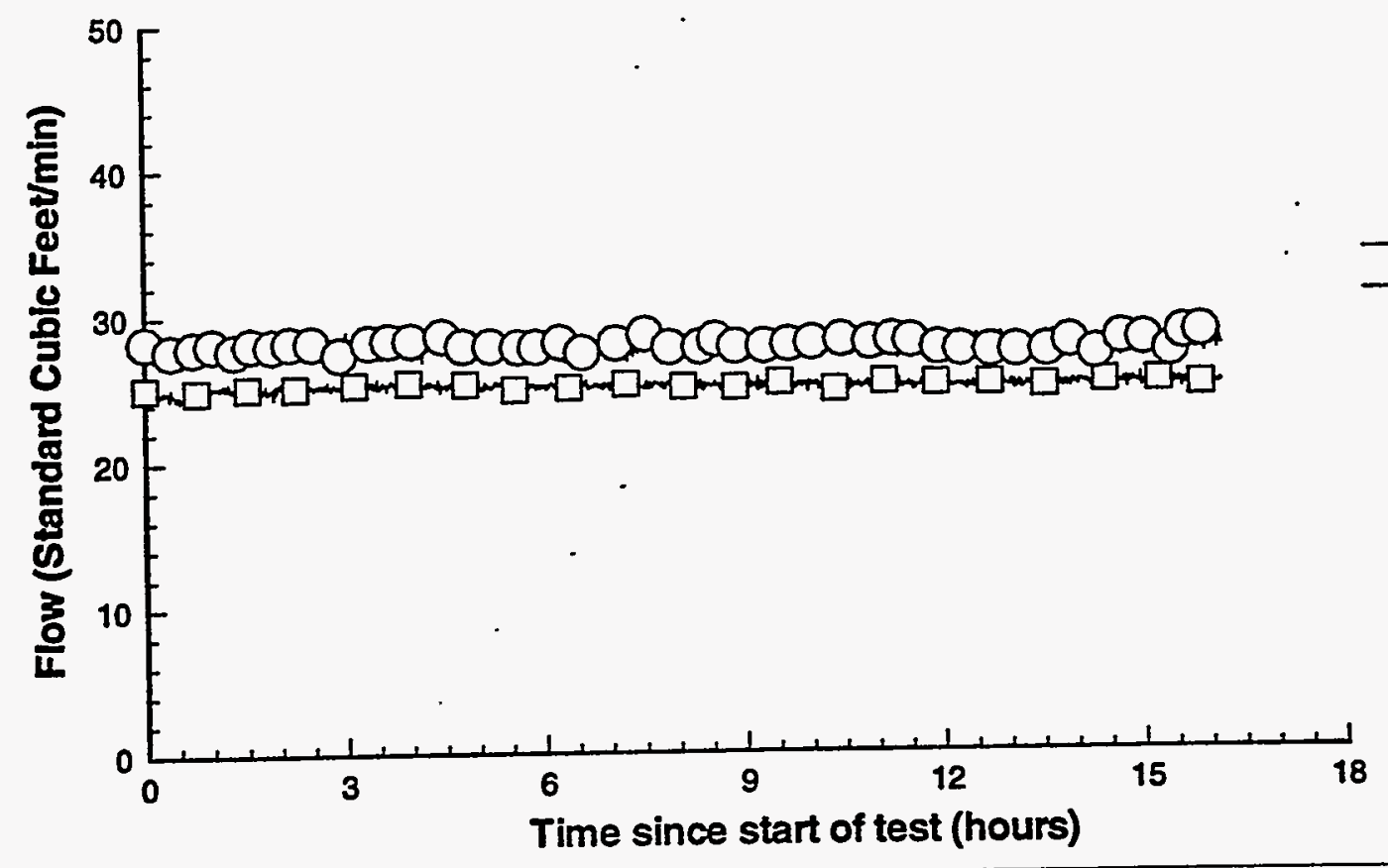




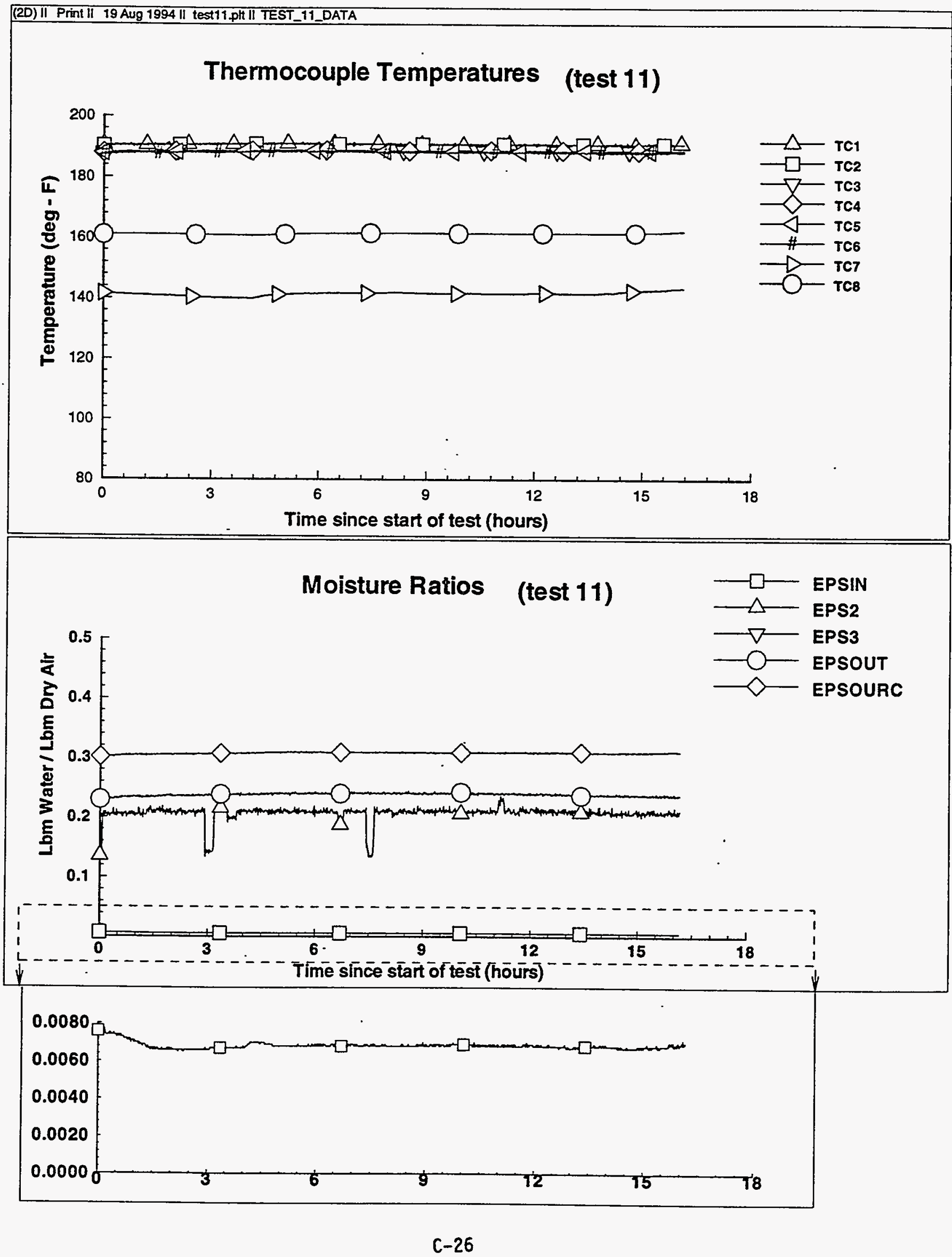




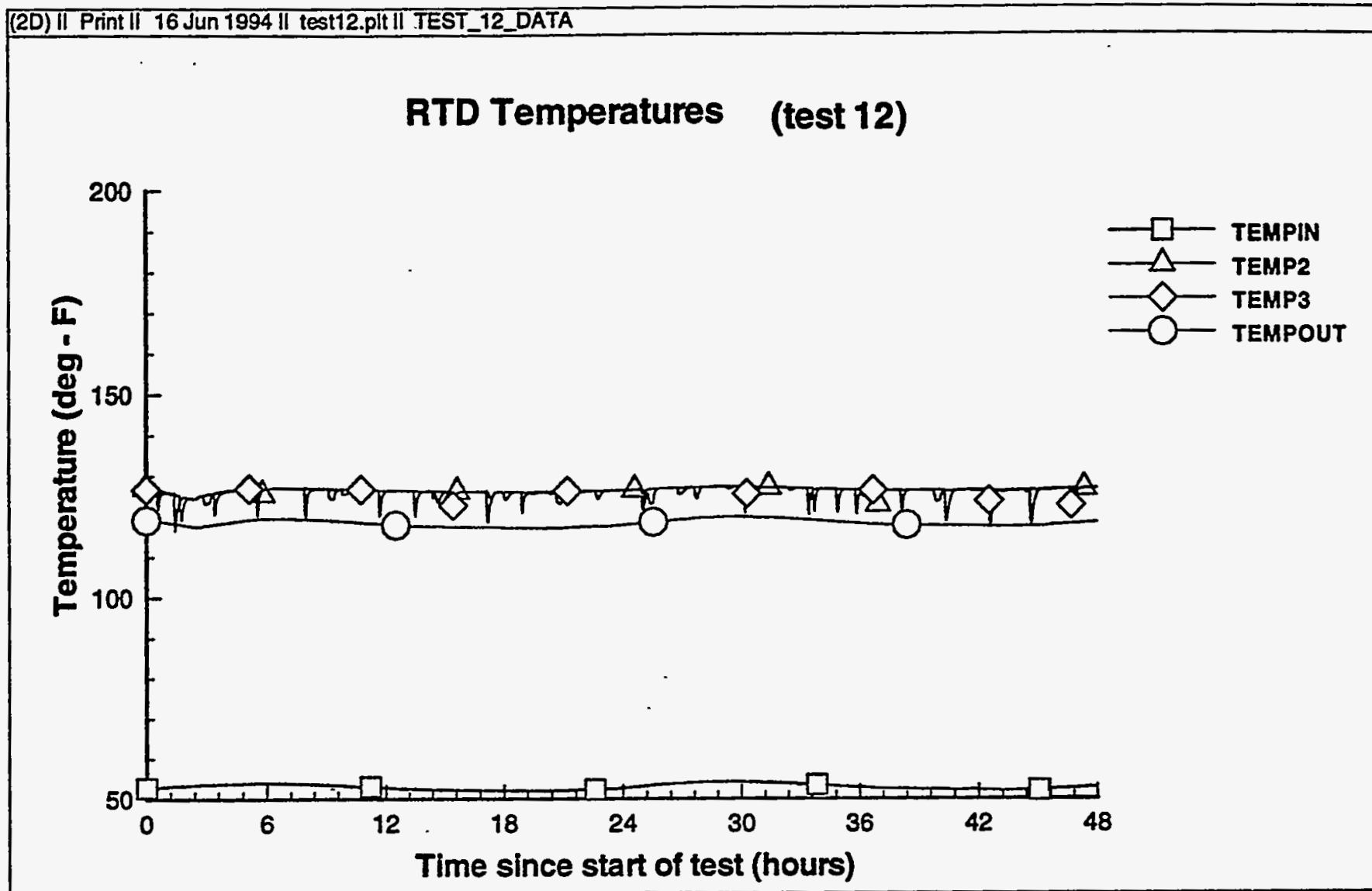

Vapor Space Air Flow (test 12)

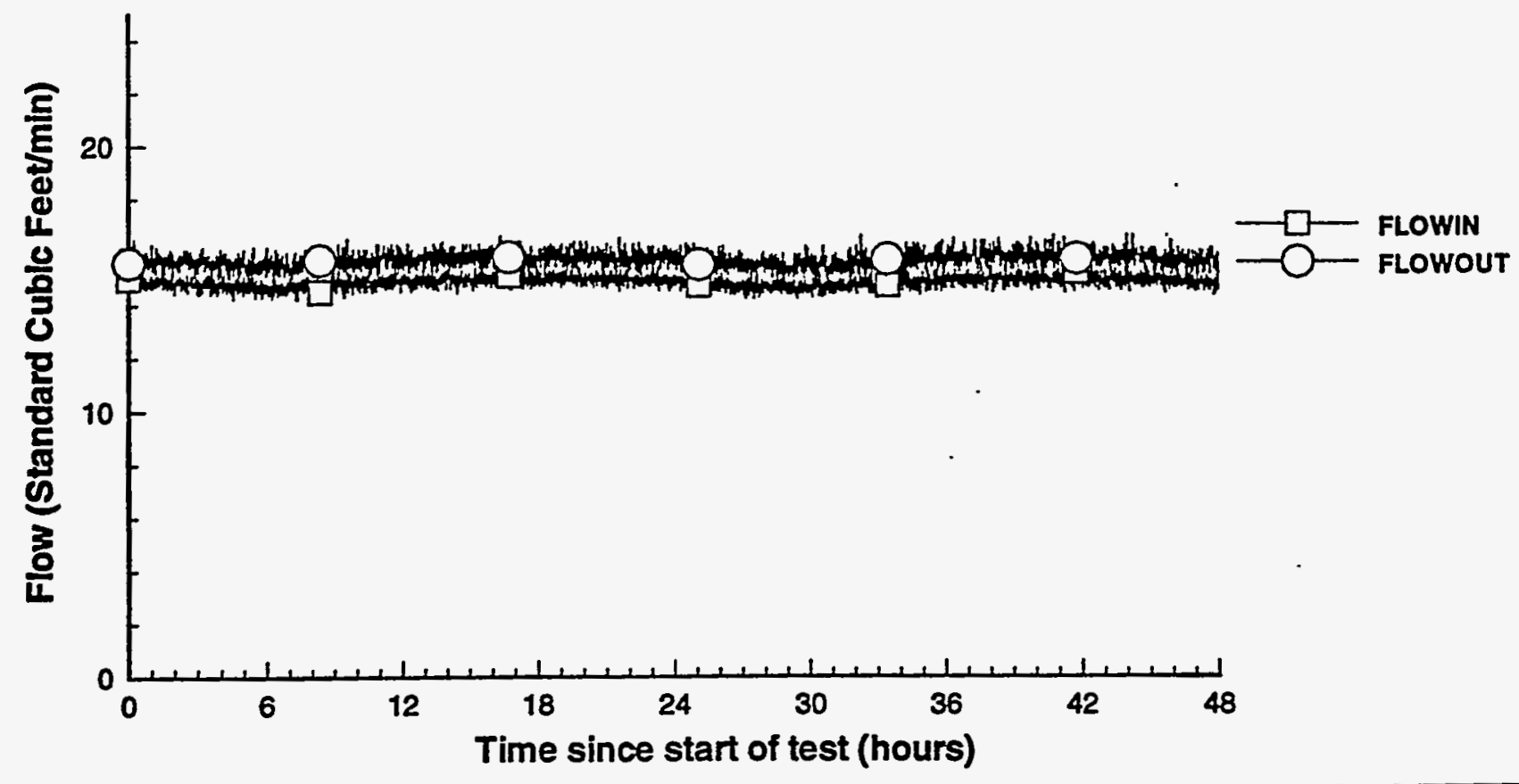


HHC-SD-W236A-ER-009.

Rev. 0

(2D) II Print II 19 Aug 1994 || test12.plt II TEST_12_DATA

Thermocouple Temperatures (test 12)
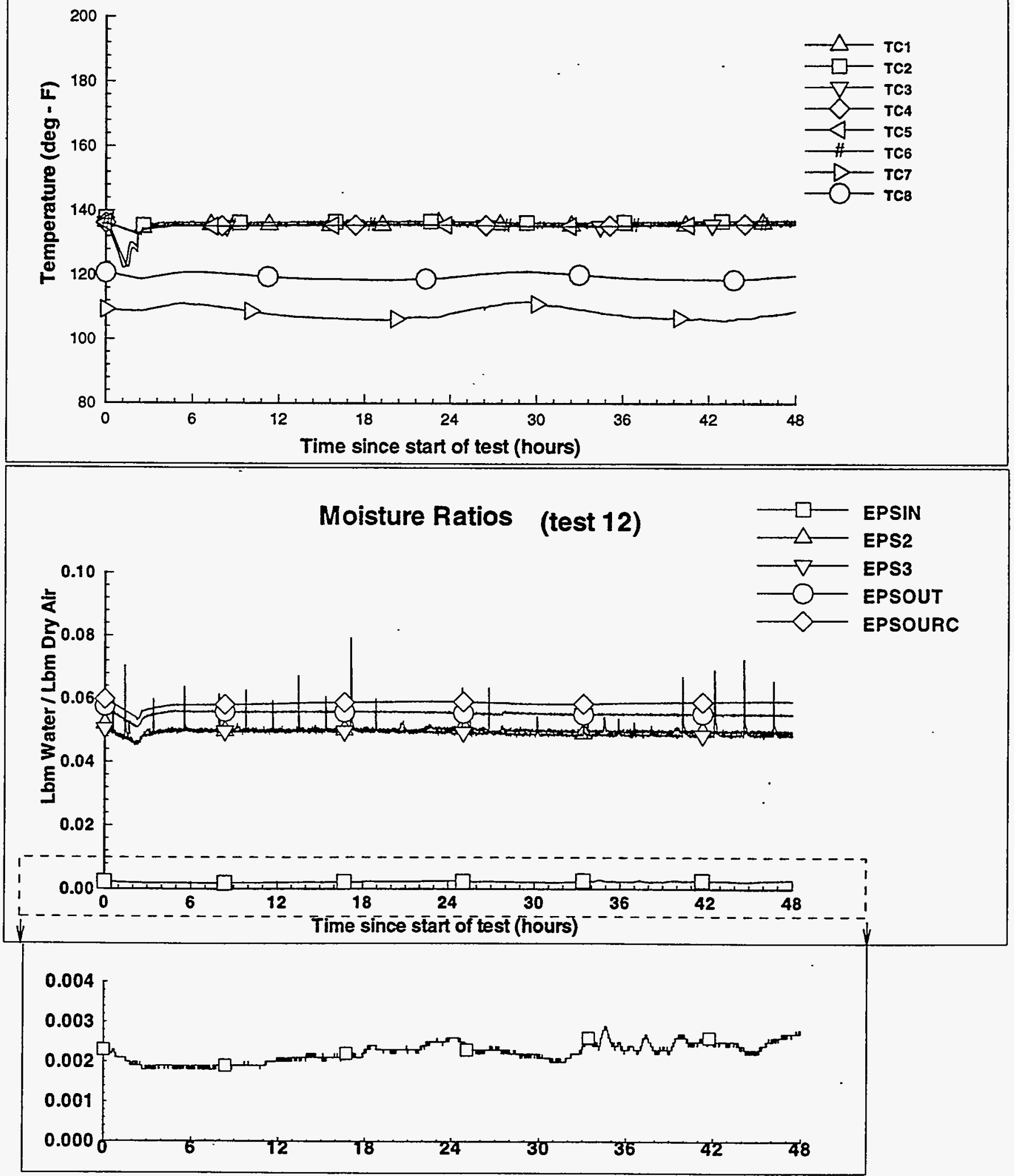
WHC-SD-W236A-ER-009

Rev. 0

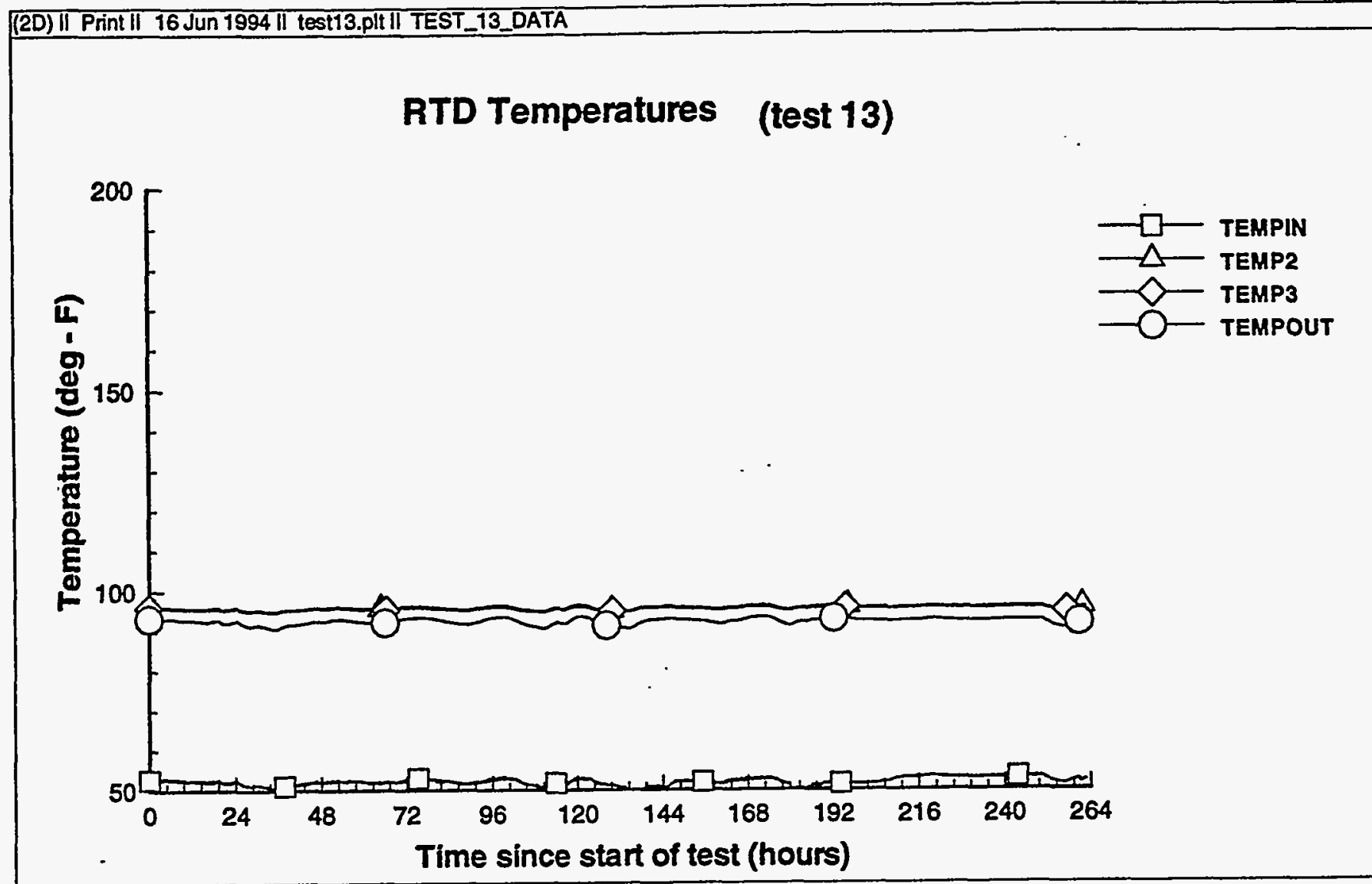

Vapor Space Air Flow (test 13)

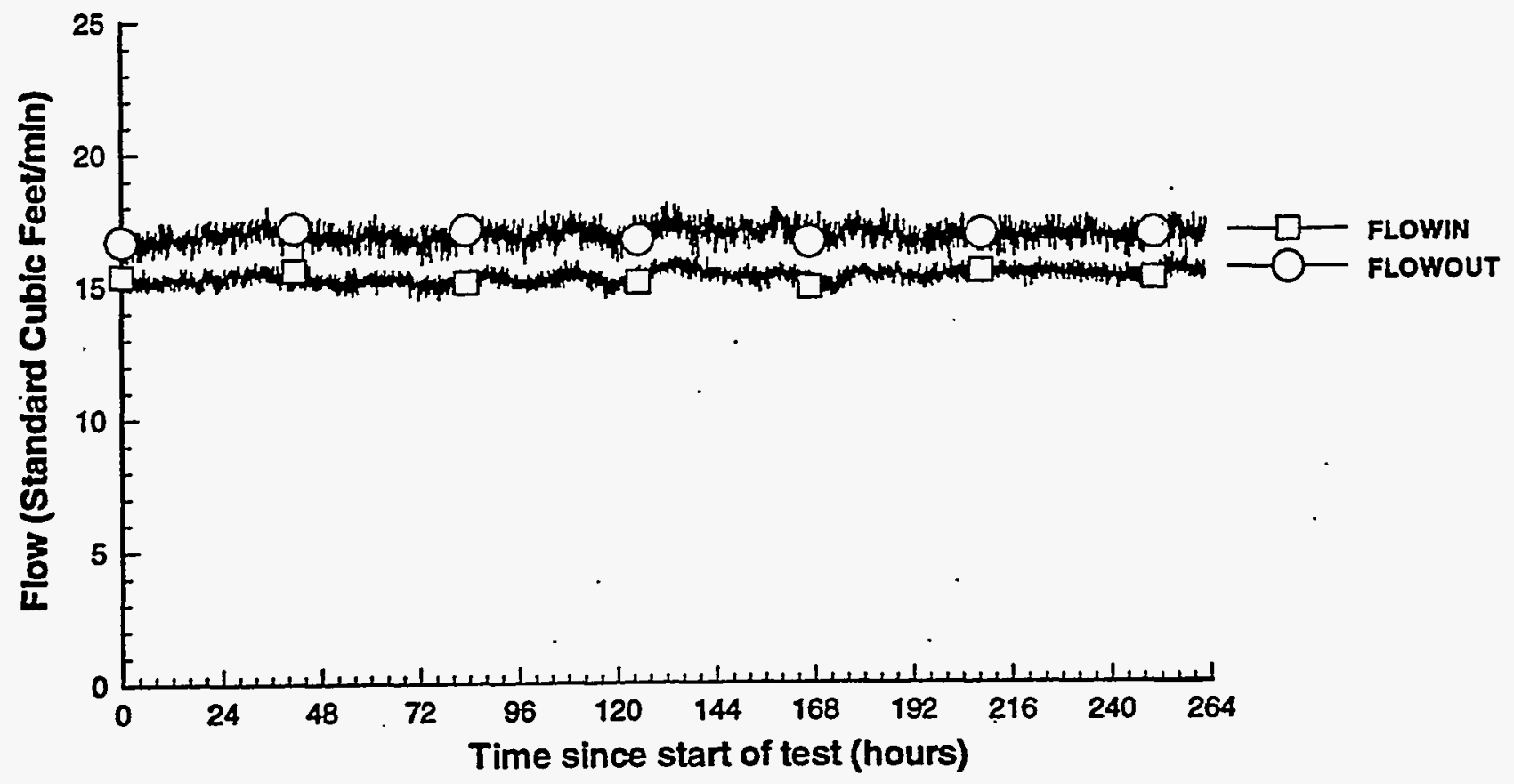

C-29 


\section{Thermocouple Temperatures (test 13)}
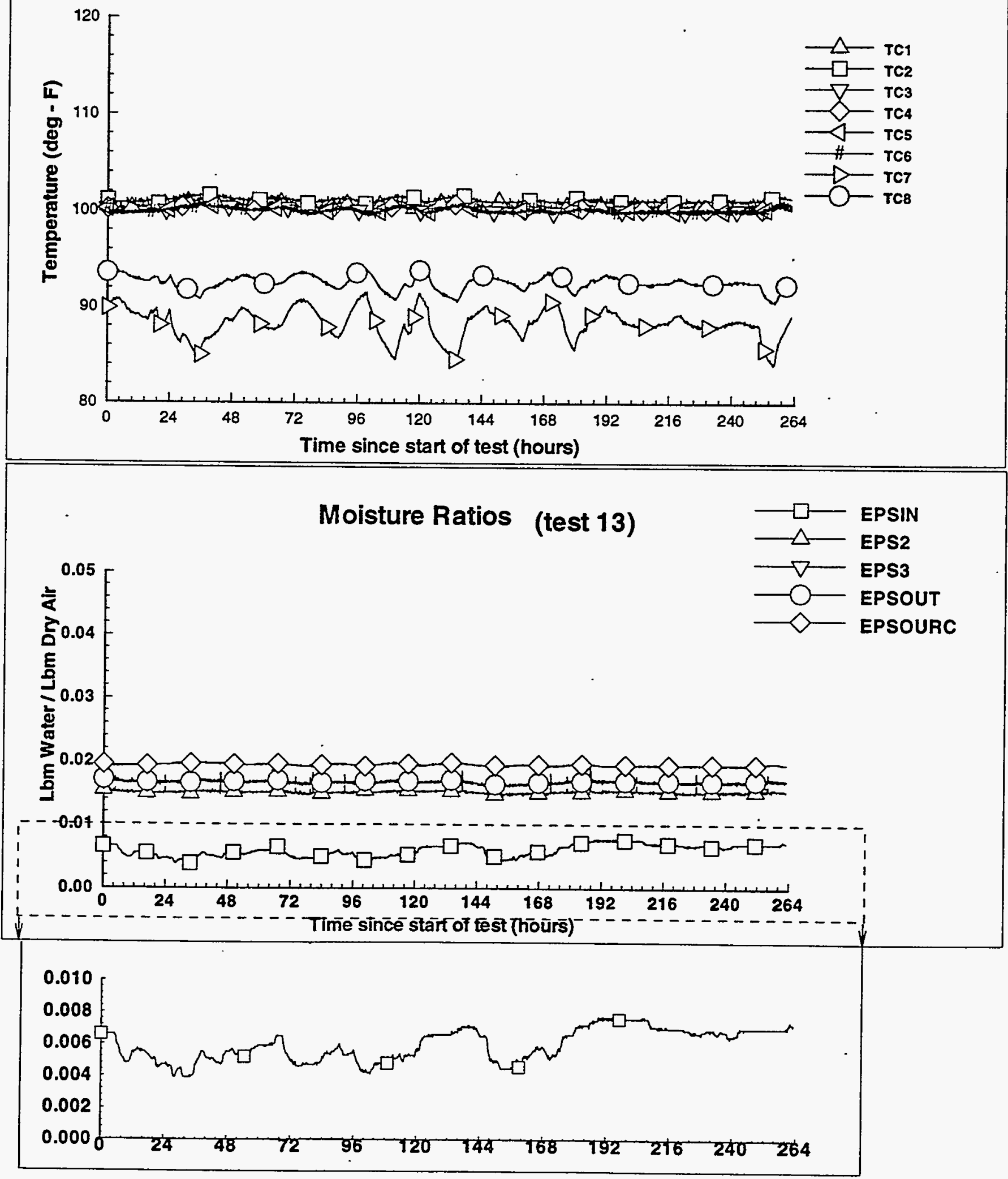


\section{RTD Temperatures (test 17)}

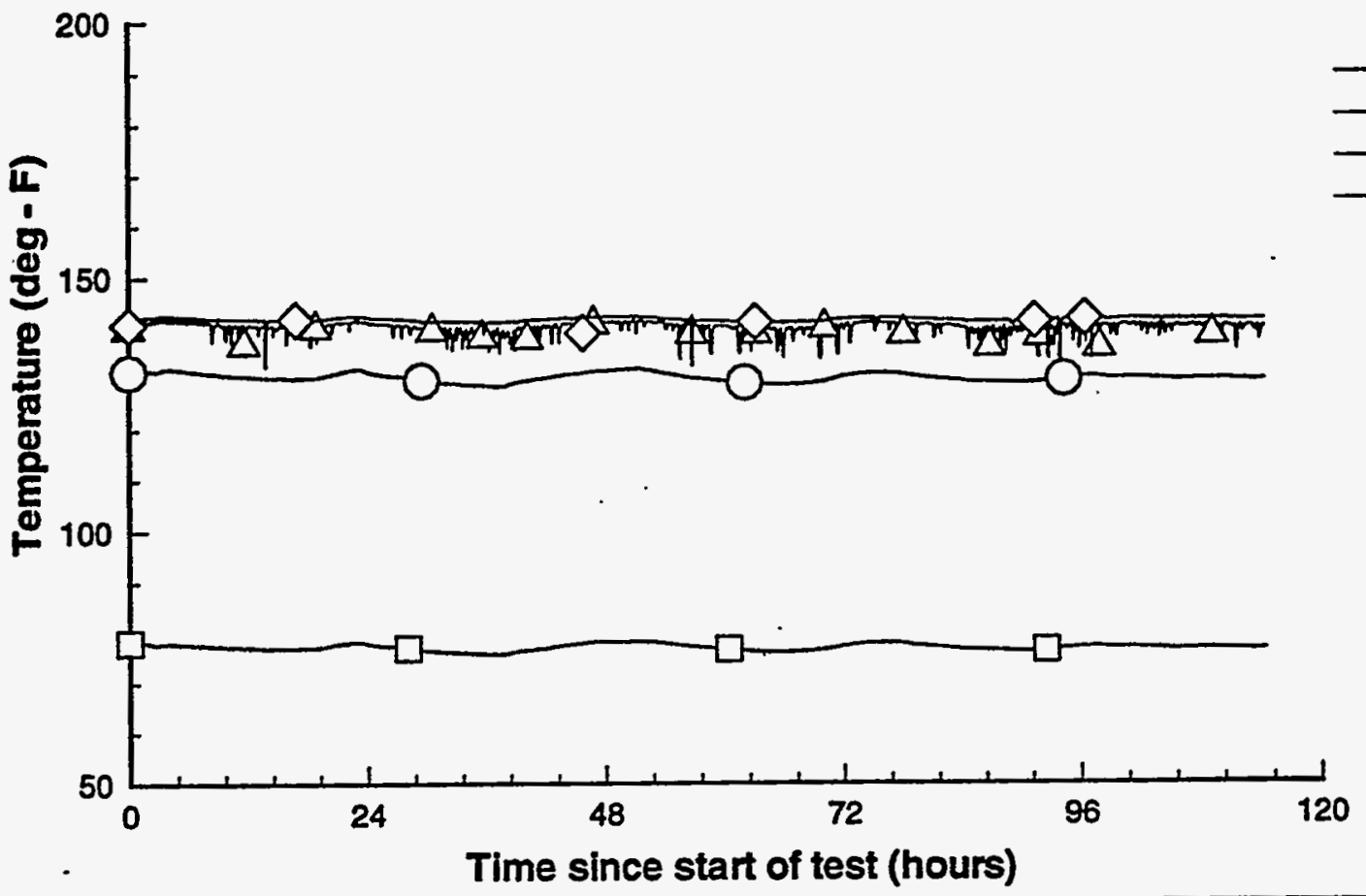

Vapor Space Air Flow (test 17)

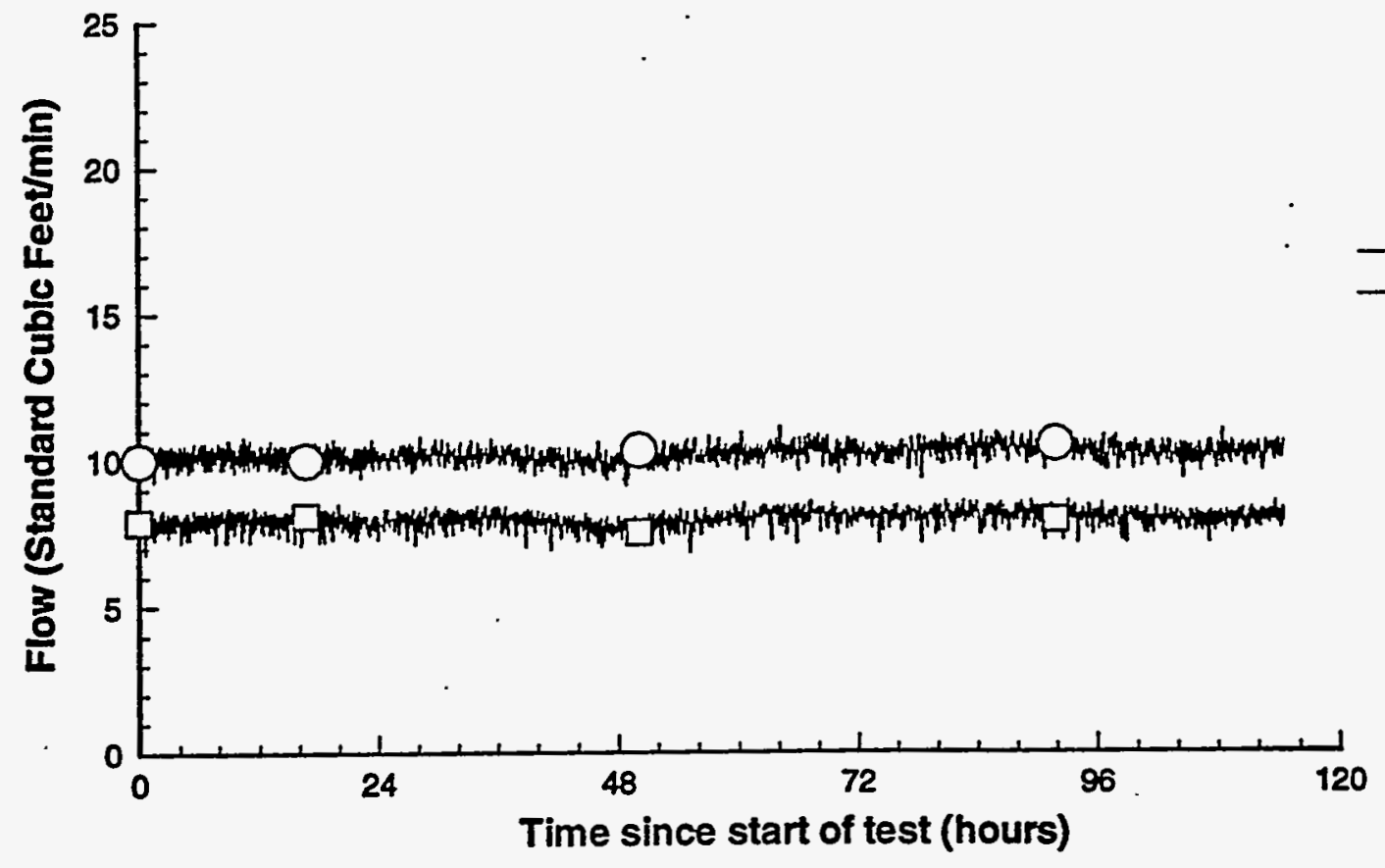


Thermocouple Temperatures (test 17)
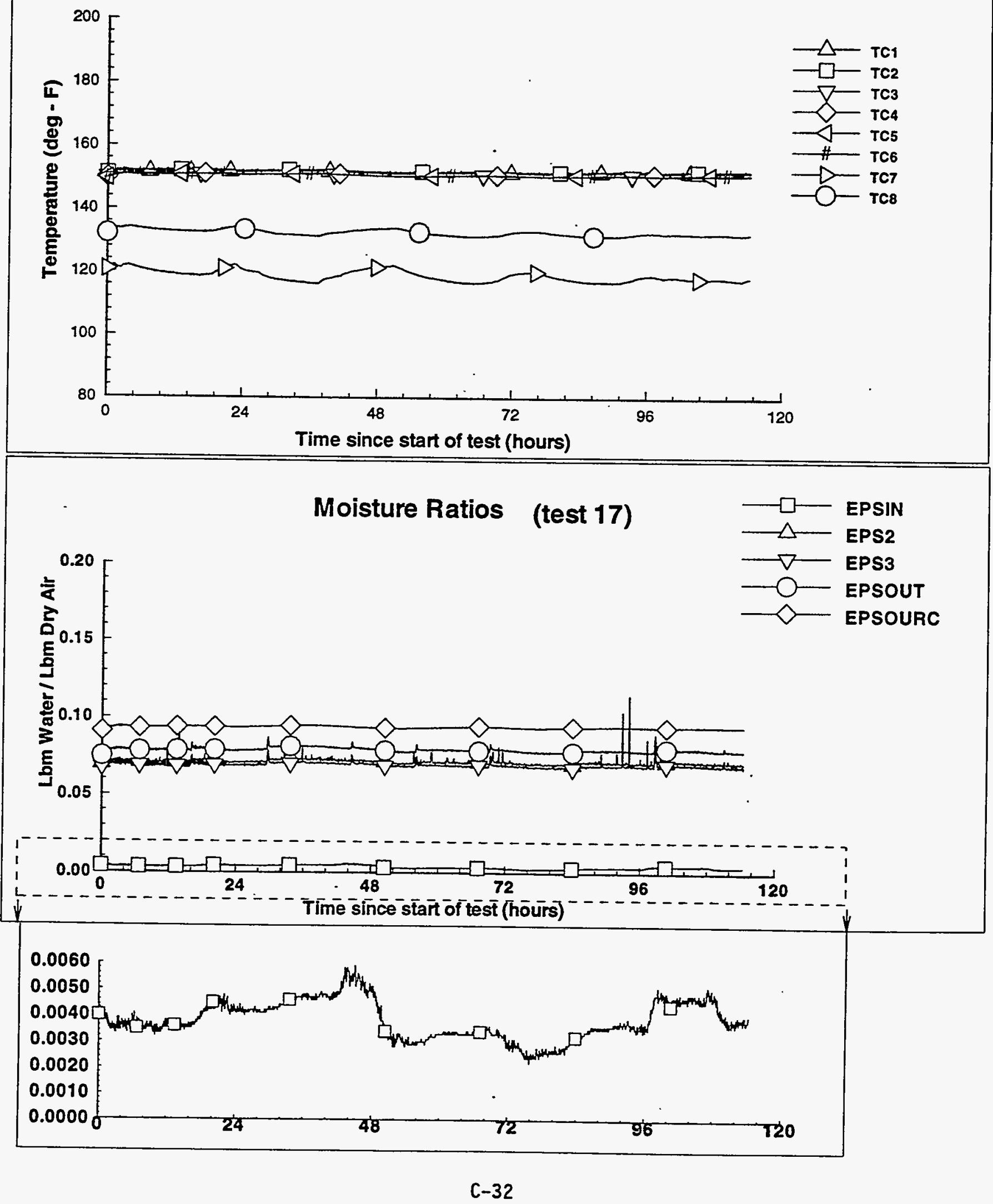


\section{RTD Temperatures (test 20)}

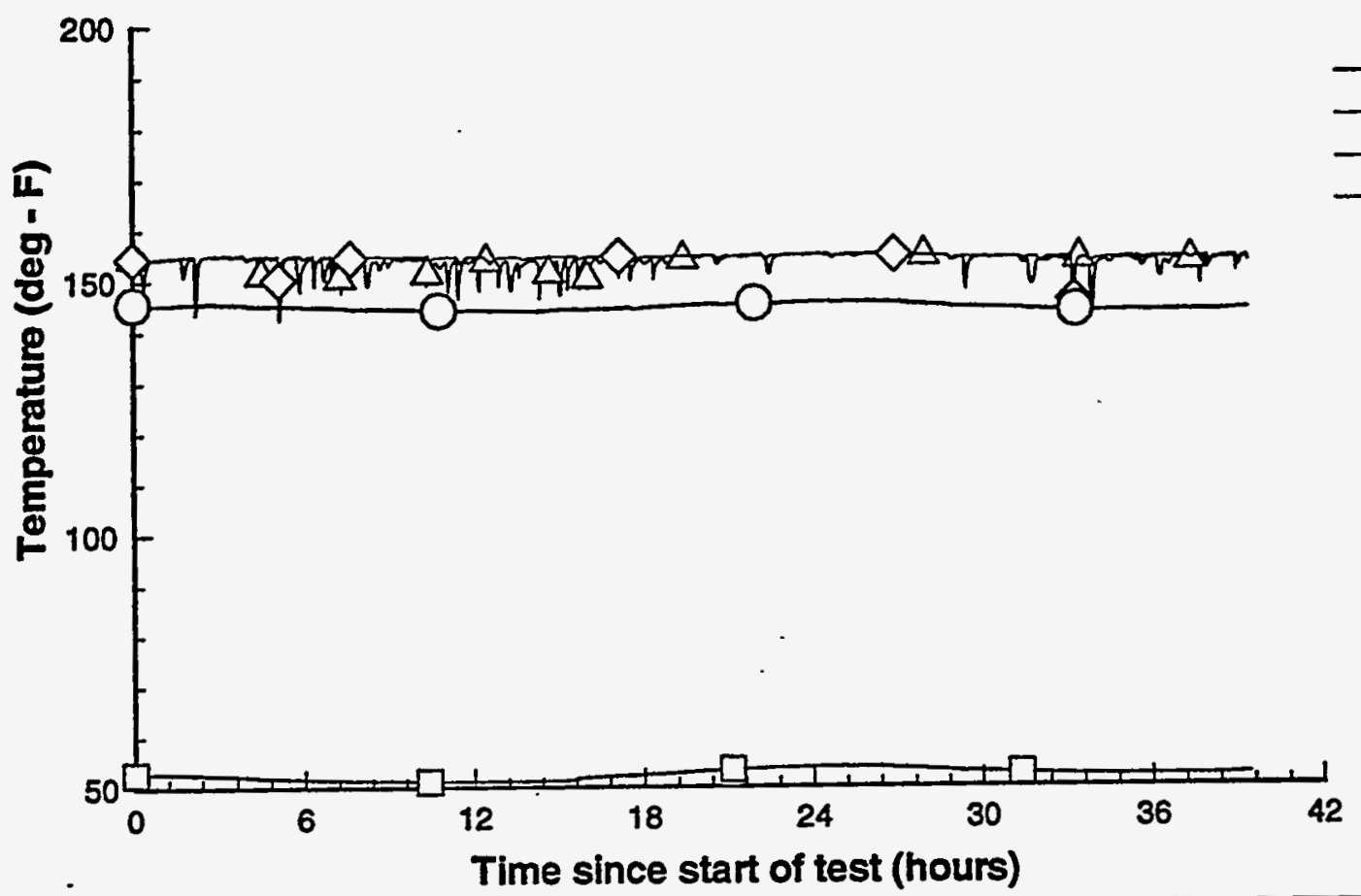

Vapor Space Air Flow (test 20)

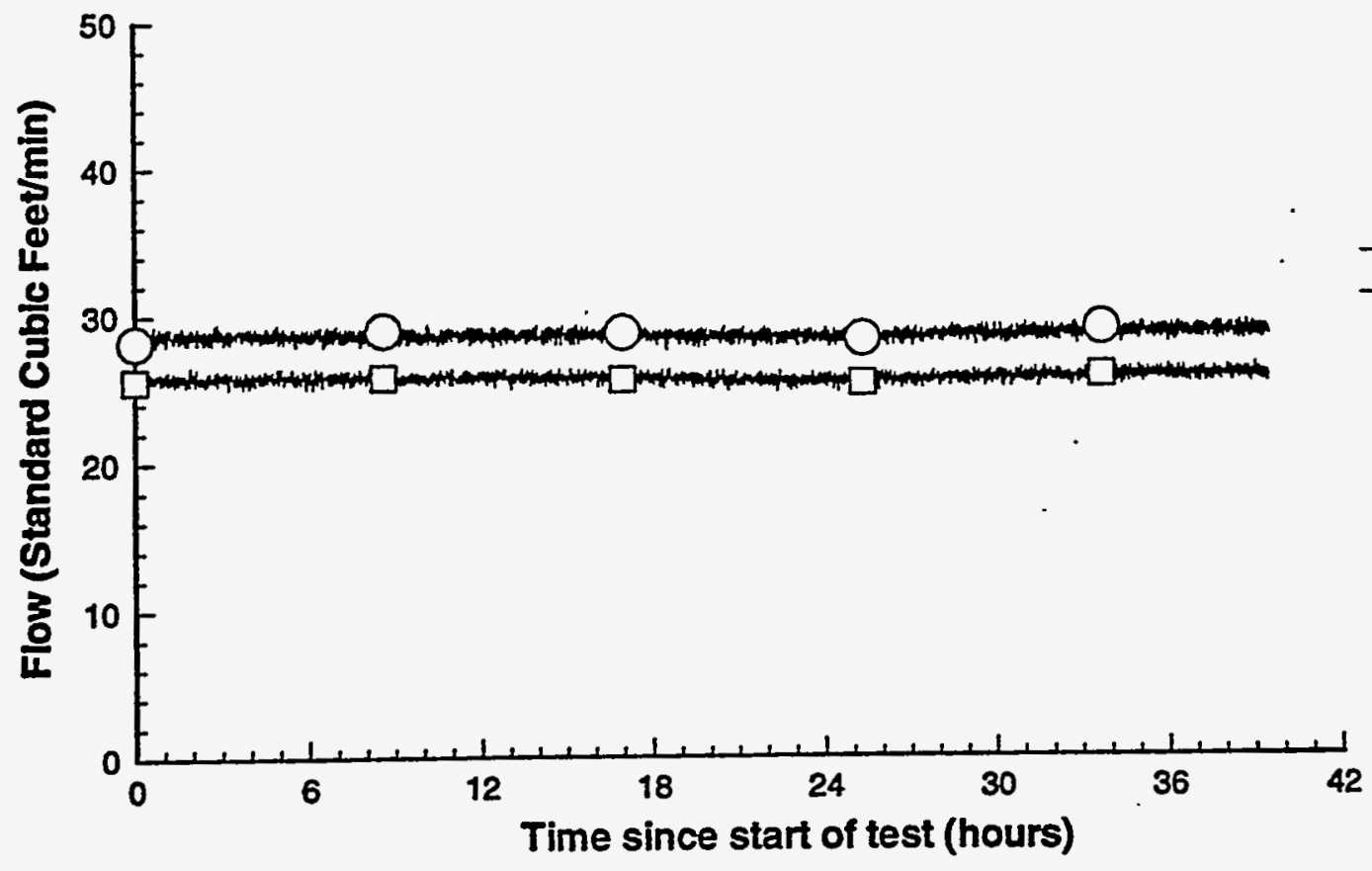




\section{Thermocouple Temperatures (test 20)}
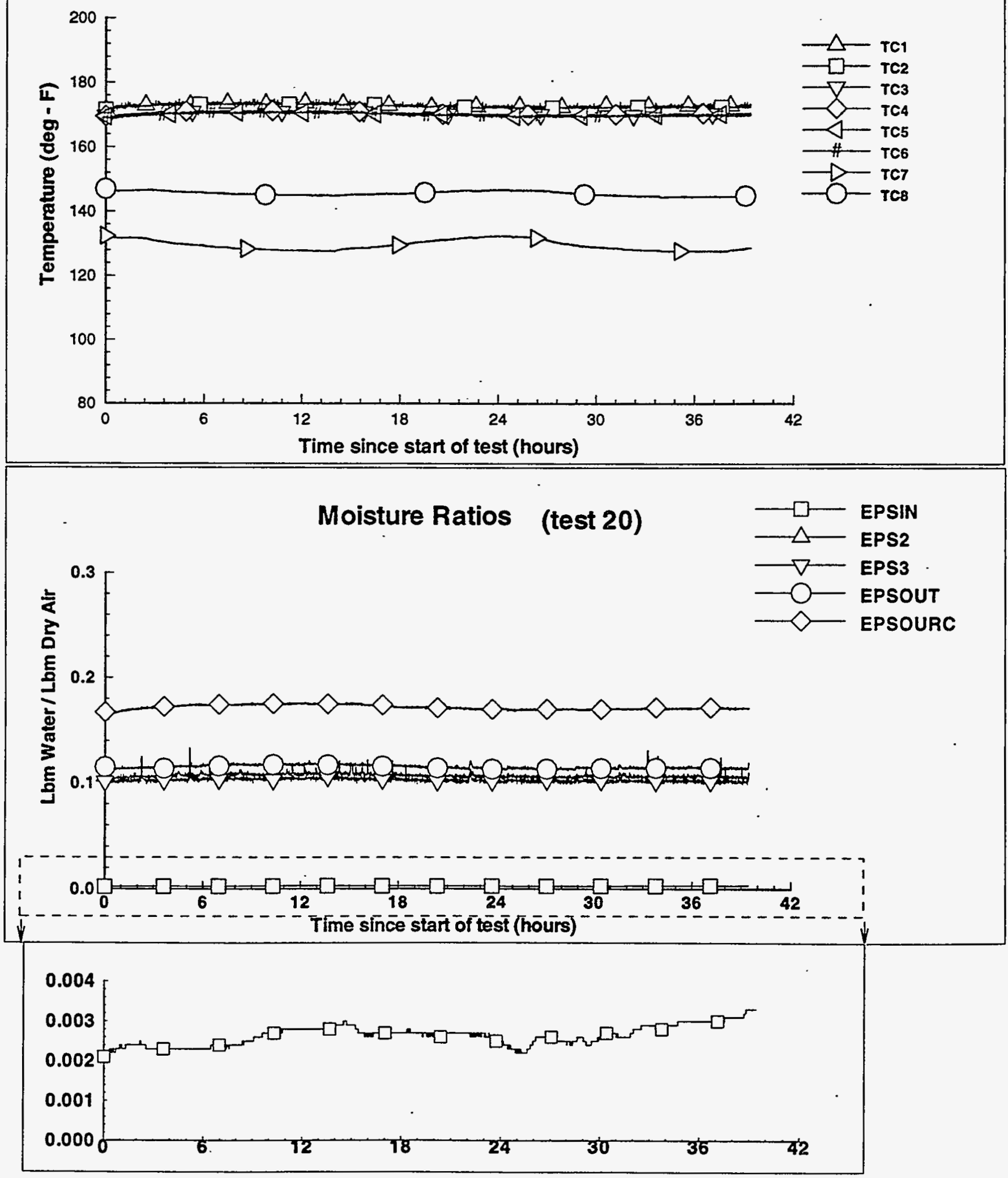


\section{RTD Temperatures (test 21)}

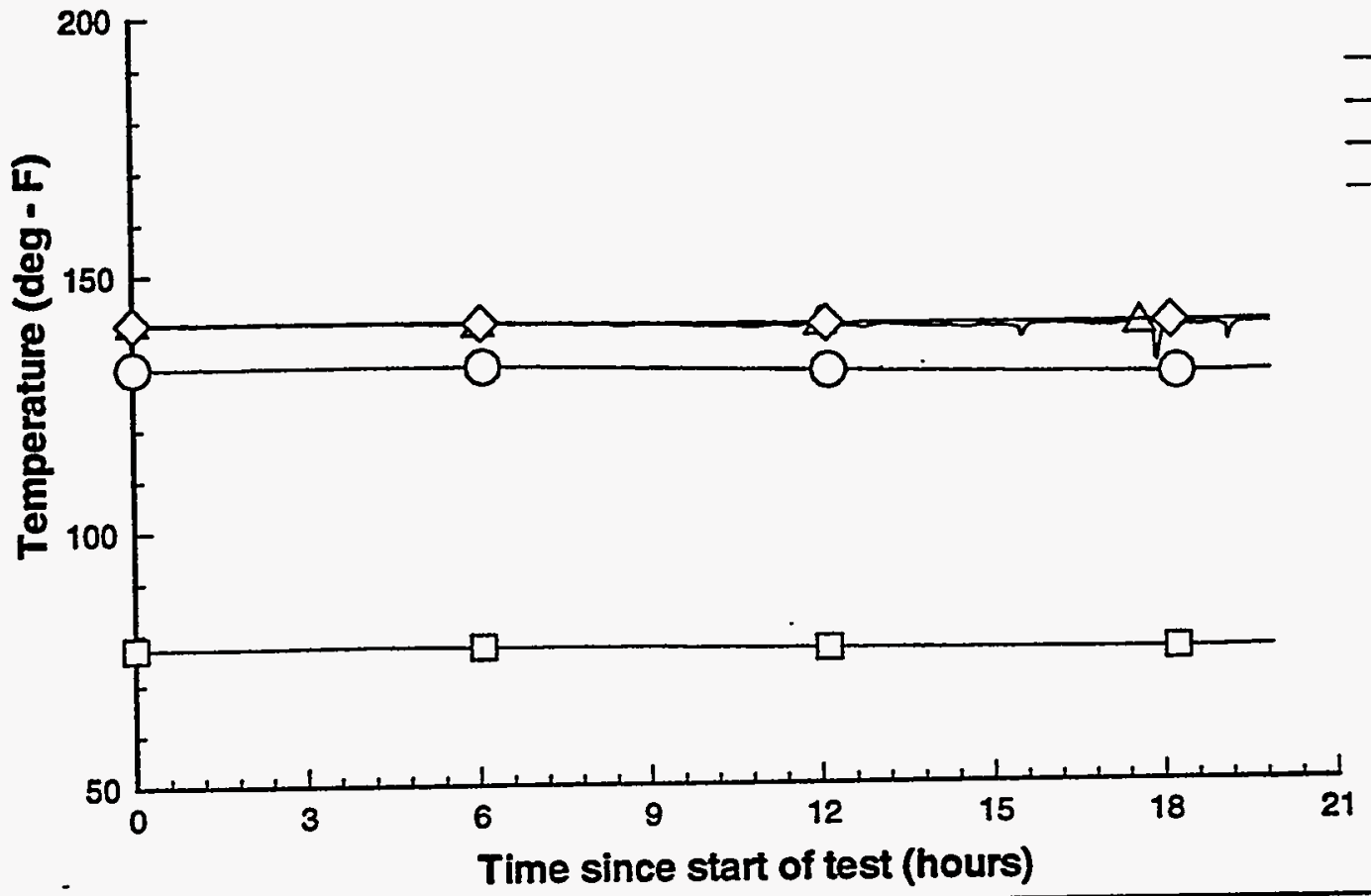

Vapor Space Air Flow (test 21)

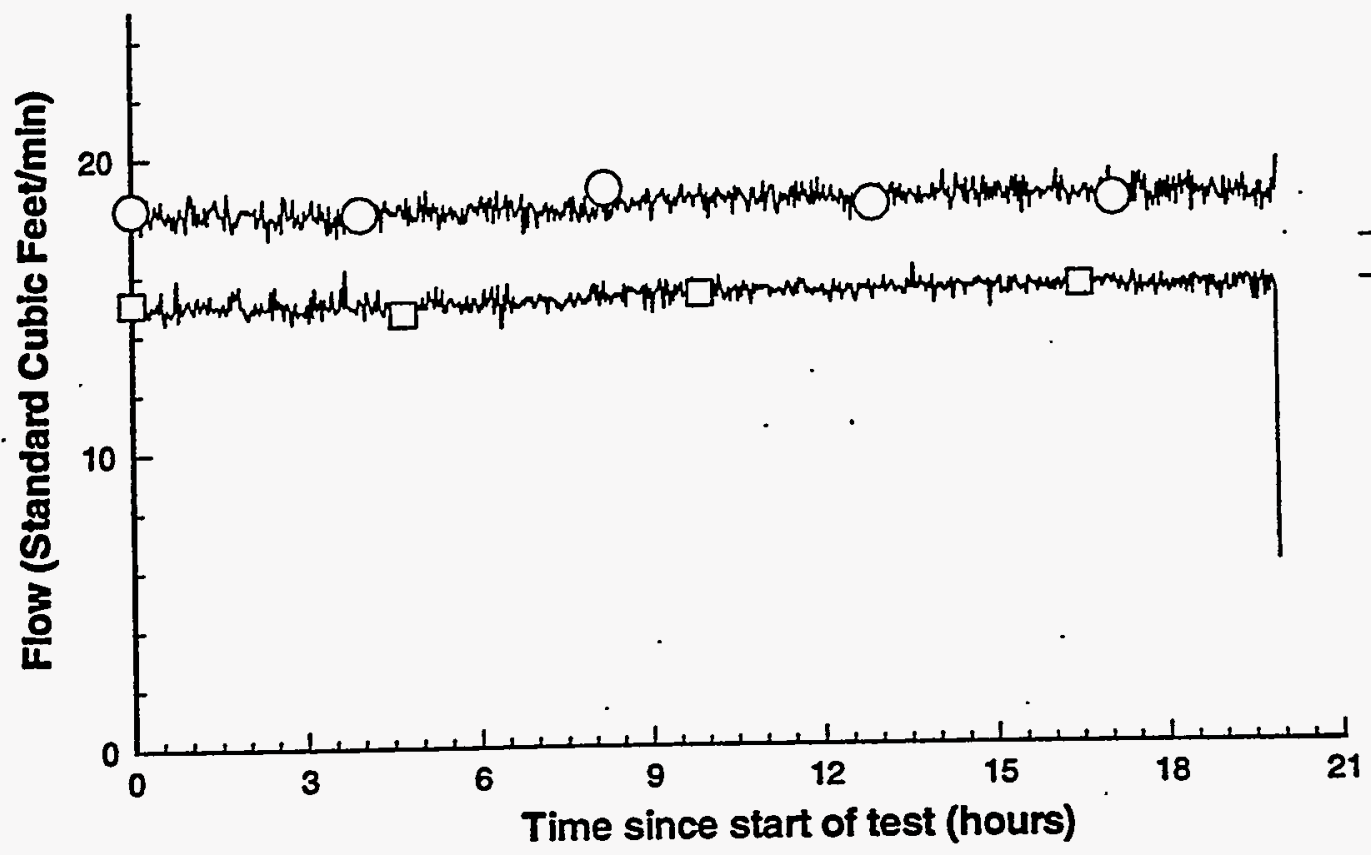




\section{RTD Temperatures (test 22)}

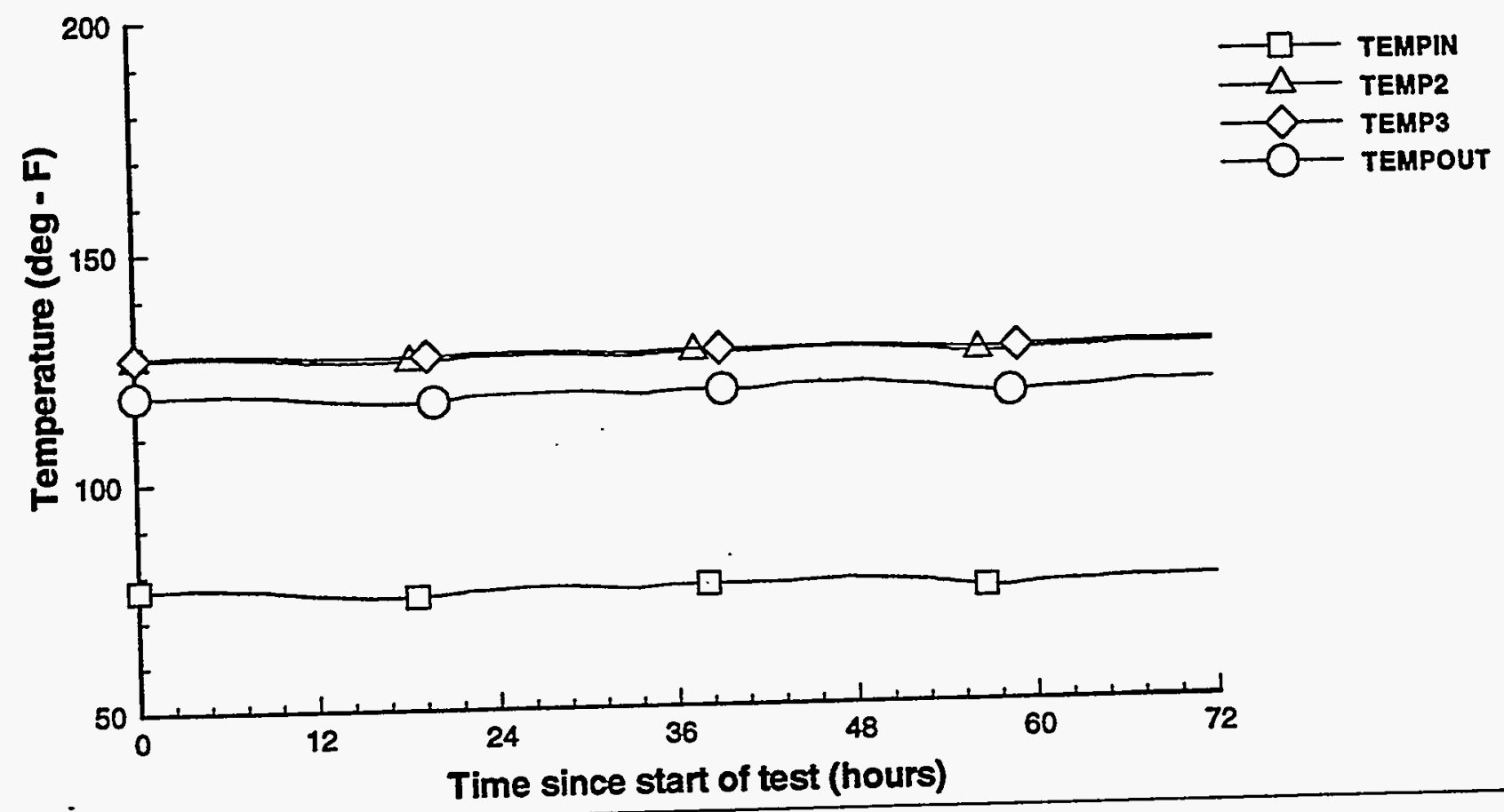

Vapor Space Air Flow (test 22)

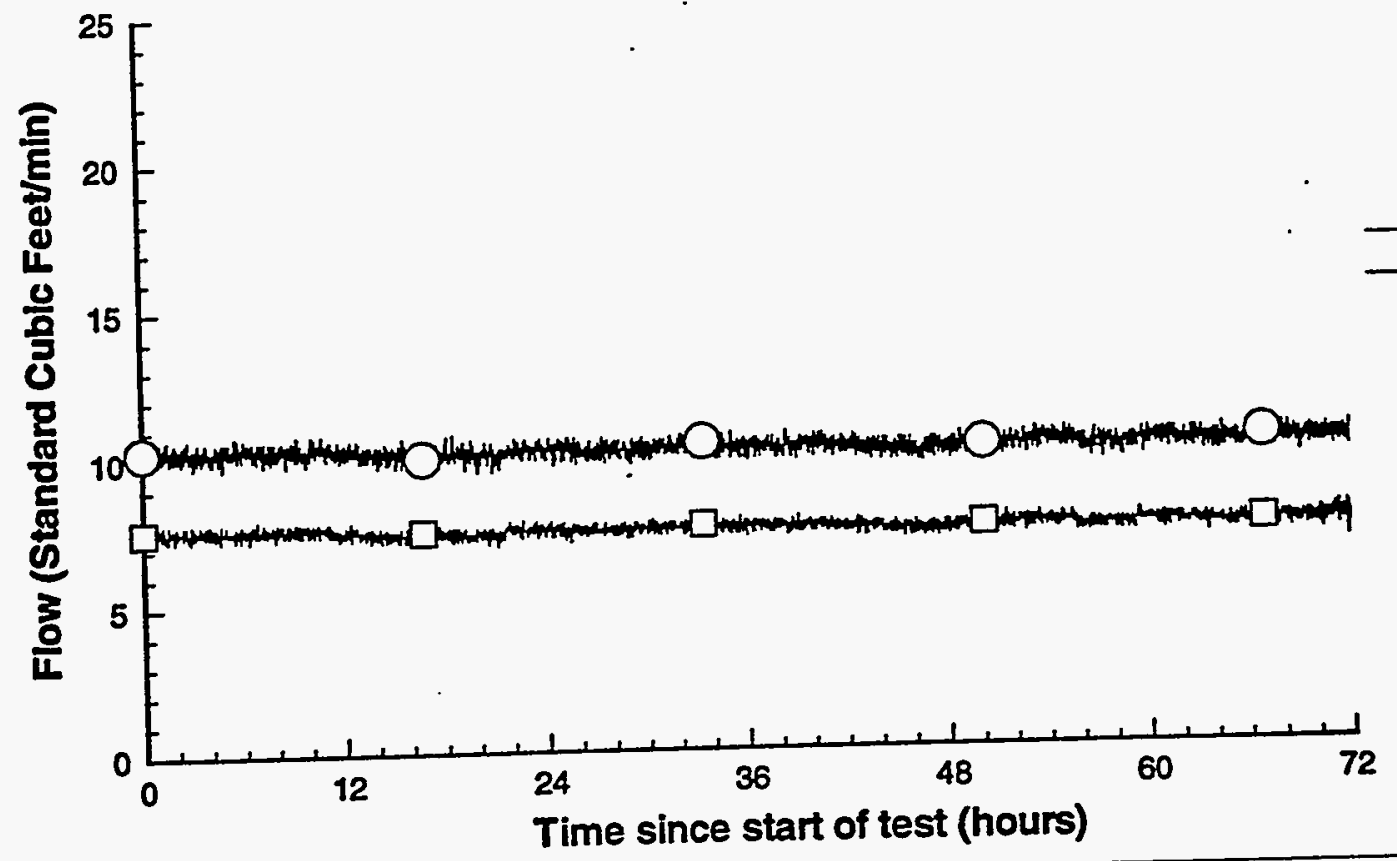




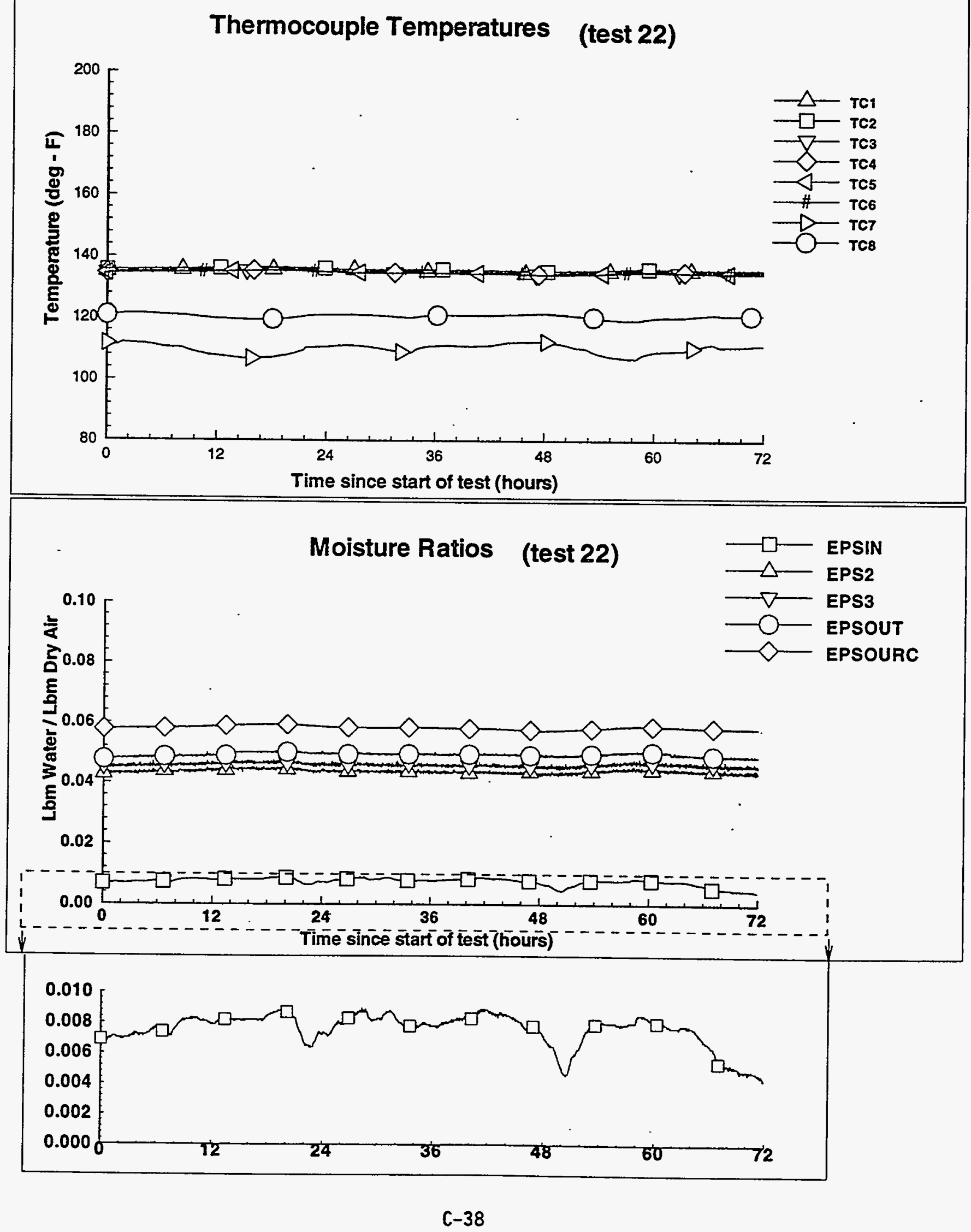


WHC-SD-W236A-ER-009

Rev. 0

Appendix D. Vapor Pressure Experiment on MWTF Surrogate Solution.

D-i 
From: Chemical Engineering Laboratory

$12130-93-043$

Phone: $\quad 3-1102$ S4-25

Date: May 26, 1993

SUbject: RESULTS FROM VAPOR PRESSURE EXPERIMENT ON MHTF SURROGATE SOLUTIONS

To:

C. A. Hinman

HO-33

$\begin{array}{lll}\text { cc: C. J. Berglund } & 54-25 \\ \text { M. J. Kupfer } & \text { H5-46 } \\ \text { M. J. Schliebe } & \text { S4-25 Zy } \\ \text { J. P. Sloughter } & \text { T6-07 }\end{array}$

Project file 13.2

EJS file/LB

References: (1) Internal Memo, P. J. Certa, J. R. Divine, and M. J. Kupfer, "Recommended Waste Composition Changes to the MWTF FDC," Dated February 25, 1993.

(2) Internal Memo, J. S. Garfield, "TWRS Systems Engineering Study Double She 77 Tank Waste Inventories, Rev 1," Number 25900-92-29, Dated September 18, 1992.

(3) CRC - Handbook of Chemistry and Physics $62^{\text {nd }}$ Edition, CRC Press, Inc, Boca Raton, Florida, 1981, pgs D-168 and 9.

The vapor pressures (VP) for two surrogate solutions of tank waste that will be stored in the Multiple Waste Tank Farm (MWTF) have been experimentally determined. The two solutions are expected to have the largest impact on VP due to their high salt concentrations and are, therefore, limiting. Data from this experiment is to be used to perform a thermodynamic balance around the tanks. The balance can be used to calculate such things as cooling requirements and water losses.

The experimental procedure and equipment for both solutions were nearly identical. Appropriate amounts of the reagents were weighed out, and demineralized water was added to make $700 \mathrm{~mL}$ of solution. The resulting solution was poured into a triple-necked flask, and the flask was placed in a heating mantle. In one neck of the flask, a mercury thermometer was placed (via a rubber stopper); in the second a thermocouple was placed (via a rubber stopper); and, in the third a condenser was placed. A cooling water 7 ine was attached to the condenser in order to condense the vapors exiting from the flask and, therefore, keep the solution at constant molarity. A tube connected the exit port of the condenser with a Jarge Erlenmeyer flask via a rubber stopper. Also attached to the fiask was a digital pressure gauge (absolute) and a vacuum pump. The bleed valve on the pump was manipulated to vary the systems pressure. The pump was then turned on, the lowest pressure set $(\sim 380 \mathrm{~mm} \mathrm{Hg})$, and then the heating mantle turned 
Page 2

May 26, 1993

on. Once the solution started to boil and the thermocouple showed no temperature increase, the temperature from the thermometer was logged. Previous work showed that the thermocouple was calibrated incorrectly, so it was used solely as an indicator of when a steady state temperature was reached. After the temperature reading was taken, the pressure was increased and the process repeated.

The first solution was the maximum expected molarities listed in the MHTF Functional Design Criteria (Certa, 1993). In order to simplify the experiment, only the specifications for nitrate $(5.1 \mathrm{M})$, nitrite $(1.8 \mathrm{M})$, and hydroxide $(6.9 \mathrm{M})$ were met. The sodium forms of the three anions were used in this experiment. The results follow:

\section{Solution I}

\begin{tabular}{|c|c|}
$\begin{array}{r}\text { Pressure } \\
(\mathrm{mm} \mathrm{Hg})\end{array}$ & $\begin{array}{c}\text { Temperature } \\
\left({ }^{\circ} \mathrm{C}\right)\end{array}$ \\
\hline 380.4 & 106.2 \\
\hline 474.9 & 113.0 \\
\hline 568.8 & 118.4 \\
\hline 593.4 & 119.8 \\
\hline 743.3 & 130.0 \\
\hline
\end{tabular}

The tolerance on temperature and pressure readings are assumed to be less than $+1-0.5^{\circ} \mathrm{C}$ and $+1-0.5 \mathrm{~mm} \mathrm{Hg}$.

The second solution used the inventory of the DSS/DSSF waste listed in the TWRS Systems Engineering Study letter (Garfield, 1992). Any component less than $0.1 \mathrm{M}$ and TOC (total organic carbon) were assumed to be inconsequential. For this solution, it was assumed that the $\mathrm{Al}^{+3}$ listed in the inventory was actualiy present as $\mathrm{AlO}_{2}^{-}$(aluminate). In order to keep a charge balance, the amount of $\mathrm{OH}^{-}$was decreased from $28.7 \mathrm{M}$ to $4.13 \mathrm{M}$. The chemical make-up of this surrogate is:

\section{Solution 2}

Chemical
\begin{tabular}{|l|c|}
\hline $\mathrm{NaCl}$ & Molarity \\
\hline $\mathrm{NaOH}$ & 0.17 \\
\hline $\mathrm{NaAlO}$ & 4.13 \\
\hline $\mathrm{NaNO}_{2}$ & 1.14 \\
\hline $\mathrm{NaNO}_{3}$ & 1.80 \\
\hline $\mathrm{KNO}_{3}$ & 2.26 \\
\hline
\end{tabular}


Page 3

May 26, 1993

The result for solution 2, experiment 1 follow:

$\begin{gathered}\text { Solution 2 - Experiment 1 } \\
\begin{array}{c}\text { Pressure } \\
(\mathrm{mm} \mathrm{Hg})\end{array}\end{gathered}$
\begin{tabular}{|c|c|}
\hline $\begin{array}{c}\text { Temperature } \\
\left({ }^{\circ} \mathrm{C}\right)\end{array}$ \\
\hline 380.3 & 96.1 \\
\hline 569.9 & 107.6 \\
\hline 745.6 & 119.7 \\
\hline
\end{tabular}

Comparing these results with pure water VPS (CRC, 1981), the first solution decreases the VP by approximately $60 \%$ and the second solution by $47 \%$. The attached figure (Figure l) compares the data obtained from the two experimental runs with published data (CRC, 1981) on pure water. The $110^{\circ} \mathrm{C}$ line was used to calculate the VP depression for the two solutions. The values for the two solutions at $110^{\circ}$.C were interpolated.

For solution 2, a second experiment was performed in order to obtain a larger array of data. The lower limit on pressure was decreased from $380 \mathrm{~mm}$ $\mathrm{Hg}$ to $83 \mathrm{~mm} \mathrm{Hg}$ (the 7 imit for the vacuum pump). The results follow:

Solution 2 - Experiment 2

\begin{tabular}{|c|c|}
$\begin{array}{c}\text { Pressure } \\
(\mathrm{mm} \mathrm{Hg})\end{array}$ & $\begin{array}{c}\text { Temperature } \\
\left({ }^{\circ} \mathrm{C}\right)\end{array}$ \\
\hline 83.0 & 59.2 \\
\hline 85.0 & 60.0 \\
\hline 100.1 & 63.9 \\
\hline 150.0 & 73.1 \\
\hline 200.5 & 80.2 \\
\hline 250.2 & 85.8 \\
\hline 300.3 & 90.5 \\
\hline 350.4 & 95.0 \\
\hline 380.4 & 97.1 \\
\hline 480.5 & 104.4 \\
\hline 580.5 & 109.7 \\
\hline 742.6 & 120.2 \\
\hline
\end{tabular}

These values compare favorably with the numbers obtained from the first experiment. The slight variations can be attributed to possible water vaporation between runs (change in solution molarity) or experimenter error. 
Rev. 0

C. A. Hinman

Page 3

May 26, 1993

Figure 2 compares the data for solution 1 from experiment 1 and 2 with literature data on pure water. As can be seen from the graph, solution 2 closely mimics the curvature of pure water. The average vapor pressure depression is approximately $44 \%$. This agrees, within reason, with the factor obtain from the first experiment.

If you have any questions or comments, please contact me at 3-1102.

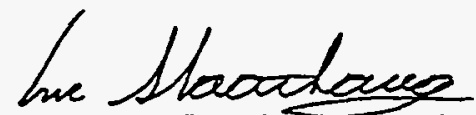

Eric J. Slaathaug, Engineer

Chemical Engineering Laboratory

ath

Attachment (2) 


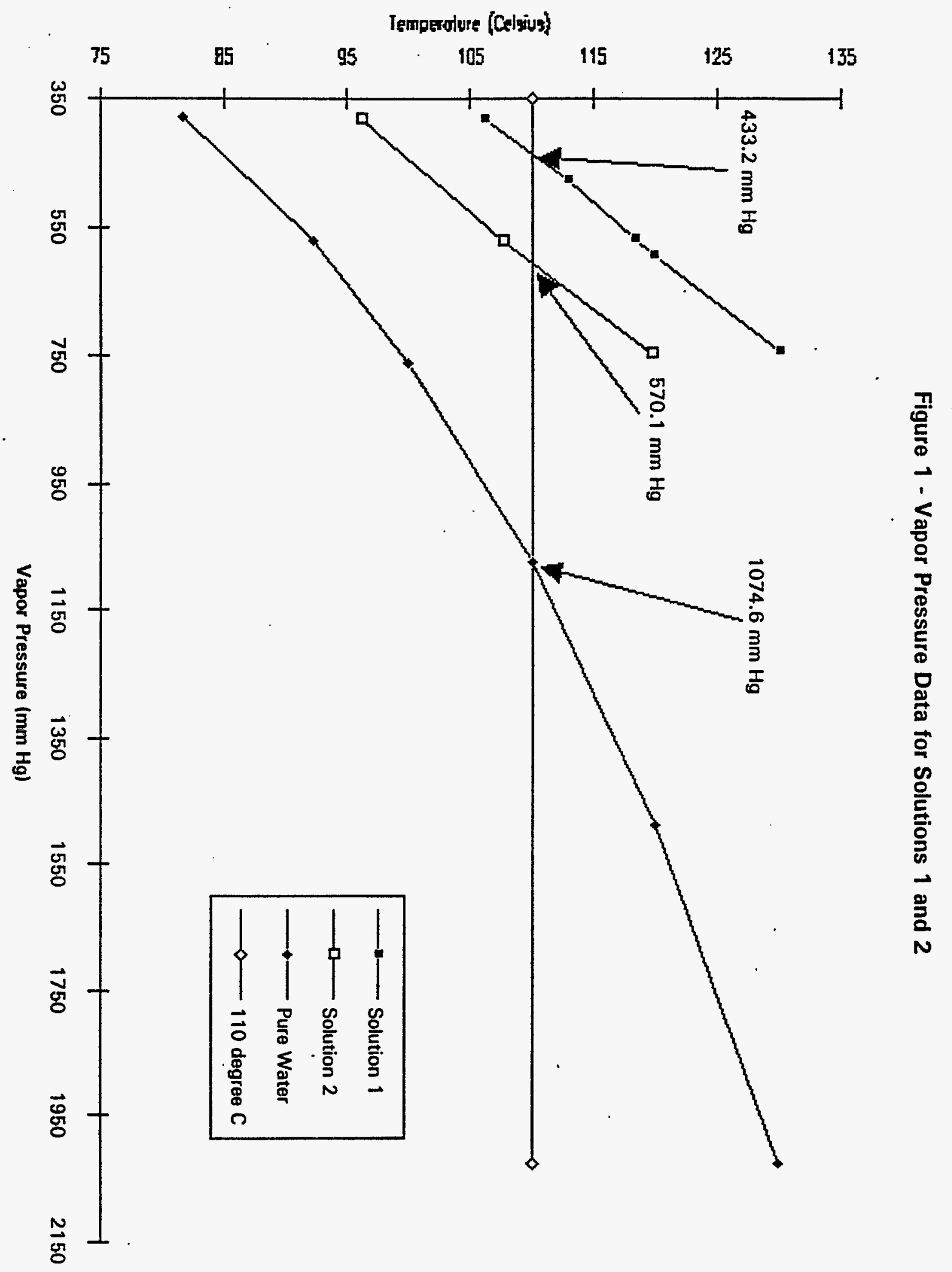




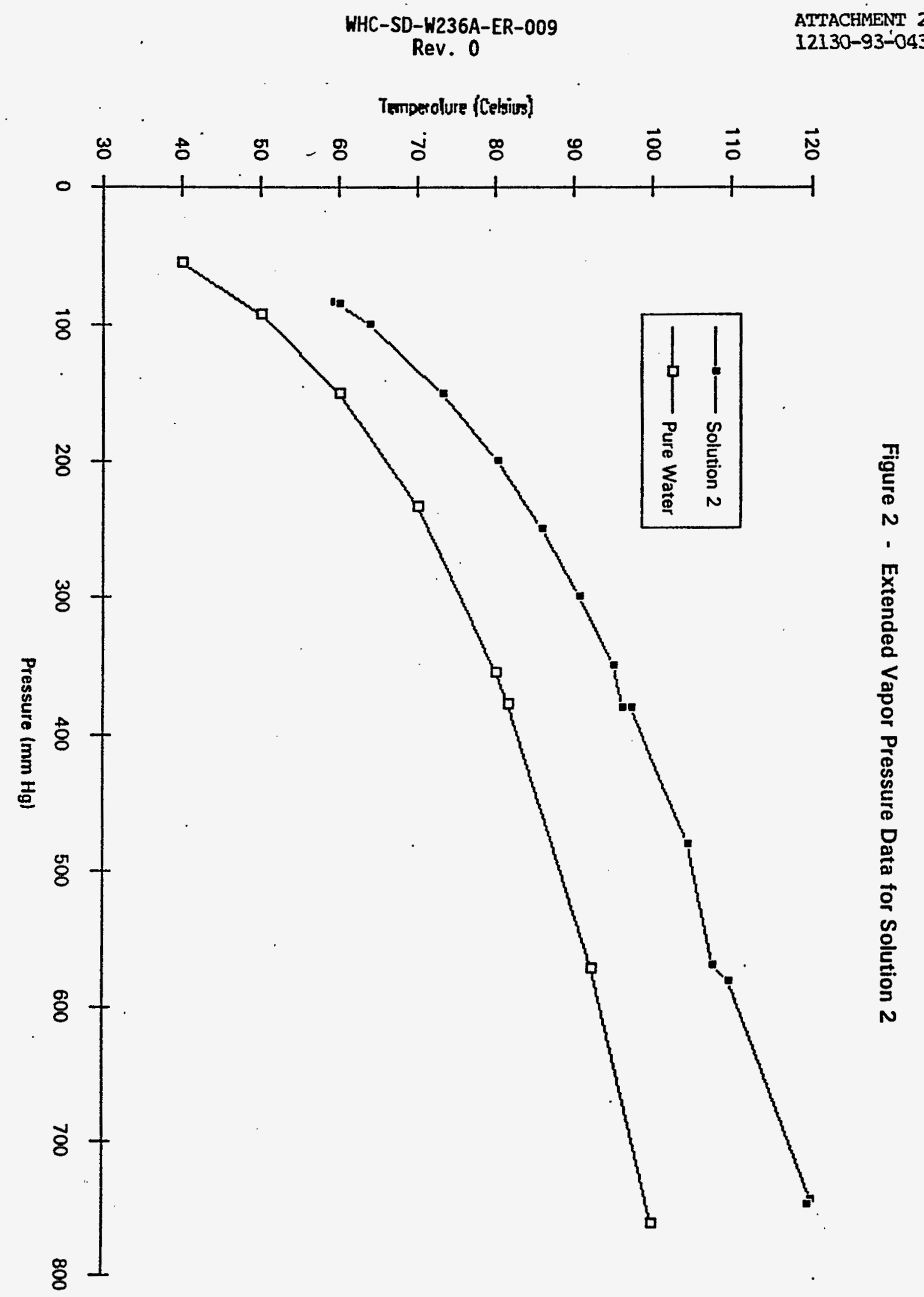


WHC-SD-W236A-ER-009

Rev. 0

Appendix E. Literature Review.

$E-i$ 
WHC-SD-W236A-ER-009

Rev. 0

\title{
. Iiterature Review on Evaporation Test
}

\author{
By Y. Lee
}

Extensive literature review on the evaporation of the water into still air has been performed, including the library data base search. Even though the interest on the process of evaporation begins from early 19th century, there are a limited number of literatures dealing with the evaporation of water into still air. Much of the previous research was focused on the evaporation of water into moving air.

Since earlier reports by Dalton', Hinchley ${ }^{2}$, and Hinchley and Himus $^{3}$ have been discussed thoroughly in the paper by Pauker et al.4, they will not be repeated in this report. The most significant experimental report in this field was presented by Sharpley and Boelter ${ }^{5}$ and Boelter et al. ${ }^{6}$ based on their measurement of evaporation rate from one-foot diameter pan into still air. Their reports cover. the evaporation of distilled water within the temperature limit 63 and $200 \mathrm{~F}$, into quiet air at 65 to $80 \mathrm{~F}$. They, also, have established an empirical relationship to calculate the evaporation rate as a function of surface and bulk water vapor pressure as follows:

$$
\begin{aligned}
G= & 0.067\left(P_{s}-P_{b}\right)^{1.22} \\
\text { where, } & G \quad \text { Evaporation rate }\left(1 \mathrm{~b} / f t^{2} \mathrm{hr}\right) \\
& \left.P_{s} \quad \text { Water vapor pressure at surface (in } \mathrm{Hg}\right) \\
& \left.P_{b} \quad \text { Water vapor pressure at bulk (in } \mathrm{Hg}\right)
\end{aligned}
$$

Recently, Pauker et al. ${ }^{4}$ have shown that the measurements of the evaporation rates for water at temperature ranging from 25 to $50 \mathrm{C}$ into still air at $20 \mathrm{C}$ using 47 -inch diameter pan are close agreement with the results of Boelter et al. 5 , thus confirming the above relationship. These experiments, however, were limited to the lower air temperature ranges than the air temperature expected for the MWTF tank design, and it is questionable at best to extrapolate the above empirical relationship into the higher air temperature case for the design calculation.

As mentioned previously, there are a large number of studies reported on the evaporation of water into moving air representing the water loss at ponds or lakes $7,8,9.10$. In these studies, attempts were made to relate the water loss during moving air to the loss into still air assuming that the still air case is the limiting case for the moving air. Their results, however, are not as credible as the results from the experiments with still air. Adams et al." have presented an excellent literature review on this subject. Also, Scarrow et al. ${ }^{12}$ have reported the messurement of the evaporation rete in the system where the temperature of the water 
WHC-SD-W236A-ER-009

Rev. 0

layer is depressed relative in order to the air temperature to study the natural convection caused by the concentration difference alone.

A number of attempts have been made in order to develop the semi-empirical relationship to predict the evaporation rate. The relationship between temperature gradient and the strength of the natural convection for the horizontal plate has been expressed through the Rayleigh Number, and the relation between Rayleigh number and heat transfer coefficient has been well established for the wide range of the Rayleigh number ${ }^{13}$. Since the transfer of heat and mass are analogous, the relationship developed for the heat transfer can be applied to the mass transfer of water vapor between the interface and bulk phase during the evaporation. As pointed out by Eckert and Drake ${ }^{14}$, an equation for free convection heat transfer may be applied for free convection mass transfer simply by replacing the Nusselt number by the sherwood number, and the Prandtl number by the schmidt number. The driving force in the Rayleigh number, however, cannot be simply replaced by the concentration difference, since the evaporation system has not only the concentration difference but also the temperature difference. Somers ${ }^{15}$ and Wilcox ${ }^{16}$ solved the governing equations for simultaneous heat and mass transfer in laminar free convection from a vertical plate, and concluded that the effect on the natural convection due to temperature and concentration differences are additive for nearly equal the Prandtl and schmidt numbers. It is clear from these studies that both differences will enhance the degree of natural convection more than a single difference. The exact magnitude of the contribution from one to another, however, is required for further study.

Assuming that the concentration gradient is the dominant driving force. Shah ${ }^{17}$ has been developed the equation representing the evaporation rate from the heat and mass transfer analogy as follows:

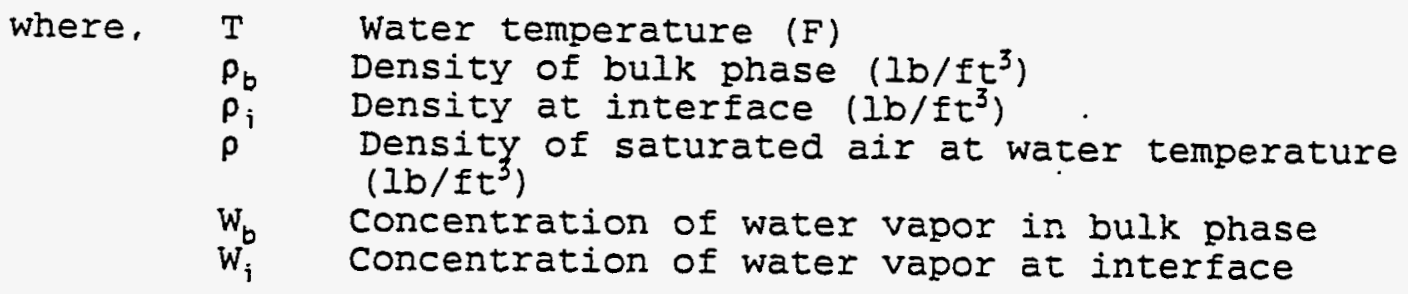

Assuming that both driving forces, temperature ans concentration differences, are additive, Paik and Henry ${ }^{18}$ have suggested the following equation: 
Rev. 0

\author{
where, D Molecular diffusivity of diffusing gas in \\ mixture $\left(\mathrm{It}^{2} / \mathrm{hr}\right)$ \\ $p_{0}$. Density of mixture $\left(I \mathrm{~b} / \mathrm{ft}^{3}\right)$ \\ $Y_{i} \quad$ Interface mass fraction of diffusing gas \\ $Y_{b} \quad$ Bulk phase mass fraction of diffusing gas \\ $v \quad$ Kinematic viscosity of gas mixture ( $\mathrm{ft}^{2} / \mathrm{hr}$ ) \\ $g$ gravitational force ( $\mathrm{ft} / \mathrm{hr} \mathrm{r}^{2}$ ) \\ $T_{i}$ Temperature at interface $(F)$ \\ $T_{b} \quad$ Temperature at buIk phase (F) \\ $\mathrm{M}_{\mathfrak{i}}$ Molecular weight of diffusing gas \\ $M$ Molecular weight of inert gas
}

Also, Adams et al. ${ }^{10}$ suggested a similar but more complex equation. Since the predictions of these equations have not been validated by the experimental data for the water and air temperature ranges applicable to the MWTF design, the accuracy of these predictions is questionable at best for the temperature range covering the MWTF design. Also, it is worth stating that all literatures discussed in this section presented the study on the evaporation of pure water into still air while the waste water vapor pressure is much lower than that of the pure water due to the vapor pressure suppression. The effect of vapor suppression on the evaporation rate has never been addressed in the existing literature. 


\section{References}

1. Dalton, J., "Meteorological Observation and Essays," 2d Ed., 1834 .

2. Hinchley, J. W., "The General Problem of Evaporation," J. society of Chem. Industry, Vol. 41, pp. 242, 1922.

3. Hinchley, J. W. and G. W. Himus, "Evaporation in Currents of Air," Trans. Inst. Chem. Eng., Vol. 2, pp. 57, 1924.

4. Pauker, M. T., et. al., "A Novel Method for Measuring Water Evaporation into Stili Air," ASHRAE Trans. Vol. 99, pt. 1, pp. 297, 1993.

5. Sharpley, B. F. and I. M. K. Boelter, "Evaporation of water into quit air from a one-foot-diameter surface," Ind. Eng. Chem., Vol. 30, pp. 1125, 1938 .

6. Boelter, I. M. K., et. al., "Free Evaporation into Air of Water from a Free Horizontal Quiet Surface," Ind. Eng. Chem., Vol. 38. pp. $596,1946$.

7. Carrier, W. H., "The Temperature of Evaporation," ASHVE Trans., Vol. 24, pp. 25, 1918.

8. Herbeck, G. E. and E. P. Anderson, "Water Loss Investigation: Vol. I - Lake Hefner Studies Technical Report," U.S. Geological Survey Paper 269, Washington, D.C., 1954.

9. Ryan, P. J., et. al. " "Surface Heat Loss from Cooling Ponds," Water Resources Research, Vol. 10, pp. 930, 1974.

10. Adams, E. E., et. al., "Evaporation from Heated Water Bodies: Predicting Combined Forced Plus Free Convection, "Water Resources Research, Vol. 26, pp. 425, 1990.

11. Adams, E. E., et. al., "Water and Energy Budget Analysis. Evaporation from Heated Waterbodies: Analysis of Data from the East Mesa and Savannah River Sites," Rep. CS-5171, EPRI, Palo Alto, Ca., 1987.

12. Sparrow, E. M., et. al., "Evaporation of water from a Horizontal surface by Natural convection," J. of ieat Transfer, Vol. 105, pp. 469, 1983.

13. Goldstein, R. J., et. al., "High-Rayleigh-Number Convection in a Horizontai Enclosure," J. Fluid Mech., Vol. 2:3, pp. 285, 1973. 
14. Eckert, E. R. G., and R. M. Drake, "Analysis of Heat and Mass Transfer," pp. 731-733, McGraw-Hill, New York, 1972.

15. Somers, E. V., "Theoretical Consideration of combined Thermal. and Mass Transfer from a Vertical Flat plate," J. Apl. Mech., Vol. 23, pp. 295, 1956.

16. Wilcox, W. R. " "Simultaneous Heat and Mass Transfer in Free Convection," Chem. Eng. Sci., Vol. 13, pp. 113, 1961.

17. Shah, M. M.. "Estimating of Evaporation from Horizontal surfaces," ASHRAE Trans., Vol. 87., Pt. 1, pp. 35, 1981.

18. Letter from M. A. Grolmes at Fauske \& Associates, Inc. to D. Waters at Westinghouse Hanford Co., August 3, 1990. 


\section{WHC-SD-W236A-ER-009}

Rev. 0

Appendix F. Scaling Discussion.

$F-i$ 
May 1994

\section{Application of Small-Scale Evaporation Test to Full-Size Tank \\ Multi-Function Waste Tank Facility Project $W-236 A$}
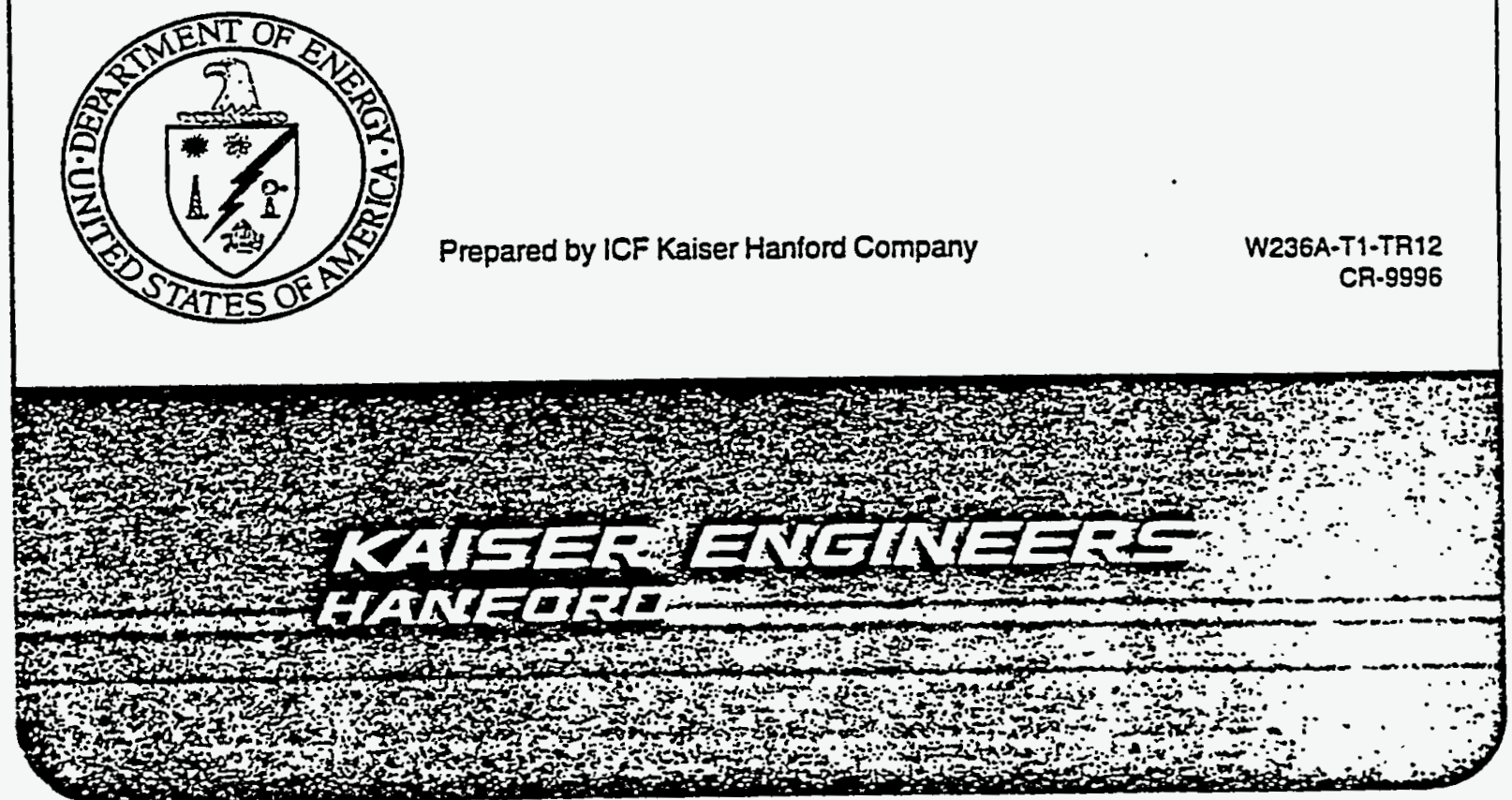

F-1 
WHC-SD-W236A-ER-009

Rev. 0

\title{
LETTER REPORT \\ Application of Small-Scale Evaporation Test to Full-Size Tank
}

\section{Project W-236A}

\author{
Prepared by \\ ICF Kaiser Hanford Company \\ for \\ Westinghouse Hanford Company
}

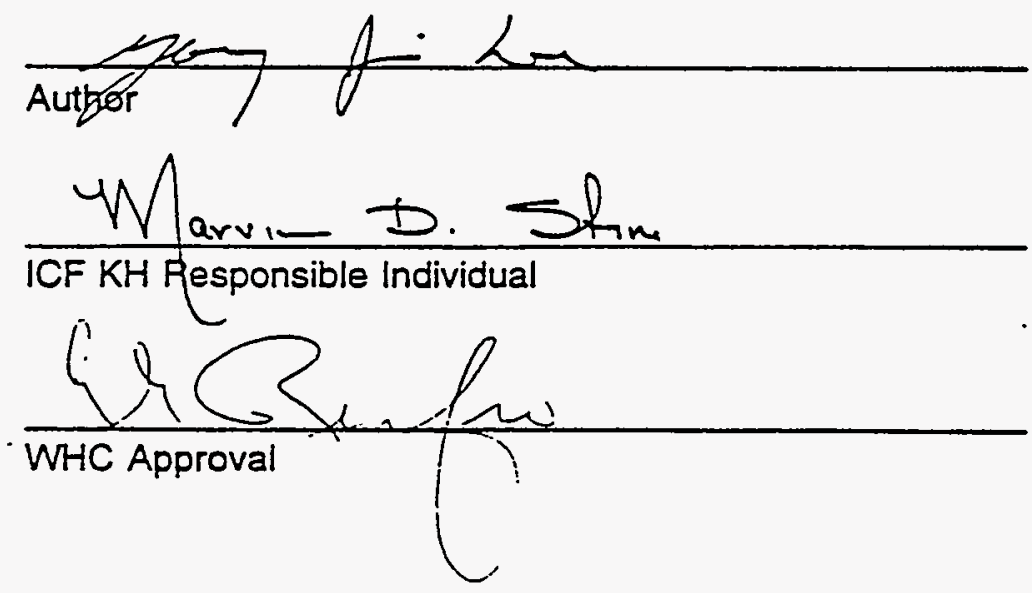

$$
\begin{aligned}
& \frac{5 \cdot 6.94}{\text { Date }} \\
& \frac{5 / 6 / 94}{\text { Date }}
\end{aligned}
$$

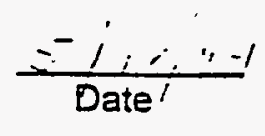




\section{CONTENTS}

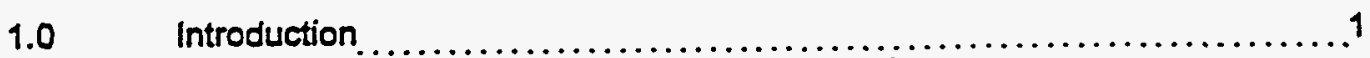

2.0 Ra Number and Natural Convection...........................2

R.0 Ra Number and Mass Transfer.................................

4.0 Ra Numbers for Test Configuration and Waste Tank.................5

4.1 Characteristic Length ..................................

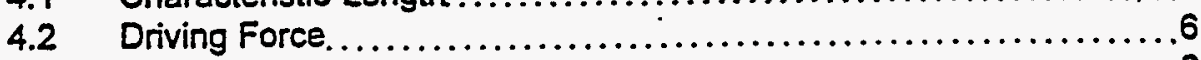

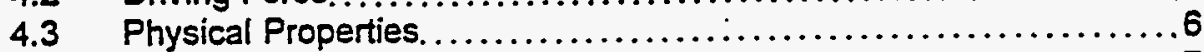

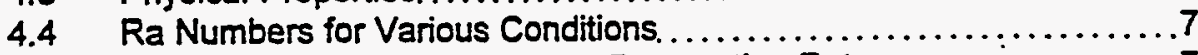

4.5 Mass Transfer Coefficients and Evaporation Rate............... 7

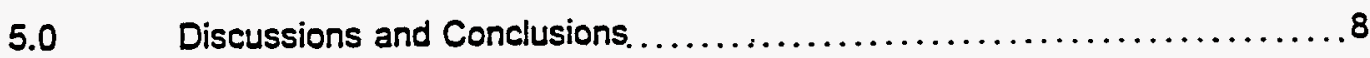

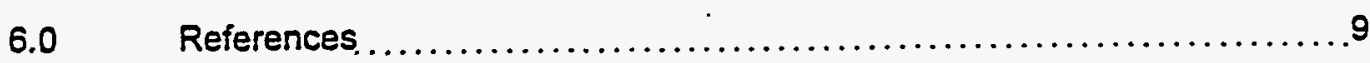

\section{FIGURES}

Figure 1 Ra Number vs. Concentration Difference for Various Characteristic Lengths

Figure 2 Ra Number vs. Temperature Difference for Various Characteristic Lengths

Figure 3 Mass Transfer Coefficient vs. Concentration Difference

Figure 4 Evaporation Rate vs. Mass Transfer Coefficient at 300 SCFM

Figure 5 Evaporation Rate vs. Mass Transfer Coefficient at 1000 SCFM 


\section{Application of Small-Scale Evaporation Test to Full-Size Tank}

\subsection{Introduction}

In the current design of the MWTF tank, a large portion of the heat generated by the mixing pump and radioactive decay in the tank will be removed by the circulation of air through the primary vapor space of the tank. This circulating air will remove the heat from the waste, mainly by carrying away the vaporized water from the waste. The evaporation and removal of the water is dependent on the natural convection in the primary vapor area. Understanding the process of the evaporation and removal of the water from the waste is essential in determining the circulation rate of the air through the tank primary vapor area.

There are a number of experimental studies reported in the literature on the measurement of water evaporation into air at various conditions ${ }^{12.3}$. However, these data were obtained at lower water and air temperatures than the conditions expected in the MWTF waste tank. As part of the thermal/heat transfer analysis of the waste tank design, the thermal/hydraulics group at Westinghouse Hanford Company (WHC) has studied the natural convection and evaporation of the water in the primary vapor area using FIDAP, the finite element fluid dynamics code. The results are inconclusive at best. In general, the computational fluid dynamics codes are in the developmental stage for predicting the behavior of highly turbulent natural convection found in the tank primary vapor area. Therefore, experimental testing to determine the evaporation and removal rate of the water from the waste is required to ensure proper design of the cooling systems for the waste tanks. Presently, the thermal/hydraulics group at WHC is testing to determine heat removal rates by the evaporation and removal of water in the tank primary vapor area.

Since it is not practical to build a 75-foot-diameter full-size tank for this test, a 12-foot-diameter scale model tank was constructed for the test. As discussed previously, the evaporation and removal of the water from the waste will depend on the natural convection of the air in the primary vapor area. The degree of the natural convection is typically represented by the Rayleigh number (Ra), a nondimensional parameter. The Ra number is proportional to the cube of the characteristic length of the system. The characteristic length is generally the size or diameter of the system itself. Since the size for the evaporation test is smaller than the actual tank, the Ra number for the test configuration is much smaller than that for the actual tank. in other words, the natural convection in the test configuration is less turbulent than that in the actual tank. Therefore, it is very important to understand how the test data can be related to the design of the waste tank heat removal system. This report will examine the problems, if any, in applying the small-scale evaporation test data to design the waste tank cooling system. 


\subsection{Ra Number and Natural Convection}

The primary vapor region of the waste tank resembles a system enclosed by two horizontal surfaces with different temperatures, where the temperature of the bottom surface is higher than that of the top surface. In this system, the primary parameter describing the degree of the disturbance is the Ra number, as discussed previously. The Ra number is expressed as:

$$
\begin{aligned}
& R a=\frac{g \beta \Delta Z^{3}}{v \alpha} \cdot-(1) \\
& \text { Where, } \quad R a-\text { Rayleigh number } \\
& \Delta T-\text { Temperature difference between thie } \\
& \quad \text { bottom surface and the bulk } \\
& g-\text { Acceieration of gravity } \\
& \beta-\text { Coefficient of thermal volumetric } \\
& v-\text { expansion } \\
& \alpha-\text { Thematic viscosity } \\
& L-\text { Characteristic length }
\end{aligned}
$$

A similar relationship has been suggested for a system in which the fluid density is different at the bottom due to a concentration gradient as follows:

$$
\begin{aligned}
& R a=\frac{g \beta_{m} \Delta Y L^{3}}{D}-(2) \\
& \text { Where, } \quad \begin{aligned}
\Delta Y & - \text { Mass fraction difference } \\
& D-\text { Molecular diffusivity of diffusing } \\
& \text { substance in gas mixture }
\end{aligned} \\
& \beta_{m}-\text { Concentration coefficient of voiumetric expansion, }\left(M_{i}-M\right) / M \\
& M_{i}-\text { Molecular weight of inert gas } \\
& M-\text { Molecular weight of diffusing gas }
\end{aligned}
$$

As shown in these equations, the Ra number represents the degree of natural convection and is a function of the driving force (density difference), a geometric constant, and physical properties. More precisely, the Ra number is proportional to the driving force and the cube of the characteristic length and is inversely proportional to the kinematic viscosity and diffusivity of 
the fluid. As clearly demonstrated in this definition, higher Ra numbers will increase the disturbance in the system. Other nondimensional parameters affecting the natural convection are the Prandtl ( $\mathrm{Pr}$ ) and Schmidt (Sc) numbers, which represent the physical characteristics of the fluid. Since our system is used with an air and steam mixture, the $\mathrm{Pr}$ and $\mathrm{Sc}$ numbers are near 1.0. Only the cases with $\mathrm{Pr}$ and Sc numbers near 1.0 will be examined in this report.

A critical Ra number is defined as a value below which the transport of the heat is by conduction (or the transport of mass by diffusion), and the fluid is essentially motionless. Based on both theoretical analysis and experimental observation, this critical $\mathrm{Ra}$ for the onset of convection has a value of about 1703 and is independent of Pr or Sc numbers 4 . For Pr numbers less than 5 , an increase in the Ra number beyond the critical value leads to a direct transition from steady two-dimensional flows to a time-dependent flow. The Ra number for this transition is an increasing function of the Pr number, ranging from below 2500 at $P r=0.01$ to 20,000 at $P r=5^{5}$.

As the Ra is increased further, the flow becomes turbulent. There is no general agreement on when this transition occurs. One reference ${ }^{6}$ has reported that this transition occurs at $R a=2 \times 10^{7}$ for air, while another references has presented that the transition occurs at $R a=10^{4}$ for a Pr number approaching unity. In other words, for the present system with the Pr number near 1 , the natural circulation will be fully turbulent when the Ra number is between $10^{4}$ and $2 \times 10^{7}$.

\subsection{Ra Number and Mass Transfer}

As discussed in the previous sections, the evaporation and removal of water from the waste in the tank depends on the degree of the natural convection, and the intensity of the natural convection can be expressed by the Ra number. Consequently, relationships have been developed to express the heat and mass transfer rate as a function of the Ra number. These relationships vary significantily depending on whether the natural convection is laminar or turbulent.

In the laminar region, the Nussel number (Nu) and Sherwood number (Sh), representing heat and mass transfer, respectively, become:

$$
\begin{aligned}
& N u=0.54 R a^{1 / 4}-(3) \\
& \text { and } \\
& S h=0.54 R a^{1 / 4} \quad-(4)
\end{aligned}
$$




$$
\text { Where, } \begin{array}{ll} 
& N u-\text { Nussel number }(=h L / k) \\
& h-\text { Heat transfer coefficient } \\
& k-\text { Conductivity } \\
& S h-\text { Sherwood number }\left(=h_{m} L / D\right) \\
& h_{m}-\text { Mass transfer coefficient }
\end{array}
$$

In the turbulent region, the relationships become:

$$
\begin{aligned}
& N u=0.14 R a^{13}-(5) \\
& \text { and } \\
& S h=0.14 R a^{1 s} \quad-(6)
\end{aligned}
$$

As shown in these equations, the relationship is the same between the heat transfer phenomena and the Ra number, and between the mass transfer phenomena and the Ra number. Since our main interest in this study is the mass transfer phenomena, the discussion will be limited to the relationship between the mass transfer phenomena and the Ra number.

Introducing the definition of the Sh and Ra numbers, Equations (4) and (6) become:

$$
h_{m}=0.54\left(\frac{g \beta_{m} \Delta Y D^{3}}{v L}\right)^{1 / 4} \quad-(7)
$$

for the laminar region, and

$$
h_{m}=0.14\left(\frac{g \beta_{m} \Delta Y D^{2}}{V}\right)^{13} \quad-(8)
$$

for the turbulent region.

These relationships have been developed based on a large number of experiments conducted by various researchers. The constants in these equations vary somewhat depending on the experimental results, but the power relationships of $1 / 4$ for the laminar fiow and $1 / 3$ for the turbulent flow is well accepted in this field. As shown in Equation 7, the mass transfer coefficient is inversely proportional to the $1 / 4$ power of the characteristic length in the laminar flow regime, and is not a function of the characteristic length at all in the turbulent flow regime. In other words, the mass transfer rate between the interface and bulk phase is not influenced by the size of the equipment in the turbulent flow regime. This finding agrees well with the following explanation. In the turbulent flow regime, the natural convection will be presented by a 
large number of small flow cells, which are much smaller than the test geometry and are not influenced by the test boundary. Since the mass transfer will be carried out by these flow cells, the mass transfer rate will not be a function of the equipment size.

\subsection{Ra Numbers for Test Configuration and Waste Tank}

In the first step to compare the test configuration with the actual waste tank, the Ra numbers will be calculated for the test configuration and the actual waste tank. Before presenting the results of the calculation, it is worthwhile to discuss how each parameter affecting the Ra calculation is selected.

\subsection{Characteristic Length}

The most significant difference between the test configuration and the waste tank will be the characteristic length representing the size. The size of the test tank will be $1 / 6.25$ that of the waste tank. Since the Ra number is proportional to the cube of the characteristic length, as shown in Equation 1, the difference in the Ra numbers, due to the characteristic length, will be more than two orders of magnitude.

Also, there are a number of different definitions for the characteristic length. The most common definition is that the characteristic length is a dimension of the side for a square surface or 0.9 times of the diameter for a round surface ${ }^{6.7}$. On the other hand. Goldstein et. al. ${ }^{4}$ and others ${ }^{8}$ have used the height of the system as the characteristic length. Also, it has been suggested that the characteristic length should be defined as ${ }^{0}$ :

$$
\begin{aligned}
& \frac{1}{L}=\frac{1}{L_{h}}+\frac{1}{L_{v}} \\
& \text { Where, } \quad \begin{aligned}
L_{v} & - \text { Vertical length } \\
L_{n} & - \text { Horizontal length }
\end{aligned}
\end{aligned}
$$

The objective of this report is not to settle the dispute on the proper definition of the characteristic length. Instead, it will show how the definition of the characteristic length will affect the use of the experimental data in the design of the waste tank. The characteristic length of the test geometry can vary from one foot (smallest height) to 10.8 feet (diameter $\times 0.9$ ), while that of the actual waste tank can vary from a few feet to 67.5 feet. To maximize the effect of the characteristic length, the smallest possible characteristic length for the test configuration and the largest length for the tank are selected for this evaluation. In other words, the characteristic lengths of one foot and 67.5 feet are selected for the test configuration and the waste tank, respectively. 


\subsection{Driving Force}

The Ra number is proportional to the driving force for the natural circulation, and the driving force is the difference in density between the interface and the bulk phase, caused by either the temperature or the concentration difference; or both. As shown in Equations 1 and 2, the Ra number is defined differently for the case with the temperature difference and for the case with the concentration difference. In the present system, both temperature and concentration differences will become the driving force for the natural convection. Most of the experimental and the analytical studies presented in the literature are based on only one of the differences as the driving force. A limited number of studies have been reported on natural convection caused by both differences. Somers ${ }^{10}$ and Wilcox" solved the governing equations for simultaneous heat and mass transfer in laminar free convection from a vertical plate, and conciuded that the effect on the natural convection due to temperature and concentration differences are additive for nearly equal Prandtl and Schmidt numbers. It is clear from these studies that both differences will enhance the degree of natural convection more than a single difference.

In this study, the Ra number will be evaluated for the wide range of concentration and temperature differences anticipated for the waste tank operations. However, the estimation of the evaporation rates for the experimental configuration and waste tank will be based solely on the concentration difference in order to be conservative in estimating the effect of the geometry. The concentration difference between the bulk and the interface will depend on the bulk phase concentration, since the interface concentration is constant. The bulk concentration will be balanced between the amount removed from the bulk phase and the amount transferred to the bulk phase from the interface. Therefore, the concentration difference becomes larger when more water vapor is removed from the bulk phase. Consequently the Ra number will be higher for the case in which a higher flow rate of air is introduced to the primary vapor area.

In the present design, the concentration difference expressed in mass fraction is expected to be 0.029 for 300 SCFM air flow at $77^{\circ} \mathrm{F}$ and $40 \%$ humidity inlet conditions, and 0.064 for the 1000 SCFM air flow rate. Both of these estimates are based on the empirical equation deve!oped by Bolter, et. al.'. The FIDAP code calculates the approximate concentration difference of 0.1 at 300 SCFM inlet air flow rate. Since the empirical equation predicts lower concentration difference and a lower Ra number, only the concentration differences evaluated by the empirical equation will be considered in this study.

\subsection{Physical Properties}

Other factors affecting the Ra number are the physical properties, such as viscosity, thermal and molecular diffusivity, and density. These physical properties are not only a function of the

APPROVAL 
temperature, but are also dependent on the concentration. Since the physical properties are rather insensitive to these variables, the physical properties of air at $190^{\circ} \mathrm{F}$ were selected and used as constants in this study. It is expected that the Ra number calculated by these constant values of physical properties will be lower than other possible combinations of the physical property values. Therefore, the results of the analysis will be conservative.

\subsection{Ra Numbers for Various Conditions}

The Ra numbers for the experimental configuration and waste tank were evaluated for various concentration differences, and the results are presented in Figure 1. Other parameters, including the characteristic length used in this evaluation, are selected conservatively as discussed above. The results show that natural convection in the waste tank will be turbulent for the range of the concentration difference of concern $(0.01-0.1)$. The natural convection in the experimental configuration will be either laminar or turbulent, depending on whose definition we trust. In order to make this evaluation conservative, it will be assumed that the natural convection in the experimental configuration is laminar.

In Figure 1, the Ra numbers based on the maximum height (2.87 feet) of the experimental configuration and the minimum liquid-level height (13 feet) of the waste tank is presented to examine the degree of natural convection based on the selection of the characteristic length. Also, the Ra numbers calculated for various temperature differences and results are summarized in Figure 2. The magnitude of the Ra number based on the temperature differences in the range of interest $\left(10^{\circ}-50^{\circ} \mathrm{F}\right)$ is similar to that due to concentration differences.

By examining the Ra numbers and the degree of natural convection, there may be difficulty in interpreting the data from the test to the actual waste tank design. As discussed above, we are not interested in the Ra number or the degree of natural convection. We are interested in the amount of mass transfer from the interface to the bulk phase, expressed as the mass transfer coefficient.

\subsection{Mass Transfer Coefficients and Evaporation Rate}

Figure 3 shows the plot of the mass transfer coefficients as a function of concentration differences for the test configuration and the waste tank. For the test configuration, it is assumed that the characteristic length is one foot and the natural convection is laminar. As shown in this Figure, the mass transfer coeficient varies less than $15 \%$ between the experimental configuration and actual waste tank geometry for the concentration difference ranging from 0.01 to 0.1. This range of concentration differences will envelop the conditions created by the inlet air flow rate of 300 to 1000 SCFM. In particular, the error is expected to be $5 \%$ for the 300 SCFM flow 
rate and $2 \%$ for the 1000 SCFM flow rate. It is important to note that the mass transfer coefficient at a laminar flow condition (test configuration) is higher than that at a turbulent flow condition for lower concentration differences according to Figure 3 . This indicates that the present correlation to calculate the mass transfer coefficient from the Ra number needs further improvement. The mass transfer coefficient is strongly dependent on the concentration difference but is almost independent of the characteristic length for characteristic length larger than one foot.

The objective of this test is not to evaluate the mass transfer coefficient, but to determine the evaporation rate from the waste surface. The mass transfer coefficients can be converted into the evaporation rate by the following equation:

$$
\begin{aligned}
& W_{w}=h_{m} \rho\left(C_{1}-\frac{W_{w} S+W_{w}}{W_{i}+W_{w} S+W_{w i}}\right)-(10) \\
& \text { Where, } \quad W_{w}-\text { Evaporation rate }\left(\mathrm{lb} / \mathrm{f}^{2} \mathrm{hr}\right) \\
& W_{w i} \text { - Inlet water vapor flow rate (lb/hr) } \\
& W_{1} \text { - Air flow rate }(\mathrm{ib} / \mathrm{hr}) \\
& \rho \text { - Density } \\
& C_{1} \text { - Mass fraction at interface } \\
& S \text { - Waste suriace area }\left(\mathrm{At}^{2}\right)
\end{aligned}
$$

The evaporation rates corresponding to the various mass transfer coefficients are shown in Figures 4 and 5 for 300 and 1000 SCFM inlet air flow rates, respectively. Based on these Figures, the evaporation rate increases $22 \%$ for the 300 SCFM case and $57 \%$ for 1000 SCFM case, while the mass transfer coefficients increased by a factor of three from 20 to 60 . This suggests that the error in mass transfer coefficients will be reduced to at least $80 \%$ when the mass transfer coefficient is converted to the evaporation rate. Therefore, the evaporation rate difference between the test configuration and the waste tank will be less than $3 \%$, due to their size difference.

\subsection{Discussions and Conclusions}

The possible error induced by extending the experimental measurement of the evaporation rate from the small-sized test tank to the waste tank has been examined. The results indicate that the error will be less than $3 \%$, even with the worst possible assumptions. These conservative assumptions include:

口 Smallest characteristic length

ㅁ One driving force

․ Conservative physical properties 
It can be safely concluded that the evaporation data obtained from the test is directly applicable to the design of the waste tank cooling system.

One item of minor concern in this test is the difference in inlet air residence time. The volume of the vapor space in the test is $(1 / 6.25)^{3}$ of that in the actual waste tank, but the interface area of the solution in the test is $(1 / 6.25)^{2}$ of that in the waste tank. Since the flow rate of inlet air is propotional to the interface area, the residence time of the air in the test will be $1 / 6.25$ of that in the waste tank. However, this residence time difference will not affect the evaporation rate as long as the inlet air does not disturb the interface and the air in the vapor space is well mixed. It is recommended, if readily achievable, that the inlet and outlet configuration be properly designed to achieve full mixing in the vapor space without disturbing the interface.

\subsection{References}

1. L. M. K. Boelter, et. al., Free Evaporation into Air of Water from a Horizontal Quiet Surface, Ind. and Eng. Chem., Vol. 38, pp. 596, 1946.

2. M. T. Pauker, et. al., A Novel Method for Measuring Water Evaporation into Still Air, ASHRAE Transactions, Vol. 99, Pt.1, pp. 297, 1993.

3. M. M. Shah, Estimating of Evaporation from Horizontal Surfaces, ASHRAE Transactions, Vol. 87, Pt. 1, 1981.

4. R. J. Goldstein et. al., High-Rayleigh-Number Convection in a Horizontal Enclosure, J. Fluid Mech. Vol. 213, pp. 111, 1990.

5. R. Krishnamurti, Some Further Studies on the Transition to Turbulent Convection, J. Fluid Mech., Vol. 60, pp. 285, 1973.

6. W. H. McAdams, Heat Transmission, 3rd Ed., pp. 180, McGraw-Hiil, 1954.

7. F. Kreith, Principles of Heat Transfer, 2nd Ed., pp. 340, International Text Book, 1966.

8. K. C. Cheng and T. Kimura, Observation of Convective Instability Phenomena in Slightly Inclined Air Layers Heated from Below: Effect of Air Layer Thickness, HTD-Vol. 178, ASME, 1991.

9. M. Jocobs, Heat Transfer, Vol. 1, 8th Ed., pp. 532, Jonh Wiley \& Sons, 1962. 
10. E. V. Somers, Theoretical Considerations of Combined Themal and Mass Transfer from a Vertical Flat Plate, J. Appl. Mech., Vol. 23, pp. 295, 1956.

11. W. R. Wilcox, Simultaneous Heat and Mass Transfer in Free Convection, Chem. Eng. Sci., Vol 13, pp. 113, 1961.

APPROVAL

F-13 
Figure 1. Ra Number vs. Concentration Difference for Various Characteristic Lengths

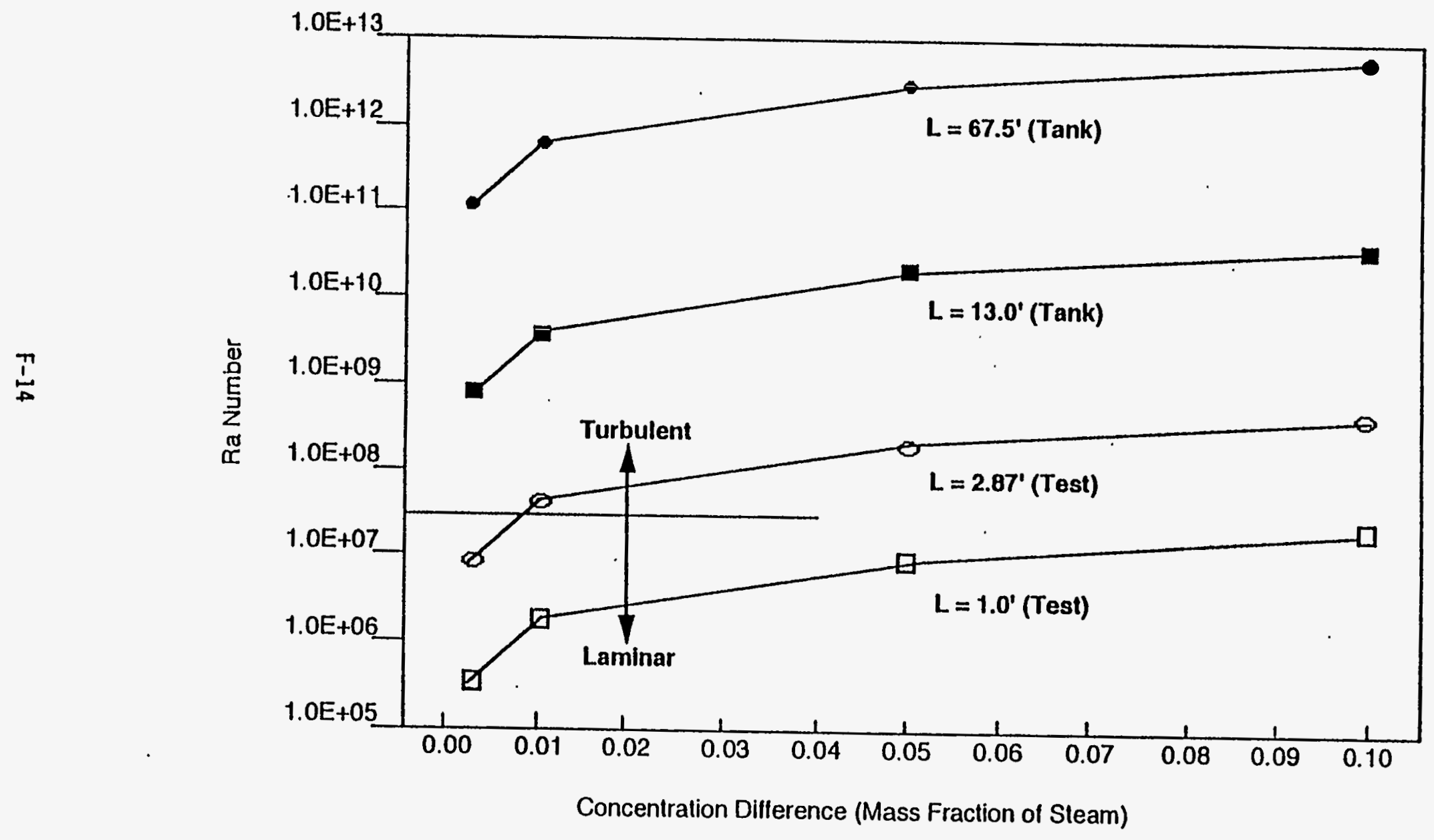


Figure 2. Ra Number vs. Temperature Difference for Various Characteristic Lengths

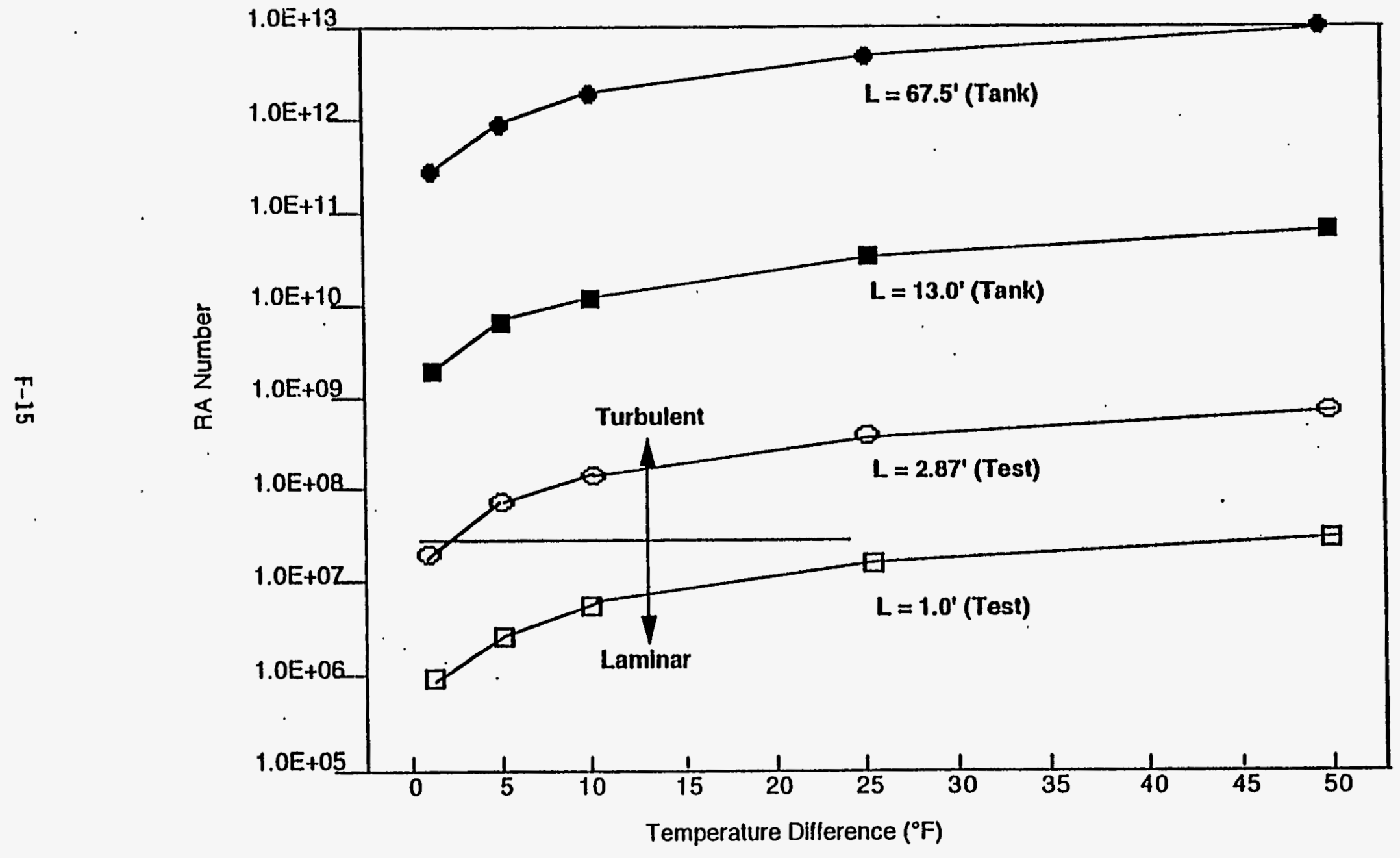


WHC-SD-W236A-ER-009

Rev. 0

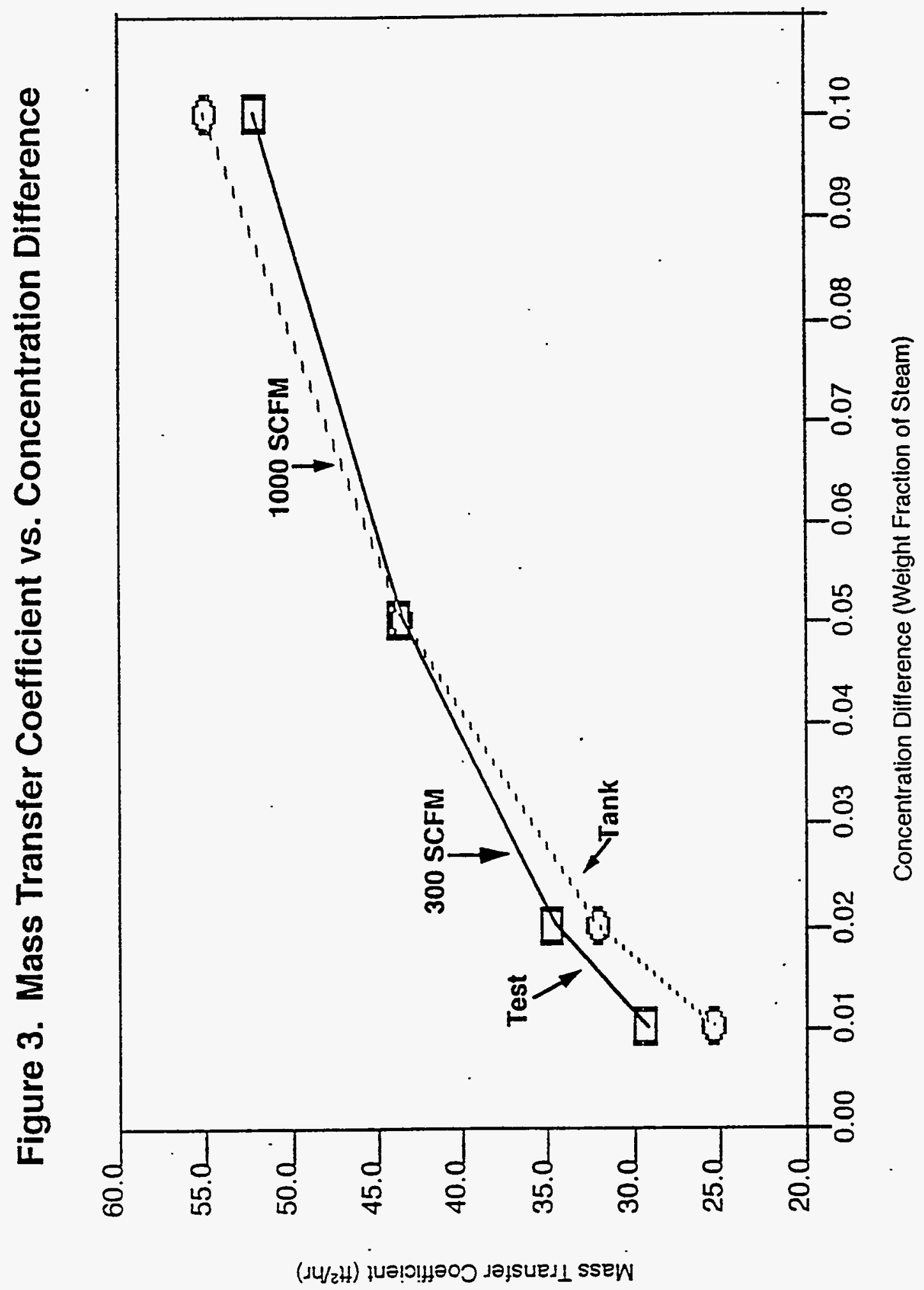




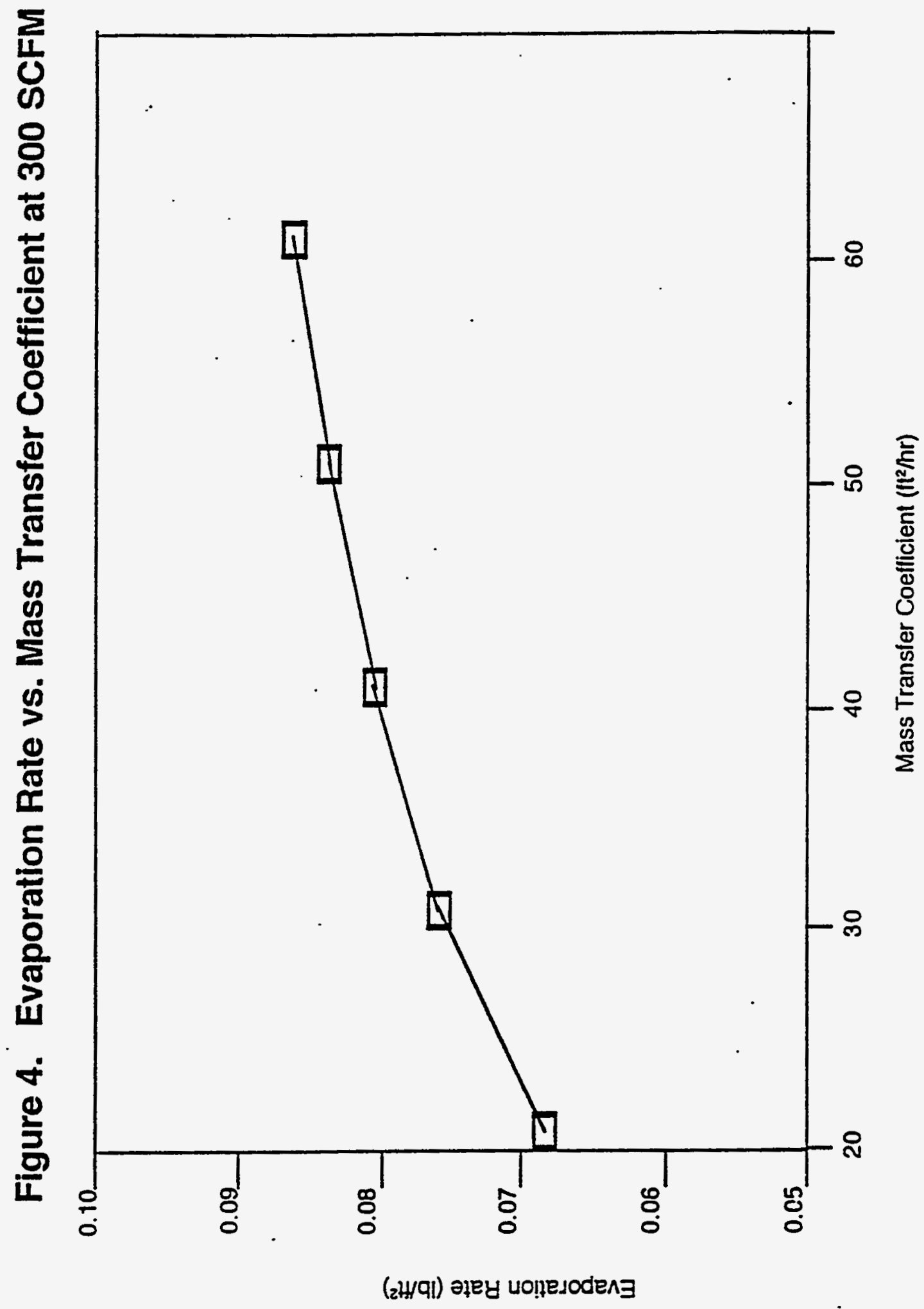

$$
\text { F-17 }
$$


WHC-SD-W236A-ER-009

Rev.. 0

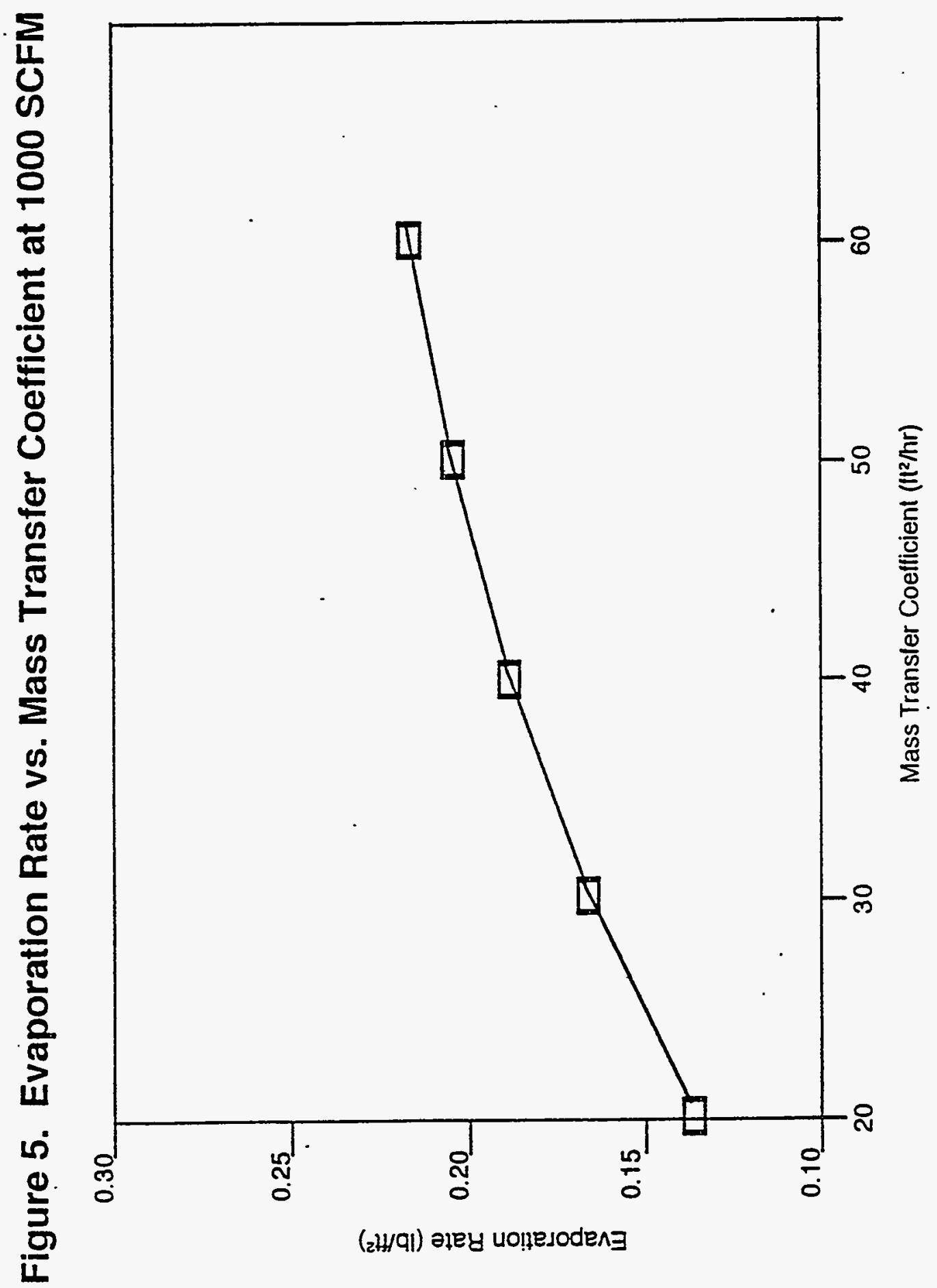

